\title{
PRÁTICAS DE RECUPERAÇÃO DE UMA PASTAGEM DEGRADADA E SEUS IMPACTOS EM ATRIBUTOS FÍSICOS, QUÍMICOS E MICROBIOLÓGICOS DO SOLO
}

\section{MARIA DA CONCEIÇĀO SANTANA CARVALHO}

Engenheiro Agrônomo

Orientador: Prof. Dr. CARLOS CLEMENTE CERRI

Tese apresentada à Escola Superior de Agricultura "Luiz de Queiroz", Universidade de São Paulo, para obtenção do título de Doutor em Agronomia, Área de Concentração: Solos e Nutrição de Plantas.

P I R A C I C A B A

Estado de São Paulo - Brasil

Fevereiro - 1999 


\section{Dados Internacionaís de Catalogação na Publicação (CIP) DIVISÃo DE BIBLIOTECA E DOCUMENTAÇÃo - Campus "Luiz de Queiroz"/USP}

Carvalho, Maria da Conceição Santana

Práticas de recuperação de um pastagem degradada e seus impactos em atributos físicos, químicos e microbiológicos do solo / Maria da Conceição Santana Carvalho. - Piracicaba, 1999.

$103 \mathrm{p}$.

Tese (doutorado) - Escola Superior de Agricultura Luiz de Queiroz, 1999. Bibliografia.

1. Degradação 2. Microbiologia do solo 3. Pastagem 4. Propriedade fisicoquímica do solo 5. Recupeção do solo I. Título

CDD 636.08422

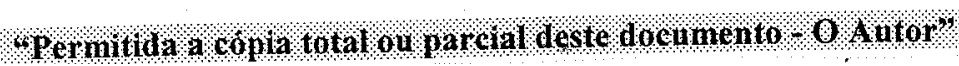


À minha família e aos grandes amigos que encontrei,

\section{OFEREÇO}

Ao Dr. Bernardo van Raij, meu orientador

no Mestrado, com toda a expressão da palavra. Pela sua

contribuição inestimável à Ciência do Solo e à Agricultura deste país,

\section{DEDICO}




\section{AGRADECIMENTOS}

Ao Prof. Dr. Carlos Clemente Cerri pela forma incentivadora e amiga com que conduziu a minha orientação;

À Escola Superior de Agricultura "Luiz de Queiroz" pela oportunidade oferecida e ao seu corpo docente pelos ensinamentos e incentivo intelectual, especialmente aos professores: Dra. Elke J.B.N. Cardoso, Dra. Maria Emília MattiazzoPrezotto, Dr. Álvaro Pires da Silva, Dr. Francisco Antônio Monteiro, Dr. Klaus Reichardt, Dr. José Carlos Chitolina, Dr. Quirino A. C. Carmello e Dr. Paulo L. Libardi;

Ao Centro de Energia Nuclear na Agricultura (CENA/USP) por permitir utilizar a sua estrutura logística;

Ao CNPq, pela concessão de bolsa de estudo e à FAPESP pelo auxílio financeiro a esta pesquisa;

Às pesquisadores da Seção de Biogeoquímica de Solos do CENA: Dra. Brigitte J. Feigl e, em especial, à Dra. Marisa C. Piccolo pelo incentivo e apoio em todas as fases deste rabalho. E também aos pesquisadores da ORSTOM, França, Drs. Christian Feller e Vincent Eschenbrenner, pelas sugestões;

Aos amigos e colegas da Seção: Silvana A. P. Fernandes, João Carlos Sá, Martial Bernoux, Solismar Venke, Dinaílsom Campos, Marciano Brito, Leandro Minitti e Edgar, pelo convívio saudável e enriquecedor sob os aspectos técnicos e humano; especialmente à amiga Silvana pela leitura, sugestões e correção do texto final da tese; ao Martial pela valiosa ajuda na confeção do "Summary" e ao Solismar, pela auxílio na coleta de amostras no campo;

Aos funcionários da Seção de Biogeoquímica de Solos do CENA: José Roberto Martins, Sandra Maria Nicolette e Dacir Bortoleto pela valiosa ajuda nos trabalhos de laboratório e, à sempre eficiente secretária, Antonia Mara P. Casarin, pelo apoio burocrático em inúmeras ocasiões;

Ao Sr. Eduardo Ferraz, proprietário da Fazenda Santa Maria, por pormitir que os trabalhos de campo fossem realizados em sua propriedade, pelo apoio logístico quando necessário e pelas informações sobre o manejo da área; 
Ao Dr. Lorival Fante Júnior pelas instruções e efetiva participação na coleta de amostras, separação, obtenção e digitalização das imagens de raízes, além da realização das análises físicas; e à Seção de Física do Solo do CENA por ter permitido o uso de seus equipamentos para análise física do solo;

À Cleusa Cabral pela leitura de $\mathrm{Ca}$ e $\mathrm{Mg}$ no espectrofotômetro de absorção atômica;

Ao Prof. Dr. Moacyr Corsi e à Patrícia Perondi Anchão Oliveira, do Departamento de Zootecnia da ESALQ, por compartilharem a sua área experimental e fornecerem todas as informações necessárias à condução do presente trabalho;

Às estagiárias Andreia Varsoni, Juliana Verdi, Roberta Navarro e Adriana pela incansável ajuda na coleta de amostras no campo e nos trabalhos de laboratório;

À Professora Sônia Piedade do Departamento de Matemática e Estatística da ESALQ e ao Marcelo Alves (CIAGRI/USP) pelos constantes esclarecimentos sobre utilização dos programas estatísticos SAS e SANEST;

Aos funcionários da Biblioteca Central da ESALQ e da Biblioteca do CENA, pela disposição, carinho, atenção e eficiência com que sempre fui atendida, particularmente na seção de empréstimos e nas consultas às bibliotecárias Kátia e Eliana.

Meu agradecimento especial à grande amiga Letícia F. dos Santos, por socorrer-me nos momentos que mais precisei, desde a coleta de amostras no campo até a leitura do texto e digitação de referências bibliográficas;

Aos meus amigos geograficamente distantes, mas sempre presentes com o seu incentivo, sua palavra de conforto nos momentos de dificuldade e seu orgulho nos momentos de vitória, contribuindo desta forma para a realização deste trabalho: Maria do Rosário e Ayres, Nildes Celeste e Domingos Barbosa, Claudia Cardoso, Dário Eloy Ribeiro;

Às colegas de república, por terem suportado e compreendido meus melhores e também piores humores, dando-me a tranquilidade necessária à condução dos trabalhos de tese: Luciana Guerra de Gusmão e Sílvia Cenci;

A todos que contribuíram de alguma forma e não foram mencionados. 


\section{SUMÁRIO}

Página

RESUMO

viii

SUMMARY

1 INTRODUÇÃO ...................................................... 1

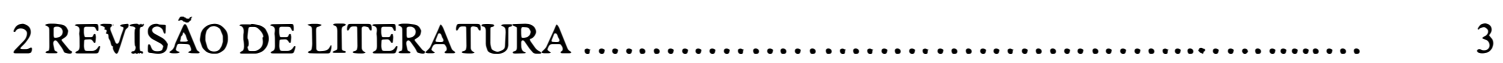

$2.1 \mathrm{O}$ ecossistema pastagem e a qualidade do solo ............................... 3

$2.2 \mathrm{O}$ sistema de pastagens e os efeitos sobre os atributos do solo ................ 4

2.2.1 Atributos químicos e matéria orgânica do solo ........................... 4

2.2.2 Biomassa e atividade microbiana ................................... 7

2.2.3 Atributos fisicos ..................................................... 9

2.3 Impacto ambiental das pastagens ....................................... 9

2.4 Causas de degradação de pastagens ...................................... 11

2.5 Respostas de pastagens às estratégias de recuperação ...................... 14

2.6 Efeitos das práticas de recuperação de pastagens na alteração dos atributos do solo .

3. MATERIAL E MÉTODOS

3.1 Localização e descrição do meio físico

3.2 Tratamentos e delineamento experimental

3.3 Instalação e condução do experimento de campo

3.4 Avaliação da produção de massa seca da parte aérea

3.5 Análise química da parte aérea da braquiária

3.6 Avaliação do sistema radicular da braquiária

3.6.1 Método auxiliado por processamento de imagens digitais

3.6.2 Método do monolito

3.7 Coleta de amostras e análises químicas do solo

3.8 Coleta de amostras e análises físicas do solo

3.9 Biomassa microbiana $\mathrm{C}, \mathrm{N}$ e $\mathrm{P}$ do solo 
3.9.2 Biomassa $\mathrm{N}$................................................. 36

3.9.3 Biomassa P ........................................................ 37

3.10 Atividade microbiana ............................................... 38

3.11 Taxas líquidas de mineralização e nitrificação do nitrogênio do solo ...... 38

3.12 Forma de análise dos resultados ........................................ 39

4. RESULTADOS E DISCUSSÃO …..................................... 40

4.1. Resposta da pastagem de braquiária aos tratamentos de recuperação ........ 40

4.1.1 Produção de massa seca da parte aérea ................................. 40

4.1.2 Distribuição do sistema radicular ....................................... 44

4.1.3 Teores totais de macro e micronutrientes na massa seca da parte aérea .... 52

4.2 Efeitos dos tratamentos sobre os atributos do solo ......................... 58

4.2.1 Atributos fisicos ................................................... 58

4.2.2 Atributos químicos ................................................. 62

4.2.3 Atributos microbiológicos do solo .................................... $\quad 70$

4.2.3.1 Biomassa microbiana $\mathrm{C}, \mathrm{N}$ e $\mathrm{P}$ do solo ............................. 70

4.2.3.2 Atividade microbiana ................................................ 75

4.2.3.3 Taxas líquidas de mineralização e nitrificação do nitrogênio do solo ..... 77

5 CONCLUSÕES ........................................................ 81

REFERÊNCIAS BIBLIOGRÁFICAS ..................................... 83 


\title{
PRÁTICAS DE RECUPERAÇÃO DE UMA PASTAGEM DEGRADADA E SEUS IMPACTOS EM ATRIBUTOS FÍSICOS, QUÍMICOS E MICROBIOLÓGICOS DO SOLO
}

\author{
Autora: MARIA DA CONCEIÇÃO SANTANA CARVALHO \\ Orientador: Prof. Dr. CARLOS CLEMENTE CERRI
}

\section{RESUMO}

O presente trabalho foi desenvolvido a partir de um experimento de campo, conduzido no período de 06/1996 a 08/1997, em São Pedro (SP), com os seguintes objetivos: a) avaliar os efeitos da gradagem, calagem e adubação como práticas de recuperação de uma pastagem degradada de Brachiaria decumbens Stapf., estabelecida em areia quartzosa, na alteração de atributos químicos, físicos e microbiológicos do solo; b) relacionar as alterações acima com a produção de massa seca, teores de nutrientes da parte aérea e o desenvolvimento do sistema radicular da gramínea; e c) estudar a variação da absorção de nutrientes e dos atributos químicos e microbiológicos do solo na estação chuvosa e na estação seca. Os tratamentos, dispostos em blocos ao acaso, foram: testemunha $(T)$; gradagem $(\mathrm{G})$; calcário aplicado na superficie do solo, sem incorporação (CS); calcário incorporado com grade (CG); calcário aplicado em cobertura mais fertilização com macro e micronutrientes $(\mathrm{N}, \mathrm{P} \mathrm{K}$, $\mathrm{B}, \mathrm{Cu}$ e $\mathrm{Zn}$ ) (CSF); e calcário incorporado mais fertilização com macro e micronutrientes (CGF). Os quatro tratamentos com calcário (CS, CG, CSF e CGF) alteraram de modo similar a reação do solo na camada de $0-10 \mathrm{~cm}, 20$ meses após a sua aplicação, aumentando $\mathrm{o} \mathrm{pH}$, neutralizando $\mathrm{o} \mathrm{Al}^{3+}$ trocável e reduzindo a acidez potencial. Contudo, a presença dos fertilizantes aumentou a disponibilidade dos 
nutrientes adicionados e proporcionou melhor distribuição de $\mathrm{Ca}$ e $\mathrm{Mg}$ no perfil do solo, elevando a saturação por bases e reduzindo a saturação por $\mathrm{Al}$ até $60 \mathrm{~cm}$ de profundidade. Como resultado disso, houve aumento da densidade de raízes, da absorção de nutrientes e da relação $\mathrm{N}: \mathrm{S}$ e $\mathrm{K}:(\mathrm{Ca}+\mathrm{Mg})$ na mssa seca da parte aérea, que culminaram em acréscimos superiores a $200 \%$ na produção total de forragem, promovendo a recuperação da pastagem. $\mathrm{Na}$ ausência de adubação, os tratamentos com calcário promoveram o aumento da densidade de raízes, embora em proporções duas vezes inferiores às dos tratamentos adubados; no entanto, não alteraram a produção de forragem, à qual apresentou baixa concentração de nutrientes, notadamente $\mathrm{K}$, refletindo _os baixos teores no solo. A gradagem como prática isolada aumentou a produção de forragem apenas no primeiro ano, às custas da mineralização da matéria orgânica, evidenciada pela redução dos teores de $\mathrm{C}$ e $\mathrm{N}$ total do solo e menor atividade microbiana. A porosidade total do solo e a proporção de macroporos, na camada de 0-10 $\mathrm{cm}$, foram aumentadas nos tratamentos CSF e CGF com melhor perfórmance para o tratamento CSF, em função do melhor desenvolvimento radicular e maior teor de carbono no solo. Os conteúdos de $\mathrm{C}, \mathrm{N}$ e $\mathrm{P}$ na biomassa microbiana foram mais elevados na estação chuvosa, na camada de $0-10 \mathrm{~cm}$, e nos tratamentos CSF e CGF, refletindo a maior disponibilidade de nutrientes e substrato orgânico (exsudatos radiculares e resíduuos das plantas). A biomassa microbiana $\mathrm{P}$ foi sempre superior aos teores disponíveis encontrados no solo, constituindo um importante compartimento de reserva deste nutriente. A maior taxa líquida de mineralização do $\mathrm{N}$ ocorreu no tratamento CSF, na estação chuvosa. Nos demais tratamentos, neste mesmo período, as taxas foram negativas, indicando imobilização líquida do $\mathrm{N}$ na biomassa microbiana. $\mathrm{O} \mathrm{N}-\mathrm{NH}_{4}{ }^{+}$foi a forma de $\mathrm{N}$ mineral predominante no solo, nas duas épocas de amostragem, e as taxas líquidas de nitrificação foram muito baixas, sugerindo um baixo potencial de perdas de $\mathrm{N}-\mathrm{NO}_{3}{ }^{-}$por lixiviação. 


\title{
RECLAMATION PRACTICES ON A DEGRADED PASTURE AND THEIR IMPACTS IN SOLL PHYSICAL, CHEMICAL AND MICROBIOLOGICAL PROPERTIES
}

\author{
Author: MARIA DA CONCEIÇÃO SANTANA CARVALHO \\ Adviser: Prof. Dr. CARLOS CLEMENTE CERRI
}

\section{SUMMARY}

The present work was carried out after a field experiment, during the period from June 1996 to august 1997, in São Pedro (SP), with the following objectives: a) to evaluate the effect of harrowing, liming and fertilization as recovery practices of a degraded pasture of Brachiaria decumbens Stapf, on a sandy soil, in changes in soil physical, chemical and microbiological attributes; b) to relate these changes to dry mass production, nutrients contents of the above grounds parts and the development of the grassy roots system; and c) to study the variation of nutrients absorption and of the soil chemical and microbiological atributes during the dry and wet seasons. The treatments set in the field, using a complete randomized block design, were: control; harrowing $(\mathrm{H})$; superficial liming without incorporation (LS); liming plus harrowing (LH); superficial liming plus fertilization with macro and micronutrients (N, P, K, B, Cu and $\mathrm{Zn}$ ) (LSF); liming plus harrowing plus fertilization with macro and micronutrients (LHF). Main findings were the following. The four treatments with liming (LS, LH, LSF, LHF) modified in a similar way the soil reaction at $0-10 \mathrm{~cm}$ layer, 20 months after its application, increasing the soil $\mathrm{pH}$, and reducing the total and exchangeable acidity. Fertilization increased nutrient supply and improved $\mathrm{Ca}$ and $\mathrm{Mg}$ distribution in the soil profile, increasing the base saturation and decreasing aluminum saturation down to 
$60 \mathrm{~cm}$ depth. This resulted in increases of root density, nutrients uptake, and $\mathrm{N}: \mathrm{S}$ and $\mathrm{K}:(\mathrm{Ca}+\mathrm{Mg})$ ratios of the dry matter of the above ground plant matter, which culminated with increase of up to $200 \%$ in the total forage production, thereby promoting pasture recovery. Without fertilization, the treatment with liming resulted in an root density increase, although twice lower compared with fertilized plot, it did not change forage production which had a low nutrient concentration, mainly $\mathrm{K}$, reflecting low soil contents. Harrowing alone increased forage production, but only the first year, because of the mineralization of the organic matter, evident through reduced $\mathrm{C}$ and $\mathrm{N}$ concentration of the soil and a lower microbial activity. Total soil porosity and the macropores percentage, in the $0-10 \mathrm{~cm}$ layer, increased for the LSF and LHF treatments, and mainly for the first one which showed a higher root increase and higher $\mathrm{C}$ content. Carbon, Nitrogen and phosphorus content of the soil microbial biomass were higher during the wet season, for the $0-10 \mathrm{~cm}$ layer, and for the LSF and LHF treatments, indicating a higher availability of the nutrients and of the organic substrates (root exudates and plant residues). Phosphorus content of the microbial biomass were always superior to the soil contents, showing then a more important reserve. The highest net mineralization rate for nitrogen occurred in the LSF treatment during the wet season. In the remaining treatments, during the same season, the rates were negative pointing out a net nitrogen immobilization in the soil microbial biomass. Ammonium- $\mathrm{N}$ dominated soil inorganic-N pools, in both seasons, and the rates of nitrification were very low, suggesting a low potential for $\mathrm{NO}_{3}^{-}-\mathrm{N}$ losses trough leaching. 


\section{INTRODUÇÃO}

$\mathrm{O}$ processo de degradação de pastagens caracteriza-se, em maior ou menor grau, pela redução da produtividade da forrageira, presença de plantas invasoras e aparecimento de áreas de solo descoberto, favorecendo o processo de erosão.

$\mathrm{O}$ esgotamento da fertilidade natural do solo, aliada à ausência de adubação, têm sido apontadas como as principais causas da degradação de pastagens cultivadas no Estado de São Paulo, levando os pecuaristas a uma cíclica substituição de espécies forrageiras no sentido das menos exigentes, a exemplo da Brachiaria decumbens. Mesmo assim, em algumas regiões estas pastagens encontram-se em condições de degradação, incluindo a região de São Pedro.

O uso de práticas de fertilização e manejo de pastagens visando a sua recuperação tem preferência, em relação à reforma de pastagens, devido ao menor custo e à redução do tempo para a utilização da área para pastejo. Porém, em função das diferentes espécies forrageiras, níveis de degradação, caracteristicas do solo, do clima e da exploração, são várias as técnicas envolvidas para cada situação, de modo que faz-se necessário a realização de trabalhos de pesquisa visando, na combinação de métodos, a definição da tecnologia mais adequada para a recuperação de áreas com pastagens degradadas.

Por outro lado, as estratégias de recuperação de pastagens degradadas, tais como calagem, fertilização e revolvimento do solo, podem provocar alterações não só na produtividade e no desenvolvimento do sistema radicular da espécie forrageira, mas também nos atributos fisicos, químicos e microbiológicos do solo. Entretanto, os efeitos dessas práticas sobre a dinâmica de nutrientes no solo, especialmente do carbono (C) e nitrogênio $(\mathrm{N})$ têm sido pouco estudados no Brasil. 
Esta pesquisa baseou-se nas seguintes hipóteses: a) o efeito da calagem na correção da acidez do solo, enriquecimento de cátions básicos e no desenvolvimento do sistema radicular da braquiária em profundidade, dependerá da incorporação do calcário e/ou da presença de ânions acompanhantes, principalmente $\mathrm{NO}_{3}{ }^{-}$e $\mathrm{SO}_{4}{ }^{2-}$, provenientes dos fertilizantes ou da mineralização da matéria orgânica; b) a atividade microbiana deverá ser estimulada diretamente pelas práticas de calagem e fertilização, devido ao aumento da disponibilidade de nutrientes, e indiretamente pelo efeito positivo no crescimento da planta, que resulta em entrada de matéria orgânica no sistema. Como resultado deste efeito, a biomassa microbiana $\mathrm{C}, \mathrm{N}$ e $\mathrm{P}$ e as taxas líquidas de mineralização e nitrificação do $\mathrm{N}$ do solo serão alteradas; c) a absorção de nutrientes, a biomassa microbiana $\mathrm{C}, \mathrm{N}$ e $\mathrm{P}$ e dinâmica de nutrientes deverão variar não só em função dos tratamentos, mas também das estações de crescimento (chuvosa e seca).

Os objetivos do presente trabalho são:

a) Avaliar os efeitos da gradagem, calagem e adubação como práticas de recuperação de pastagem degradada de Brachiaria decumbens Stapf., estabelecida em areia quartzosa, na alteração de atributos químicos, fisicos e microbiológicos do solo;

b) Relacionar as alterações acima com a produção de massa seca, teores de nutrientes da parte aérea e o desenvolvimento do sistema radicular da gramínea;

c) Estudar a variação da absorção de nutrientes e dos atributos químicos e microbiológicos do solo na estação chuvosa e na estação seca.

Adicionalmente, esta pesquisa objetiva gerar informações que poderão auxiliar os pecuaristas, em condições edafoclimáticas semelhantes à desta pesquisa, na tomada de decisão quanto à adoção dos métodos empregados nesse estudo para a recuperação de pastagem degradada de $B$. decumbens, levando-se em consideração a produtividade da gramínea e as alterações nos atributos do solo. 


\section{REVISÃO DE LITERATURA}

\subsection{O ecossistema pastagem e a qualidade do solo}

As pastagens constituem sistemas complexos formados pelos componentes solo-planta-animal, os quais estão sujeitos à modificações antrópicas através do seu manejo. A maioria das pastagens cultivadas do mundo foram estabelecidas após a derrubada e queima da floresta natural (Hynes \& Williams, 1993). No Brasil, a exploração ocorreu inicialmente em áreas onde a fertilidade do solo era mais elevada em substituição à culturas abandonadas de café e cana-de-açúcar na Mata Atlântica. Porém, fatores como a pressão sobre o uso da terra próximo aos grandes centros, a demanda crescente de produção de alimentos e incentivos fiscais, levaram à exploração de áreas com maiores limitações ecológicas e de fertilidade do solo, a exemplo do que aconteceu na região do Cerrado (Bodey et al., 1996a; Rao et al., 1996; Resck, 1996) e na Amazônia (Veiga, J.B.\& Serrão, 1987), principalmente nas três últimas décadas. Assim, encontramse pastagens estabelecidas em diferentes regiões fisionômicas, ocupadas anteriormente por campos nativos, cerrados ou florestas (Corsi \& Martha Júnior, 1997).

Estima-se que o Brasil conta atualmente com cerca de 100 milhões de hectares de pastagens cultivadas, das quais mais de $60 \%$ são espécies do gênero Brachiaria (Carvalho et al., 1991; Rao et al., 1996; Zimmer et al., 1994). Dentre essas espécies, a $B$. decumbens destaca-se pela sua relativa adaptação a solos de baixa fertilidade (Botrel, 1990; Rao et al., 1996), favorecendo assim a sua disseminação.

A qualidade do solo pode ser brevemente definida, segundo Gregorich et al. (1994), como a capacidade contínua do solo de aceitar, estocar e reciclar água, nutrientes e energia, bem como reter, dipersar e transformar materiais químicos e 
biológicos, funcionando como um tampão ou filtro ambiental. A qualidade de qualquer solo depende da sua natureza, que é função dos fatores de formação, e da interferência antrópica relacionada ao seu uso e manejo (Gregorich et al., 1994). O conceito de sustentabilidade implica na passagem do tempo, ao longo do qual o solo pode ser sustentável, na sua habilidade para funcionar como um componente viável do sistema e produzir alimentos, degradado ou até mesmo melhorado. A avaliação da qualidade do solo requer um mínimo de informações, compreendendo a medida de vários atributos físicos, químicos e biológicos do solo (Gregorich et al., 1994).

Obviamente, a conversão da vegetação nativa em pastagens provoca a ruptura do estado de equilibrio original, cujas modificações recaem, principalmente, sobre um dos componentes do sistema, o solo, em função da nova cobertura vegetal e da presença do animal pastejando (Hynes \& Williams, 1993).

\subsection{O sistema de pastagens e os efeitos sobre os atributos do solo}

\subsubsection{Atributos químicos e matéria orgânica do solo}

A maioria dos solos ocupados com pastagens no Brasil são latossolos, podzólicos ou areias quartzosas, álicos ou distróficos (Resck, 1996; Macedo, 1995), portanto de baixa fertilidade natural e caracterizados por baixos níveis de matéria orgânica, fósforo, saturação por bases, micronutrientes e elevada acidez superficial e subsuperficial (Demattê \& Demattê, 1993; Lopes, 1983; Olmos \& Camargo, 1976).

Porém, têm-se verificado que a queima da vegetação nativa ocasiona um importante aporte de nutrientes ao solo via cinzas (Falesi, 1976). Em geral, ocorre aumentos no $\mathrm{pH}$, no teor de cátions básicos $(\mathrm{Ca}, \mathrm{Mg}, \mathrm{K})$ e redução da acidez trocável (Buschbacher et al., 1988; Moraes et al., 1996; Sanchez et al., 1983), o que possibilita o bom desenvolvimento das pastagens nos primeiros anos de implantação. No entanto, a manutenção da fertilidade do solo ao longo do tempo dependerá do manejo e da ciclagem de nutrientes que, segundo Monteiro \& Werner (1997), continua de forma policíclica, 
mas com variações quali-quantitativas (depende da espécie introduzida), bem como na sua velocidade pela presença do animal pastejando (Hynes \& Williams, 1993).

A importância do componente animal na ciclagem de nutrientes está associada ao aumento da taxa de desfoliação da forrageira e ao fato de que a quantidade de nutrientes exportados através de produtos animais é muito reduzida em relação ao total reciclado (Wilkson \& Lorey, 1973). Estima-se que entre 60 e $99 \%$ dos nutrientes ingeridos são excretados na forma de urina ou fezes (Hynes \& Williams, 1993). Entretanto, a distribuição das excreções é bastante desuniforme, alcançando de 5 a $35 \%$ da área total da pastagem (Hynes \& Williams, 1993; Monteiro \& Werner, 1997; Silva, 1995), dependendo da taxa de lotação, forma de pastejo, área de descanso, tipo de animal (espécie, raça, sexo), quantidade e frequência de excreção, sistema de manejo das pastagens e localização de águas e sombras (Monteiro \& Werner, 1997). A distribuição irregular das excreções no pasto tem como consequência o acúmulo de elevadas concentrações de nutrientes em pequenos volumes de solo, favorecendo as perdas por volatilização $(\mathrm{N})$, desnitrificação $(\mathrm{N})$ e lixiviação, além de imobilizações na biomassa microbiana (Hynes \& Williams, 1993).

A matéria orgânica do solo (MOS) é um atributo chave quando se pretende avaliar a qualidade do solo (Grgorich et al., 1994). O seu papel no fornecimento de nutrientes e melhoria das propriedades do solo é fato amplamente conhecido. Nas regiões tropicais, a importância da MOS é ainda mais acentuada, pois é a principal responsável pela capacidade de troca de cátions (CTC) dos solos (Raij, 1969; Uehara \& Gillman, 1981), cuja maioria possui mineralogia caulinítica ou oxídica de baixa atividade (Olmos \& Camargo, 1976; Demattê \& Demattê, 1996). Neste aspecto, um dos impactos positivos verificados com a implantação de pastagens, tanto em áreas de cerrado como de floresta, é o sequestro de carbono (Cerri, 1989; Cerri \& Androux, 1990; Feamside \& Barbosa, 1998; Fischer, 1994), especialmente quando as espécies introduzidas são do gênero Brachiaria e Andropogon (Boddey et al., 1996b; Fischer, 1994; Moraes et al., 1995). Estas pastagens possuem uma elevada capacidade de acumular carbono no solo 
devido à produção de grande quantidade de massa seca e, principalmnte, à intensa renovação de seu sistema radicular abundante e permanente (Fisher, 1994).

Segundo Aguiar (1997), a produção de massa seca do sistema radicular das forrageiras corresponde a cerca de $50 \%$ da produção da parte aérea e representa em torno de $40 \%$ do total de nutrientes da planta. Cadish et al. (1994) estimaram que pastagens de Brachiaria e Andropogon estabelecidas em áreas de Cerrado depositam entre 6 a $10 \mathrm{t} \mathrm{ha}^{-1}$ de liteira por ano. Fisher et al. (1994) reportaram que, em diferentes áreas da Colômbia, solos sob pastagens de Brachiaria e Andropogon gayanus, com 5 e 9 anos de idade continham mais carbono do que a vegetação nativa de cerrado. Através de estudo conduzido no Sul da Bahia (região de Mata Atlântica), Cantarutti et al. (1995) demonstraram que, embora não tenha havido mudança significativa no conteúdo de $\mathrm{N}$ total do solo, o teor de carbono aumentou em $24 \%$ na camada 0-30, cm oito anos após a conversão de floresta secundária em pastagem de B. humidicola.

Estudos recentes utilizando técnicas modemas de medida da abundância natural do ${ }^{13} \mathrm{C}\left(\delta^{13} \mathrm{C}\right)$ na matéria orgânica do solo, que permitem determinar se a origem do material orgânico é de plantas do ciclo fotossintético $\mathrm{C}_{3}$ (leguminosas) ou $\mathrm{C}_{4}$ (gramíneas das pastagens), têm demonstrado que ocorre um decréscimo do carbono originado fa floresta na camada superficial do solo $(0-20 \mathrm{~cm})$ nos primeiros anos, seguido de acréscimo do carbomo total na década subsequente à introdução da pastagem, muitas vezes superando o teor de carbono original (Bonde et al., 1992; Chonè et al., 1991; Cerri et al., 1992; Feigl et al., 1995; Fernandes, 1993; Moraes et al., 1995).

Com relação ao teor de nutrientes, os resultados de estudos conduzidos em diferentes regiões do Brasil (Correa, 1989; Dadalto, 1983; Fernandes, 1993; Mores et al., 1995) demonstraram que, a curto prazo, a implantação de pastagens conduzem à alterações favoráveis sob o ponto de vista agronômico, havendo aumentos no $\mathrm{pH}$, teores de cátions básicos e fósforo disponível, enquanto a acidez trocável normalmente decresce. Entretanto, com o tempo de uso pode haver redução da disponibilidade de nutrientes dependendo do tipo de solo e, em especial, do manejo da pastagem (Dadalto, 
1983; Moraes et al., 1995). O fósforo e o nitrogênio normalmente mostram-se limitantes com o tempo (Serrão et al., 1982; Diez et al., 1991).

Nota-se que o padrão de variação dos nutrientes minerais em pastagens tem uma direção oposta daquela discutida anteriormente para o carbono, cujos teores tendem a acumular com o tempo após uma queda inicial. Pode-se inferir, com base nestes resultados, que a melhoria da fertilidade do solo, após a queima e derrubada da vegetação nativa, favorece a intensa mineralização da matéria orgânica originária da floresta. Porém, com o passar dos anos, a redução da disponibilidade de nutrientes devido, provavelmente, à imobilização nos diversos estratos do ecossistema e à perdas por lixiviação e volatilização, limitam a taxa de mineralização com consequente acúmulo de carbono no solo.

A taxa de alteração de matéria orgânica é função de adições (resíduos orgânicos animais e vegetais) e perdas (mineralização mediada pelos microrganismos), variando com o nível de matéria orgânica inicial, tipo de solo, teor de argila, clima e manejo (Sanchez et al., 1981). Por exemplo, os solos com maiores teores de argila tendem a estabilizar e acumular mais matéria orgânica do que aqueles mais arenosos (Jenkinson et al., 1977). Assim, Dadalto (1983), avaliando as alterações decorrentes de implantação de pastagens em diferentes solos, em áreas de caatinga hipoxerófila, verificou que o solo mais arenoso (areia quartzosa) e de menor fertilidade natural mostrou-se mais suscetível à degradação, apresentando decréscimos significativos nos teores de carbono orgânico, $\mathrm{pH}$ e nutrientes, a partir do quinto ano do estabelecimento.

\subsubsection{Biomassa e atividade microbiana}

$\mathrm{O}$ entendimento dos mecanismos biogeoquímicos que mantêm a fertilidade do solo sob pastagem são extremamente importantes para implementar o seu manejo. Neste contexto, as taxas líquidas de mineralização e nitrificação do $\mathrm{N}$ do solo são importantes indicadores da sua fertilidade, pois refletem a capacidade do solo em fornecer este nutriente para o crescimento das plantas. Alguns estudos realizados no 
Brasil (Fernandes et al., 1997; Neill et al., 1995, 1997; Piccolo et al., 1994), utilizando cronossequências de floresta-pastagem, mostraram que os solos sob pastagem apresentaram menores taxas líquidas de mineralização e nitrificação de $\mathrm{N}$ em relação à floresta, mesmo nos casos onde a implantação da pastagem resultou em aumento do estoque de $\mathrm{C}$ e $\mathrm{N}$ total do solo (Neill et al., 1997). Tais resultados, por um lado, sugerem um efeito benéfico na conservação do $\mathrm{N}$ no sistema, mas, por outro lado, indicam possivel redução da disponibilidade do nutriente para a pastagem.

O reconhecimeto da importância dos microrganismos do solo tem despertado o interesse em se medir os contéudos de nutrientes em sua biomassa, cuja estimativa apresenta um bom potencial de utilização como indicadores ecológicos do impacto das práticas de manejo agrícola (Jenkinson \& Powlson, 1981; Powlson, 1987). A biomassa microbiana do solo, definida como a parte viva da matéria orgânica do solo, excluindo-se as raizes e animais maiores que $5.000 \mu \mathrm{m}^{3}$ (Jenkinson \& Ladd, 1981; Wardle, 1992), atua como agente de transformação da matéria orgânica, no ciclo de nutrientes e no fluxo de energia, além de constituir uma fonte potencial de $\mathrm{N}, \mathrm{P}, \mathrm{S}$ e outros nutrientes para as plantas.

Devido à sua dinâmica, a biomassa microbiana responde mais rapidamente às mudanças de manejo do solo do que a matéria orgânica total ou atributos físicos e químicos (Powlson \& Jenkinson et al., 1981; Ross et al., 1982, 1994). No Brasil, estudos realizados na Amazônia em cronossequências de floresta-pastagens têm demonstrado que a biomassa microbiana do solo apresenta um padrão semelhante ao do conteúdo de carbono, ou seja, sofre uma redução nos primeiros anos (cerca de 3 a 5 anos) e volta a aumentar nas pastagens mais velhas, podendo alcançar níveis superiores àqueles da floresta (Fernandes et al., 1997; Geraldes et al., 1995; Phenning et al., 1992). 


\subsubsection{Atributos físicos}

Considerando os diversos tipos de uso da terra, a pastagem é provavelmente aquele que causa uma menor degradação fisica do solo, por mantê-lo coberto durante o ano inteiro, constituindo uma proteção contra o impacto das gotas de chuva, evitando a deterioração da estrutura na superficie do solo e reduzindo as perdas de água por evaporação. Além disso, o vasto e permanente sistema radicular das gramíneas forrageiras atua efetivamente na melhoria da estrutura, tanto pela ação fisica direta na agregação das partículas (Oades, 1993), como indiretamente através da liberação de exsudatos e deposição de resíduos orgânicos. Os exsudatos orgânicos liberados pelas raizes, ricos em carboidratos e proteínas, são quimicamente atrativos para os microrganismos, os quais produzem polissacarídeos e outros metabólitos conhecidos por sua influência positiva na estabilização dos agregados (Shulze \& Stott, 1996). Por conta destas características, as pastagens têm sido utilizadas, inclusive, para recuperar áreas degradadas, por exemplo, pela mineração (Ross et al., 1992).

Entretanto, em áreas pastejadas, o efeito benéfico das raizes na estrutura do solo tende a ser contrabalanceado pelo influência negativa do pisoteio dos animais, que pode causar compactação na camada superficial (Carvalho, 1976; Davies et al., 1989; Fernandes, 1993; Moraes et al., 1995). Na verdade, a predominância de um ou de outro efeito dependerá de vários fatores como espécie de forrageira, tipo e textura do solo, pressão de pastejo, entre outros (Pinzón \& Amézquita, 1991; Silva et al., 1997).

\subsection{Impacto ambiental das pastagens}

Com base na discussão apresentada até o momento, aparentemente as pastagens de gramíneas tem impacto ambiental positivo, particularmente quando comparadas às culturas anuais (DeMaria et al., 1998; Marun, 1996; Moraes, 1993). A existência de um sistema radicular denso e permanente, em especial nas pastagens de Brachiaria, contribui de forma efetiva para aumentar os conteúdos de matéria orgânica 
do solo e reduzir as perdas de nutrientes por lixiviação. Tais características compõem importantes prérequisitos para a sustentabilidade do agroecossistema. No entanto, o que vem acontecendo em áreas com pastagens em diversas regiões tropicais e subtropicais, incluindo Austrália (Myers \& Robbins, 1991; Robbins et al., 1989; Robertson et al, 1993a) e América do Sul (Bodey et al.,1996a; Soares Filho et al., 1992; Veiga \& Serrão, 1987), é uma precoce perda da capacidade produtiva, dando início ao processo de degradação.

O quadro evolutivo do processo de degradafão de uma pastagem, de acordo com Barcellos (1990) e Spain \& Gualderon (1991), tem como sequência: 1) redução da produção e qualidadde da forragem; 2) diminuição na cobertura do solo pela pastagem, e reduzido número de plantas novas oriundas de ressemeadura natural; 3) aparecimento de espécies invasoras, com processos de competição, e erosão pela ação da chuva; 4) grande proporção de invasoras e colonização da área por gramíneas nativas e processos erosivos acelerados.

As áreas com pastagens degradadas atingem grandes dimensões em várias regiões do Brasil (Barcellos, 1996; Bodey et al.,1996a; Soares Filho et al., 1992; Veiga \& Serrão, 1987). Segundo Macedo (1995), só nas áreas de Cerrado, existem, aproximadamente, 50 milhões de hectares com pastagens artificiais, sendo que cerca de 85 \% são espécies de Brachiaria e mais de 50 \% já atingem algum grau de degradação. Apesar da baixa fertilidade natural na maioria desses solos, as pastagens apresentam-se produtivas nos primeiros anos de seu estabelecimento, reduzindo rapidamente a produção após 4 a 10 anos de uso, sendo que o efeito é mais acelerado em solos mais arenosos (Spain et al., 1996).

Ao contrário das pastagens produtivas e bem manejadas, as áreas com pastagens degradadas têm, decididamente, um impacto negativo sobre o meio ambiente em escala local e regional. Além dos reflexos econômicos com a perda de produtividade e da qualidade da forrageira, têm-se ainda consequências ecológicas assinaladas, principalmente, pela degradação fisica, química e biológica do solo. Em regiões onde a pressão sobre o uso da terra é reduzida, a exploração pecuária é a atividade pioneira e 
está alicerçada no uso mínimo de insumos, a rápida degradação das pastagens provoca o abandono da área (Alvim, 1982; Serrão \& Romma, 1982). Nestes casos, novas áreas são incorporadas ao processo produtivo através do procedimento habitual de derrubada e queima da floresta nativa, contribuindo para a redução das reservas florestais e aumento da emissão de $\mathrm{CO}_{2}$ para a atmosfera.

Assim, o estudo das causas de degradação das pastagens a eficiência das estratégias de recuperação tem despertado grande interesse, tanto por razões econômicas como por questões ambientais.

\subsection{Causas da degradação de pastagens}

A degradação de pastagens pode ser causada por vários fatores como mau estabelecimento, manejo indadequado, pragas e doenças, compactação e queda da fertilidade do solo (Nascimento Júnior et al., 1994; Spain \& Gualdron, 1991; Zimmer et al. 1994). Neste trabalho dar-se-á maior ênfase àqueles fatores relacionados diretamente com o solo.

Segundo Spain et al. (1996), as causas de degradação de pastagens em áreas de cerrado podem ser resumidas em: a) deficiência de nitrogênio após dois a três anos, decorrentes de perdas por volatilização e lixiviação nos locais que receberam unina e imobilização em formas estáveis da matéria orgânica formadas por resíduos de gramíneas no solo; b) imobilização de fósforo e enxofre nessa mesma matéria orgânica, causando deficiência desses nutrientes; c) falta de adubação de manutenção; d) aumento da incidência de pragas, doenças e plantas invasoras; e) dificuldades de associações de leguminosas nas pastagens de gramíneas; f) taxas de super pastoreio e compactação pelo pisoteio animal

A redução da disponibilidade de nitrogênio tem sido apontada como uma das principais causas de degradação das pastagens tropicas (Boddey et al., 1996; Carvalho et al., 1991; Meyers \& Robbins, 1991; Nascimento Jr. et al., 1994; Sanzonowicz et al., 1987; Soares Filho et. al, 1992; Spain et al., 1996; Wemer, 1986, 1994), o que tem sido confinmado pela resposta de pastagens à fertilização nitrogenada (Alvim et al., 1990; Carvalho et al., 1991; 
Salinas \& Galdron, 1988; Soares Filho et. al., 1992; Spain et al, 1996). Entretanto, nas condições edáficas semelhantes à da região Amazônica, a deficiência de fósforo é citada como a causa primária da degradação das pastagens (Dias Filho \& Serrão, 1987; Paulino et al., 1994; Veiga \& Serrão, 1987).

A base para a manutenção da capacidade produtiva do ecossistema de pastagens é a reciclagem de nutrientes (Hynes \& Williams, 1993; Monteiro \& Werner, 1997). Nos diversos componentes do sistema onde ocorre a ciclagem existem perdas que podem estar associadas a fatores climáticos e à exportação na forma de produtos de origem animal, bem como imobilizações pelos microrganismos do solo (Boddey et al., 1996b; Cadish et al., 1994; Hynes \& Williarns, 1993; Monteiro \& Werner, 1997; Spain \& Salinas, 1984). Também reveste-se de importância, nas condições brasileiras, a alta capacidade de adsorção de fósforo pelos solos, como consequência de sua acidez e teores elevados de óxidos de ferro e de ahumínio (Lopes., 1983).

Os animais sob pastejo exerce grande influência na fertilidade do solo sob pastagens, provocando perdas significativas de nutrientes. A saída de nutrientes do sistema através de produtos animais é considerada pequena, uma vez que entre 60 e $99 \%$ dos nutrientes ingeridos são devolvidos ao pasto na forma de urina e fezes (Hynes \& Williams, 1993; ). No entanto, as dejeções são mal distribuídas no pasto e a quantidade de nutrientes, proveniente destas, excede àquela requerida pela forragem presente no local da deposição pelo animal (Hynes \& Williams, 1993). Como resultado, as perdas por lixiviação (principalmente de N, S, K) (Hynes \& Williams, 1993; Werner \& Monteiro, 1988;) e volatilização (Ferreira et al., 1995; Williams \& Hynes, 1994) podem ser expressivas, contribuindo para o enpobrecimento do sistema e degradação da pastagem.

Considerando que somente cerca de $30 \%$ da área da pastagem é coberta pelas excreções (Hynes \& Williams, 1993; Monteiro \& Werner, 1997), os $70 \%$ restantes ficam submetidos ao mesmo sistema onde a forragem é cortada e transportada para outro local. Assim, a maior parte dos elementos minerais é reciclada através dos resíduos vegetais (liteira e raízes) depositados no solo. 
Em solos de baixa fertilidade, as espécies de Brachiaria, principalmente, originam plantas com baixo teor de nutrientes e, consequentemente, resíduos com alta relação C:N e pobres em nutrientes (Boddey et al, 1996a,b; Cantarutti et al., 1997; Nascimento Jr., 1994). Os resíduos provenientes da parte aérea da planta (liteira) e das raizes em decomposição aumentam o teor de matéria orgânica do solo (Chonè et al., 1991; Cerri et al., 1992; Feigl et al., 1995; Fernandes, 1993; Moraes et al., 1995), que promove o aumento da biomassa microbiana (Fernandes et al., 1997; Geraldes et al., 1995; Phenning et al., 1992; Robertson et al., 1993a,b). Entretanto, esta biomassa microbiana é deficiente em $\mathrm{N} \mathrm{e}$ passa a competir com as plantas pelo $\mathrm{N}$ mineral disponível no solo, imobilizando-o (Cantarutti et al., 1997; Geraldes et al., 1995; Robertson et al., 1993a, 1993b). Assim, as taxas de mineralização do nitrogênio em pastagens permanentes não fertilizadas têm sido baixas ou até negativas (imobilização) (Fernandes \& Fernandes, 1997; Neill et al., 1995 Piccolo et al., 1994; Robertson et al., 1993a, 1993b) e, portanto, insuficientes para sustentar o fluxo de nutrientes que atenda às necessidades da forrageira (Nascimento Júnior et al., 1994). Como resultado disso, a taxa de crescimento da pastagem é reduzida a cada ano (Nascimento Jr., 1994).

Desse modo, a reposição dos nutrientes perdidos do sistema através da aplicação de corretivos e fertilizantes é imprescindivel para promover o equilibrio na proporção dos nutrientes demandados para a produção, contemplando a longevidade, assegurando vigor e qualidade para a forrageira, sendo mais um fator determinante para que a dinâmica da comunidade vegetal não favoreça às plantas indesejảveis (Aguiar, 1997; Corsi \& Marta Júnior, 1997; Jones \& Mott, 1980; Rayment \& Keliar, 1980). Todavia, apesar das pastagens ocuparem cerca de $20 \%$ da área cultivada no Brasil, seu consumo anual de fertilizantes é de apenas 1,2\% (ANDA, 1991). Este quadro reforça a idéia de que o esgotamento da fertilidade dos solos, somado à falta de adubação, são os principais responsáveis pela queda da capacidade produtiva destas áreas.

A degradação das pastagens também tem sido atribuída à deterioração da qualidade física do solo, evidenciadas pelo aumento da densidade do solo e da resistência à penetração e redução da porosidade total e dos macroporos (Carvalho, 1976; Correa, 1989; Costa et al., 1998; Davies et al., 1989; Femandes, 1993; Moraes et al., 1995). Tais 
modificações caracterizam o processo de compactação do solo que, no caso das pastagens, ocorre normalmente até a profundidade de $10-15 \mathrm{~cm}$ e é atribuída à pressão das patas dos animais durante o pastejo (Carvalho, 1976; Davies, 1989).

Os efeitos negativos da compactação do solo estão diretamente associados à redução da taxa de infiltração da água e restrição do crescimento radicular das plantas, com reflexos na absorção de água e nutrientes (Kiehl, 1979; Baver et al., 1972). Estudos recentes indicam que as raízes podem dispor de mecanismos de detecção de condições fisicas adversas no solo e enviam sinais (possivelmente hormonais) à parte aérea da planta que inibem o crescimento e a expansão foliar (Masle \& Passioura, 1987).

Deve-se ressaltar, no entanto, que a compactação em solos sob pastagens nem sempre é detectada (Gijsman \& Thomas, 1996) e sua magnitude, quando ocorre, é determinada por fatores como tipo e textura do solo, espécie de gramínea implantada, sistema de pastejo (rotacionado ou extensivo), taxa de lotação, idade da pastagem, umidade do solo, dentre outros (Pinzón \& Amézquita, 1991; Silva et al., 1997). Dessa forma, solos mais arenosos, cultivados com forrageiras com sistema radicular agressivo e bem manejadas, são menos suscetíveis à compactação superficial causada pelo pisoteio (Pinzón \& Amézquita, 1991).

\subsection{Respostas de pastagens degradadas às estratégias de recuperação}

As estratégias utilizadas para a recuperação da capacidade produtiva das pastagens buscam interromper o processo de degradação, atacando-se as causas a ele associadas. De um modo geral, os métodos de recuperação contemplam o uso de fertilizantes, implementos, o controle de invasoras, introdução de leguminosas e o uso de cultivos anuais (Amuda et al., 1987; Barcellos, 1990; Carvalho et al., 1990; Soares Filho et al., 1992). A abrangência das medidads adotadas irão depender do grau de degradação, de modo que as causas podem ser controladas independentemente ou associadas. Assim, as alternativas de recuperação são, na maioria das vezes, a combinação de várias outras (Arruda et al., 1987; Carvalho et al., 1990; Soares Filho et al., 1992). 
O uso de corretivos e fertilizantes, aplicados na superfície ou incorporados ao solo, visa reestabelecer o equilibrio entre os nutrientes para a retomada do crescimento normal da forrageira. O uso de implementos está condicionado ao grau de degradação e à estratégia utilizada de forma associada. Pode-se usar arados, grades leves ou pesadas, subsoladores, entre outros (Barcellos, 1990) . Neste caso, o revolvimento do solo tem como objetivos propiciar melhor aeração e capacidade de inflitração da água no solo, além de acelerar o processo de mineralizasão da matéria orgânica incorporada pela liteira.

As práticas de fertilização e manejo de pastagens visando a sua recuperação têm preferência, em relação à reforma de pastagens, devido ao menor custo e à redução do tempo para a utilização da área para pastejo. De acordo com Lopes (1997), deve-se dar prioridade à implementação de diretrizes de manejo sustentável que permitam a recuperação de áreas em fase inicial de degradação ou já degradadas, ao invés de incentivar a simples expansão da fronteira agro-silvo-pastoril nos moldes da ocupação ocorrida até hoje. $\mathrm{O}$ aumento da fertilidade do solo, por outro lado, promove a melhoria da cobertura vegetal e maior desenvolvimento do sistema radicular. Por sua vez, a maior quantidade de raízes constitui um fator importante na agregação do solo e retenção de umidade, contribuindo para a conservação do solo e da água.

Uma das práticas comumente usadas pelos pecuanistas para a recuperação de pastagens é a gradagem (Carvalho et al., 1990; Soares Filho et al., 1992). Entretanto, os resultados de pesquisas têm demonstrado que essa prática, por sí só, não é eficaz (Arruda et al., 1987; Carvalho et al., 1990; Soares Filho et al., 1992; Zimmer et al., 1994). Estes resultados foram atribuídas ao efeito depressivo nas plantas, prejudicando o desenvolvimento das raízes, que não puderam se beneficiar dos efeitos da mineralização da matéria orgânica. Além disso, Nascimento Jr. et al. (1994) salientaram que o tratamento mecânico, apesar de incorporar a massa vegetal ao solo e aumentar a aeração, pode não ser suficiente para acelerar a mineralização da matéria orgânica, cuja maior limitação está na deficiência de nutrientes. Entretanto, a gradagem associada à calagem e/ou à fertilização têm sido eficiente na recuperação de pastagens degradadadas de $B$. decumbens (Arruda et al., 1987; Carvalho et al., 1990; Soares Filho et al., 1992). 
Embora o nitrogênio seja considerado o nutriente mais limitante à produção das forrageiras, e sua deficiência a principal causa de degradação das pastagens, a maioria dos trabalhos consultados na literatura (Arruda et al., 1987; Carvalho et al., 1990; Kichel et al., 1998; Soares Filho et al., 1992) preconizam a recuperaçåo de pastagens com adubaçőes completas e não apenas com nitrogênio, com exceção da regiāo Amazônica, onde somente o fósforo tem proporcionado respostas expressivas (Dias Filho \& Serrão, 1987; Femandes et al., 1997; Serrão et al., 1982; Souza Filho et al., 1991; Veiga \& Serrão, 1987).

No Sul da Bahia, Amuda et al. (1987) combinaram tratamentos físico-mecânicos (araçāo, araçāo+gradagem, cultivador, queima, queinar gradagem, queima+cultivador), fertilização fosfatada $\left(22 \mathrm{~kg} \mathrm{ha}^{-1} \mathrm{de} P\right)$ e fertilização com macronutrientes $\left(22,45,25,28,18\right.$ e $15 \mathrm{~kg} \mathrm{ha}^{-1}$ de $\mathrm{P}, \mathrm{N}, \mathrm{K}, \mathrm{CaO}, \mathrm{MgO}$ e S, respectivamente) para a recuperação de pastagens de Brachiaria decumbens degradadas, onde $75 \%$ da fitomassa disponivel eram de invasoras. Os tratamentos físico-mecânicos isolados nåo foram eficientes. A produção de massa seca sem adubação foi de $844 \mathrm{~kg} \mathrm{ha}^{-1}$, enquanto que a aplicação $22 \mathrm{~kg}$ $\mathrm{ha}^{-1}$ de $\mathrm{P}$ aumentou a produção para $3.386 \mathrm{~kg} \mathrm{ha}^{-1}$. Já com a fertilizaçãa completa, a produção de massa seca passou a $4.266 \mathrm{~kg} \mathrm{ha}^{-1}$. O efeito principal da fertilização teve reflexos sobre a cobertura do solo pelas invasoras. Nos tratamentos sem fertilizantes a cobertura do solo pelas invasoras alcançou $66 \%$, ao passo que nos tratamentos com fertilização não superava $18 \%$.

Soares Fitho et al. (1992) realizaram um experimento na região de Marlia-SP no qual avaliaram a recuperaf̧̃̃o de uma pastagem degradada de $B$. decumbens com 10 anos de uso, estabelecida em um solo podzólico vermelho amarelo, vtilizando as seguintes estratégias: gradagem; adubação com macro e micronutrientes, incluindo $\mathrm{N}$; e associação de gradagem mais adubação com macro e micronutrientes, porém sem inchuir N. A adubação completa favoreceu a produção de massa seca da parte aérea e das rázes nos dois anos consecutivos de avaliação, enquanto que a gradagem combinada com adubação sem $\mathrm{N}$ aumentou a produção apenas no primeiro ano.

Embora a $B$. decumbens seja tida como uma das gramíneas tropicais mais tolerantes a níveis relativamente altos de alumínio trocável e baixos teores de cálcio no solo 
(Botrel, 1990; Wemer, 1994), os resultados obtidos em alguns trabahos sugerem que a prática da calagem pode ser eficiente para a recuperagäo de pastagens degradadas dessa gramínea, especialmemte aquelas que recebem adubacâo nitrogenada (Carriel et al, 1995; Canvalho et al, 1990, 1991, 1992).

Entretamto, a calagem em pastagens já formadas apresenta uma dificuldade relacionada com o modo de aplicação do calcário, que normalmente é aplicado em cobertura Nesse caso, a movimentaçäo dos cátions cálcio $\left(\mathrm{Ca}^{2+}\right)$ e magnésio $\left(\mathrm{Mg}^{2+}\right)$, adicionados como calcário dolomítico, no perfil do solo depende de uma série de fatores, tais como: quantidade de água que se move através do perfil, textura do solo, granulometria do calcário, nivel inicial

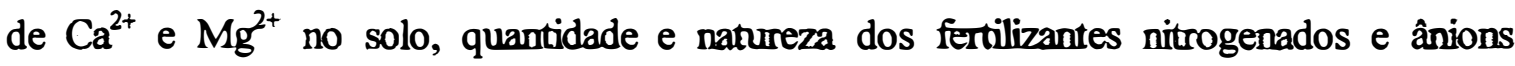
acompanhantes tais como nitrato $\left(\mathrm{NO}_{3}\right)$ e sulfato $\left(\mathrm{SO}_{4}{ }^{2}\right)$, e ácidos orgânicos, resultantes da mineralizaçăo da matéria orgânica (Gonzalez-Erico, 1979; Quaggio et al, 1985; Raij et al., 1982; Ritchey et al, 1980).

Carvalho et al. (1992) avaliaram a resposta da $B$. decumbens à calagem (0 a 4 tha) em cobertura, na presença de adubação nitrogenada, em um latossolo vermelho-amarelo álico. Os autores verificaram que a resposta da braquiária à calagem tendeu a aumentar com o tempo e com as doses do fertilizante nitrogenado.

\subsection{Efeitos das práticas de recuperação de pastagens na alteração dos atributos do solo}

Considerando que a ciclagem eficiente dos nutrientes é um fator chave na manutenção da fertilidade do solo e da sustentabilidade das pastagens, torna-se importante monitorar as alterações dos atributos do solo decorrentes das estratégias de recuperação adotadas. No entanto, a maioria dos trabalhos que focalizam esse tema limitam-se a avaliar a produção de massa seca da forrageira.

As práticas de manejo normalmente utilizadas para recuperação de pastagens, tais como o revolvimento do solo (aração, gradagem, subsolagem) e a aplicação de calcário e fertilizantes, promovem modificações em atributos fisicos e químicos do solo, como temperatura, umidade, aeração, $\mathrm{pH}$, teor de nutrientes e 
elementos tóxicos (Corsi \& Nussio, 1993; Carvalho et al. 1990). As alterações físicoquímicas no solo, por sua vez, afetam a atividade microbiana, com reflexos na ciclagem biogeoquímica dos elementos químicos, particularmente carbono, nitrogênio, enxofre e fósforo (Badalucco et al., 1992; Bardgett \& Leemans, 1995; Bolan et al., 1996; Goyal et al., 1992).

$\mathrm{O}$ aumento da fertilidade do solo influencia os microrganismos tanto pela maior dispomibilidade de nutrientes como pelo efeito indireto no crescimento das plantas, resultando em entrada de matéria orgânica no sistema (Bolan et al., 1996; Tate et al., 1991). Nesse contexto, Corsi \& Nussio (1993) demonstraram que após 19 anos de manejo intensivo (calagem e fertilizantes) de pastagem de capim elefante houve diminuição da acidez e acréscimos significativos nos teores de $\mathrm{P}$ disponível, cátions básicos, $\mathrm{pH}$ e matéria orgânica do solo. $\mathrm{O}$ conteúdo de matéria orgânica passou de 3,9 para 5,7 \%, o que foi atribuído à elevada produção de massa seca e reciclagem de resíduos da própria forrageira, as quais foram conseguidas, segundo os autores, mantendo-se a saturação por bases em tomo de $70 \%$.

Nos Estados Unidos, Schwab et al. (1990) quantificaram as alterações de atributos químicos de um solo sob pastagem fertilizada por 40 anos seguidos com nitrato de amônio e superfosfato simples. O conteúdo de matéria orgânica do solo não foi afetado pelo fertilizante fosfatado, mas aumentou significativamente com a adubação nitrogenada, a qual provocou também a redução do $\mathrm{pH}$ até $45 \mathrm{~cm}$ de profundidade.

Em um experimento de campo, Carvalho et al. (1992), testando o efeito da calagem em cobertura e de doses de nitrogênio sobre algumas características químicas do solo e a produção de $B$. decumbens, verificaram que dezenove meses após a calagem, o pH

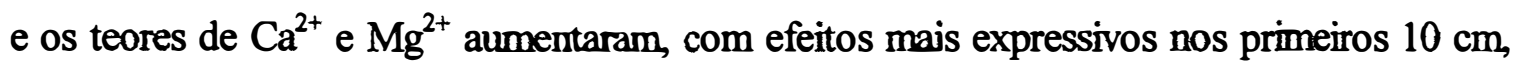
enquanto que a redução do $\mathrm{Al}^{3+}$ ocorreu até $15 \mathrm{~cm}$ de profundidade. Resultados semelhantes foram apresentados por outros autores, mesmo quando não houve resposta da forrageira (Adams, 1986; Werner et al., 1979).

A estimativa da biomassa microbiana do solo é uma importante ferramenta na compreensão do processo de ciclagem de nutrientes no sistema de pastagem, pois, 
além de atuar como agente de transformação da matéria orgânica, constiui um reservatório dinâmico de nutrientes (Jenkinson \& Ladd, 1981; Powlson, 1987). Alguns autores têm observado que a calagem em pastagens, ao aumentar o $\mathrm{pH}$ de solos ácidos, favorecem a reciclagem de nutrientes, pois a maioria das bactérias são sensiveis a acidez e a elementos tóxicos, como o Al (Adarns \& Adams, 1983; Badalucco et al., 1992; Bardgett \& Leemans, 1995).

A variação da biomassa microbiana do solo apresenta um padrão sazonal, devido a alternância das condições de umidade e temperatura durante o ano (Tate et al., 1991). Vários trabalhos têm mostrado que, em solos sob pastagens relativamente férteis, a biomassa e a atividade microbiana são mais afetadas pela variação sazonal do que pela adição de fertilizantes (Bristow \& Jarvis, 1991;Perrot et al., 1992; Tate et al., 1991). Os picos mais elevados são observados na época chuvosa, coincidindo com a estação de crescimento da pastagem e maior disponibilidade de substrato (resíduos orgânicos e exsudatos das raízes). Por outro lado, nas condições onde as pastagens são cultivadas em solos ácidos e pobres em nutrientes, como é o caso do Brasil, o uso de fertilizantes promove o aumento da biomassa microbiana e dos nutrientes nela contidos (Bolan et al., 1996; Guerra et al., 1995; Fernandes, 1997), inclusive em experimentos de curta duração, onde não são detectados acréscimos no conteúdo de matéria orgânica total (Goyal et al., 1992).

No Brasil, Guerra et al. (1995) estimaram o conteúdo de P na biomassa microbiana em um solo cultivado com pastagem de Brachiaria decumbens fertilizada com fontes de $\mathrm{P}\left(87 \mathrm{~kg} \mathrm{ha}^{-1}\right)$ em diferentes épocas de aplicação. $\mathrm{O}$ conteúdo de $\mathrm{P}$ microbiano aumentou de 7,7 a $13,7 \mathrm{mg} \mathrm{kg}^{-1}$ solo, respectivamente, no controle e com superfosfato triplo aplicado na semeadura e em cobertura. Os autores observaram que, aproximadamente cinco anos após a semeadura da braquiária, a biomassa microbiana encontrava-se mais enriquecida com $\mathrm{P}$ na parcela adubada com superfosfato do que naquela não adubada.

A determinação da biomassa microbiana do solo por sí só não fornece informações sobre sua atividade. Para isso é necessário a avaliação de alguma medida de 
sua reciclagem no solo como, por exemplo, o $\mathrm{C}-\mathrm{CO}_{2}$ respirado (Anderson \& Domsch, 1993; Brookes, 1985). A relaçõe $\mathrm{C}$ microbiano:C orgânico total $(\mathrm{Cmic}: \mathrm{Ct}$ ), tem sido útil como índice para monitorar a dinâmica da matéria orgânica em sistemas agrícolas (Anderson \& Domesh, 1989). Da mesma forma, as taxas de mineralização de C e N podem ser influenciadas pelo manejo, e as taxas líquidas de mineralização e nitrificação do $\mathrm{N}$ do solo são de particular interesse, dada a importância do nitrogênio para o crescimento das plantas. No entanto, estas medidas não têm consideradas nas pesquisas sobre recuperação de pastagens degradadas no Brasil.

Assim, acredita-se que a avaliação de parâmetros microbiológicos do solo, como a estimativa da biomassa microbiana $\mathrm{C}, \mathrm{N}$ e $\mathrm{P}$, as taxas líquidas de mineralização e nitrificação do nitrogênio e taxas de liberação de $\mathrm{CO}_{2}$, possam contribuir para a melhor compreensão do processo de ciclagem de nutrientes em pastagens degradadas, submetidas à diferentes práticas de recuperação. 


\section{MATERIAL E MÉTODOS}

\subsection{Localização e descrição do meio fisico}

O presente estudo foi desenvolvido em um experimento de campo instalado na Fazenda Santa Maria ( $22^{\circ} 30^{\prime}$ S e $48^{\circ} 00^{\prime}$ O), município de São Pedro-SP (Figura 1), em junho de 1995 pelo Departamento de Zootecnia da Escola Superior de Agronomia "Luiz de Queiróz" (ESALQ)/USP (Piracicaba-SP). O objetivo foi a recuperação de uma pastagem degradada de Brachiaria decumbens Stapf, visando sua exploração intensiva, através da aplicação de calcários de diferentes qualidaddes (PRNT $=55,70$ e $90 \%$ ), em cobertura ou incorporados ao solo com grade, para atingir níveis pré-estabelecidos de saturação por bases (40,60 e $80 \%$ ), combinados ou não com adubação completa (NPK e micronutrientes). A pastagem encontrava-se degradada, apresentando áreas de solo descoberto e presença de plantas invasoras.

A pastagem de $B$. decumbens foi implantada em 1985, onde anteriormente havia uma infestação de gramão.(Papalum notatum). No plantio foi feita a correção do solo com $2 \mathrm{t} \mathrm{ha}^{-1}$ de calcário dolomítico e adubação fosfatada com $400 \mathrm{t} \mathrm{ha}^{-1}$ de superfosfato simples ${ }^{1}$. A taxa de lotação do pasto é variável durante o ano, mas não ultrapassa 1,8 unidades animais por hectare.

O solo da área experimental é classificado como areia quartzosa álica (AQ) A moderado (Oliveira \& Prado, 1989), derivado de arenito com formação Pirambóia (IPT, 1981). A análise química do solo realizada antes da instalação do

\footnotetext{
${ }^{1}$ Comunicação pessoal do proprietário da Fazenda, Sr. Eduardo Ferraz.
} 
experimento (Tabela 1) indicou elevado nível de acidez e teores muito baixos de fósforo e saturação por bases, sendo estes mais acentuados com o aumento da profundidade.

O clima da região é Cwa (Köppen), tropical úmido, com três meses mais secos no inverno (junho, julho, agosto) e chuvas no verão. A precipitação e a temperatura média anual são, respectivamente, $1.441 \mathrm{~mm}$ e $21,7{ }^{\circ} \mathrm{C}$ e suas médias mensais, durante o período do experimento no campo, encontram-se representadas graficamente na Figura 2. A altitude média da região é de $620 \mathrm{~m}$ e o relevo característico é ondulado, sendo que a área experimental localiza-se na parte mais plana do topo da paisagem.

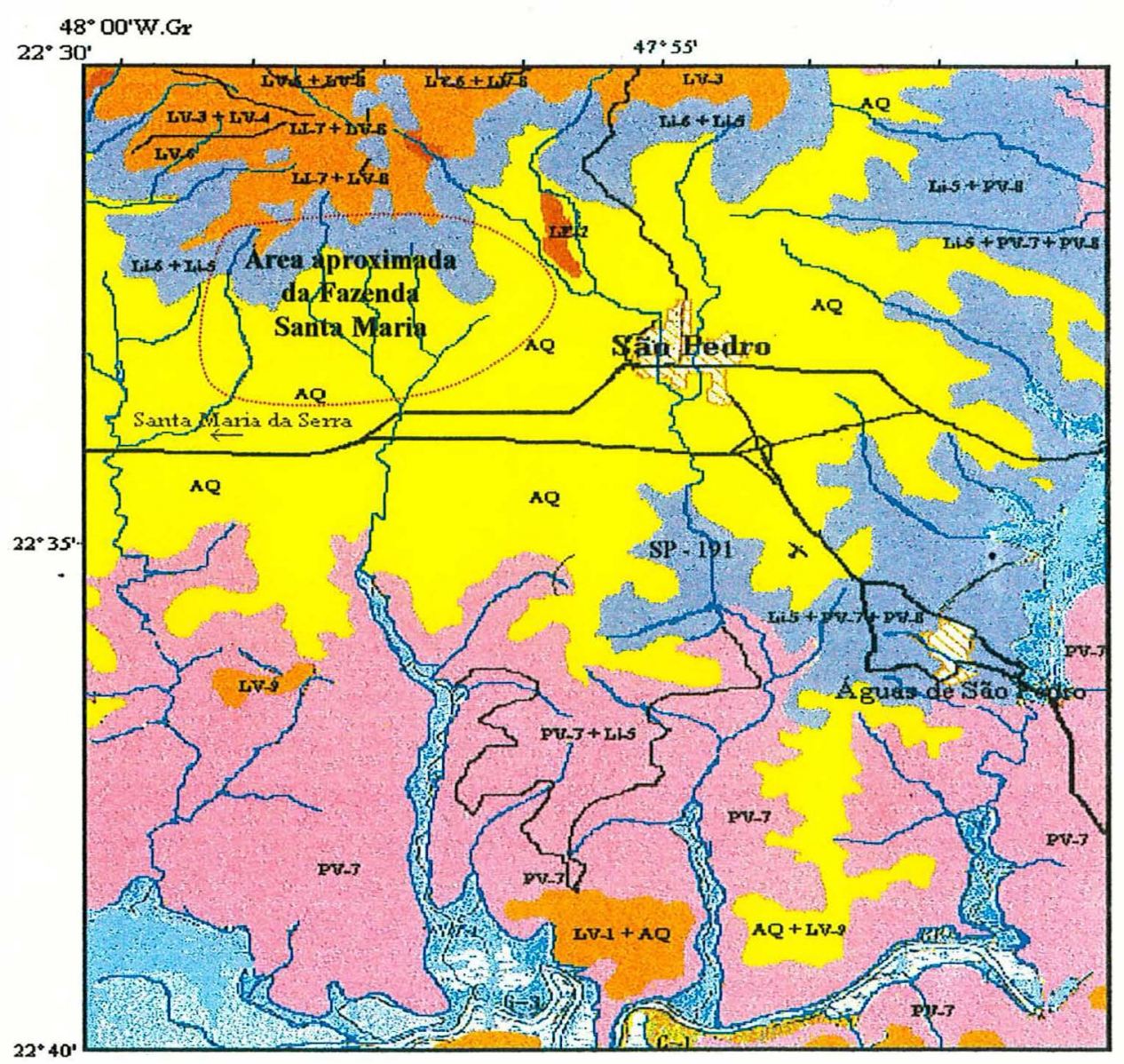

Figura 1. Mapa de solos da região de São Pedro (SP), incluindo a área aproximada ocupada pela Fazenda Santa Maria. Escala 1:100.000. Adaptado de Oliveira \& Prado (1989). 
Tabela 1. Resultados da análise quínica do solo sob pastagem degradada de Brachiaria decumbens antes da implantação do experimento (junho de 1995).

\begin{tabular}{|c|c|c|c|c|c|c|c|c|c|c|c|c|}
\hline Profundidade & $\mathrm{pH}$ & $\begin{array}{l}\text { Carbono } \\
\text { orgânico }\end{array}$ & $\begin{array}{c}\mathbf{P} \\
\text { disponível }\end{array}$ & $\mathrm{Ca}^{2+}$ & $\mathrm{Mg}^{2+}$ & $\overline{\mathrm{K}^{+}}$ & $\overline{\mathrm{Al}^{3+}}$ & $\overline{\mathrm{H}^{+}+\mathrm{Al}^{3+}}$ & SB & CTC & V & m \\
\hline (cm) & $\left(\mathrm{CaCl}_{2}\right)$ & $\left(\mathrm{g} \mathrm{kg}^{-1}\right)$ & $\left(\mathrm{mg} \mathrm{dm}^{-3}\right)$ & & & & $\mathrm{mm}$ & $\bar{l} \mathrm{~d} d \mathrm{n}$ & & - & $-\%$ & 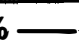 \\
\hline $0-5$ & 4,2 & 12,7 & 2 & 7,0 & 6,0 & 1,1 & 5,0 & 28,0 & 14,1 & 42,1 & 33,5 & 26,2 \\
\hline $5-10$ & 4,1 & 11,4 & 2 & 8,1 & 5,0 & 0,7 & 5 , & 34 & 13,7 & 47,7 & 28,7 & 26,7 \\
\hline $10-30$ & 3,9 & 11,4 & 3 & 5,0 & 3,0 & 0,3 & 10,0 & 38,0 & 8,3 & 46,3 & 17.2 & 54 \\
\hline
\end{tabular}

P disponivel $=$ fösforo disponível determinado pelo Método da Resina (Raij et al., 1987)

\subsection{Tratamentos e delineamento experimental}

O experimento de campo, da forma como foi instalado originalmente pelo Departamento de Zootecnia, foi constituído de 24 tratamentos, englobando as combinações de PRNT e método de aplicação do calcário, níveis de saturação por bases ( $V$ \%) e presença ou ausência de adubação. O delineamento utilizado foi o de blocos inteiramente casualizados com quatro repetições, totalizando 96 parcelas. Cada parcela possuia $10 \mathrm{~m}^{2}(2 \mathrm{~m} \times 5 \mathrm{~m})$ de área total e $3 \mathrm{~m}^{2}(1 \mathrm{~m} \times 3 \mathrm{~m})$ de área útil (Figura 3).

No presente trabalho, porém, considerando a dificuldade de realizar as análises físicas e microbiológicas em um número muito grande de amostras, optou-se por selecionar seis tratamentos, fixando-se o PRNT do calcário em $70 \%$ e o nível de saturação por bases em $80 \%$, equivalente à $3,5 \mathrm{t} \mathrm{ha}^{-1}$ de calcário dolomítico. $\mathrm{O}$ critério adotado baseou-se na produção de massa seca de forragem no primeiro ano (1995/96), buscando-se avaliar também uma possível correção da acidez do subsolo com o nível mais elevado de saturação por bases.

Assim, os seis tratamentos avaliados no presente trabalho foram:

$\mathrm{T}_{1}$ - Testemunha $(\mathrm{T})$

$\mathrm{T}_{2}$ - Gradagem (G)

$\mathrm{T}_{3}$ - Calcário aplicado na superficie do solo (CS)

$\mathrm{T}_{4}$ - Calcário incorporado a $20 \mathrm{~cm}$ de profundidade através de gradagem (CG)

$\mathrm{T}_{5}$ - Calcário aplicado na superfície + fertilização com macro e micronutrientes (CSF)

$\mathrm{T}_{6}$ - Calcário incorporado + fertilização com macro e micronutrientes (CGF) 

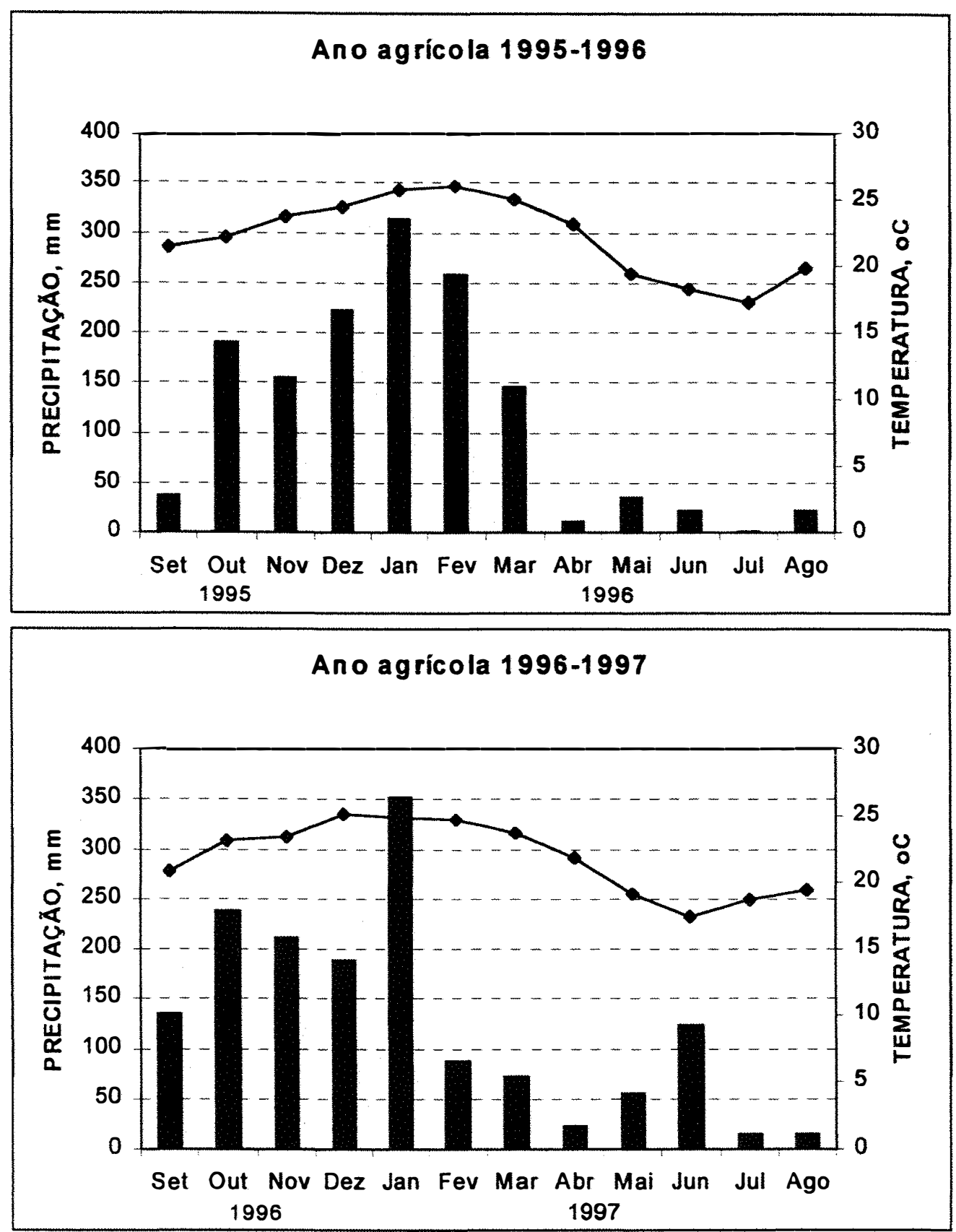

Figura 2. Precipitação e temperatura média mensal: a) ano agrícola de 1995/1996; b) ano agrícola de 1996/1997. Fonte: http://www.ciagri.usp.br/dfm/fisica.html. 


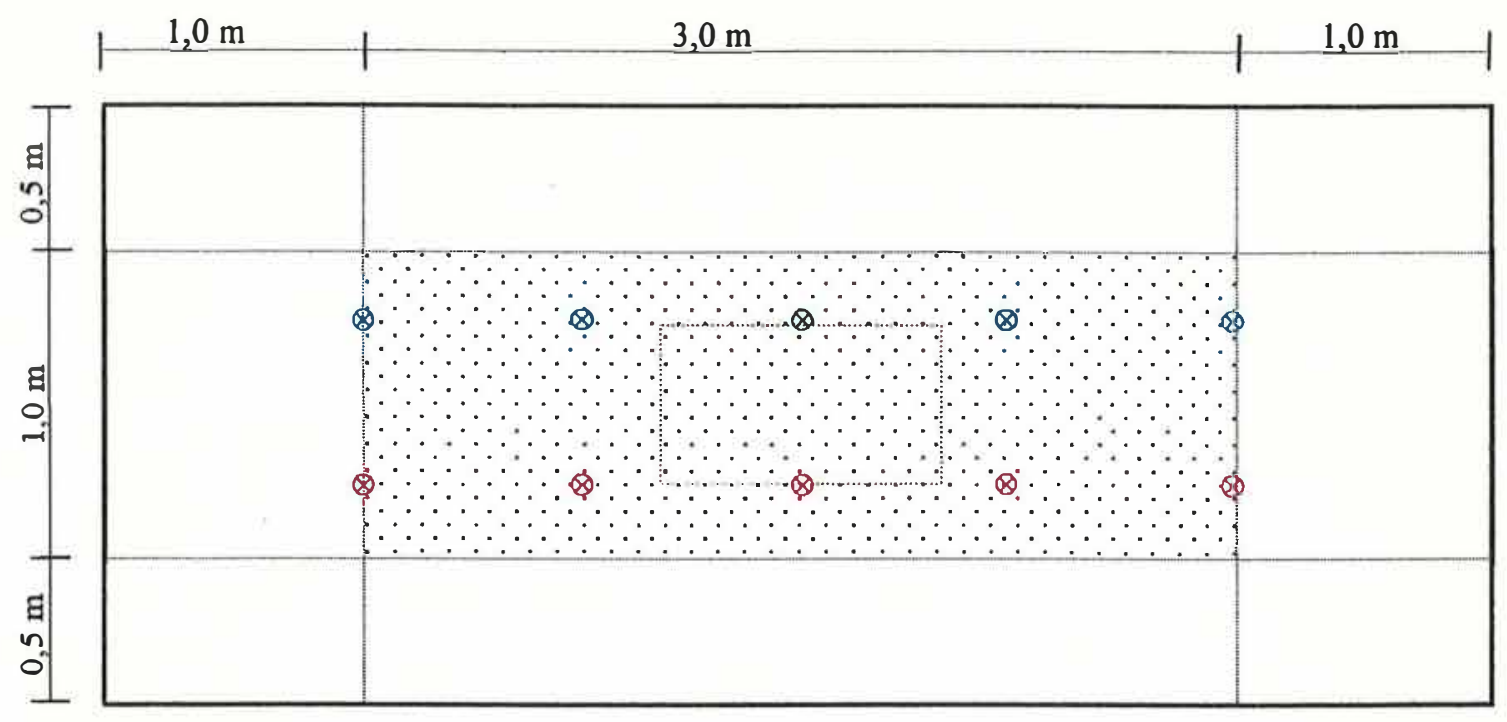

\section{Legenda:}

$\because \because$ Área útil da parcela $\quad \because \because$ Abertura de trincheira (raízes e análises fisicas)

$\otimes \quad 1^{\mathrm{a}}$ amostragem de solo $\otimes 2^{\mathrm{a}}$ amostragem do solo

Figura 3. Esquema da parcela experimental no campo, representando os pontos de amostragem do solo e o local de abertura da trincheira para coleta de amostras indeformadas e avaliação do sistema radicular da braquiária.

\subsection{Instalação e condução do experimento de campo}

O experimento foi iniciado em junho de 1995, quando a área experimental foi demarcada e cercada com arame farpado. $\mathrm{O}$ calcário foi aplicado a manualmente a lanço (parcelas $T_{3}$ a $T_{6}$ ) e a gradagem foi efetuada com grade de discos de 28 polegadas (parcelas $T_{2}, T_{4}$ e $T_{6}$ ).

Em 05 de outubro de 1995 foi realizado um corte de uniformização da braquiária em todas as parcelas a $15 \mathrm{~cm}$ da superficie do solo, com uma roçadeira, tracionada por trator. Neste mesmo dia foram adicionados os fertilizantes nas parcelas correspondentes aos tratamentos $\mathrm{T}_{5}$ e $\mathrm{T}_{6}$, nas seguintes quantidades: $160 \mathrm{~kg} \mathrm{ha}^{-1}$ de uréia $(70 \mathrm{~kg}$ de $\mathrm{N}), 500 \mathrm{~kg} \mathrm{ha}^{-1}$ de superfosfato simples (40 kg de P e $50 \mathrm{~kg}$ de S), $210 \mathrm{~kg} \mathrm{ha}^{-1}$ 
de cloreto de potássio (100 de K), $20 \mathrm{~kg} \mathrm{ha}^{-1}$ de bórax (2,2 $\mathrm{kg}$ de B), $15 \mathrm{~kg} \mathrm{ha}^{-1}$ de sulfato de zinco (3,0 kg de $\mathrm{Zn}$ e $2,7 \mathrm{Kg}$ de S) e $10 \mathrm{~kg} \mathrm{ha}^{-1}$ de sulfato de cobre $(1,3 \mathrm{~kg}$ de $\mathrm{Cu}$ e $1,8 \mathrm{Kg}$ de $\mathrm{S}$ ). As doses de $\mathrm{N}, \mathrm{P}, \mathrm{K}$ e micronutrientes utilizadas foram baseadas na análise química do solo e com o objetivo de atender as exigências da forrageira para produções elevadas e exploração intensiva da forragem.

No período das chuvas (outubro a março), após o corte para avaliação da produção de massa seca da braquiária em intervalos de aproximadamente 35 dias, as parcelas dos tratamentos $T_{5}$ e $T_{6}$ receberam $60 \mathrm{~kg} \mathrm{ha}^{-1}$ de $\mathrm{N}$ e $50 \mathrm{~kg} \mathrm{ha}^{-1}$ de $\mathrm{K}$, através da aplicação de $300 \mathrm{~kg} \mathrm{ha}^{-1}$ da fórmula 25-0-25.

\subsection{Avaliação da produção de massa seca da parte aérea}

A produção de massa seca da parte aérea da braquiária foi avaliada pelo Departamento de Zootecnia (ESALQ-USP) de outubro de 1995 a julho de 1997, a cada 35 dias durante o período das águas (outubro/março) e 60 dias no período mais seco (abril/setembro). Esta avaliação foi feita através do corte manual de quatro subamostras por parcela $(0,3 \times 0,6 \mathrm{~m})$, na altura de $15 \mathrm{~cm}$ do solo. No total, foram realizados sete cortes por ano agrícola, sendo cinco no período chuvoso e dois na época mais seca. As amostras foram secas em estufa de circulação forçada de ar à $65-70^{\circ} \mathrm{C}$ durante 48 horas, realizando-se, a seguir, a pesagem do material seco da forrageira. Os resultados de produção de massa seca apresentados no presente trabalho encontram-se publicados em Corsi et al. (1997) e foram gentilmente cedidos pelos autores para nortear a discussão.

\subsection{Análise química da parte aérea da braquiária}

As concentrações de macro e micronutrientes foram determinadas no material seco da parte aérea da braquiária, amostrado por ocasião das coletas de amostra de solo (estação chuvosa e estação seca de 1997). O corte da forrageira foi realizado da mesma forma descrita para a avaliação de produção de massa seca. O material coletado 
foi conduzido ao laboratório de Biogeoquímica de Solos (CENA-USP), onde foi imediatamente lavado com água destilada, seco em estufa a $65-70{ }^{\circ} \mathrm{C}$, moído e armazenado em frascos de vidro com tampa para posterior análise química.

A análise química do tecido vegetal foi feita pelo Laboratório de Nutrição Mineral de Plantas da ESALQ/USP, de acordo com os métodos descritos por Sarruge \& Haag (1974), Bataglia et al. (1983) e Malavolta et al. (1997), com exceção dos elementos carbono, nitrogênio e enxofre, os quais foram analisados no Laboratório de Biogeoquímica de Solos do CENA/USP:

a) Carbono (C) e enxofre (S): determinados por combustão à seco nos analisadores LECO-412 e LECO-SC132, respectivamente.

b) Nitrogênio total $(\mathbf{N})$ : analisado através de digestão à quente da matéria orgânica com uma mistura de ácido sufúrico e agentes catalisadores ( $\mathrm{Cu}$ e $\mathrm{Se})$ (micro-Kjeldahl) e posterior deteminação do $\mathrm{N}$ amoniacal formado por destilação a vapor, seguida de titulação com solução padronizada de $\mathrm{H}_{2} \mathrm{SO}_{4}$.

c) Fósforo $(\mathrm{P})$, potássio $(\mathrm{K})$, cálcio $(\mathrm{Ca})$, magnésio $(\mathrm{Mg})$, cobre $(\mathrm{Cu})$, ferro (Fe), manganês $(\mathrm{Mn})$ e zinco $(\mathrm{Zn})$ : obtenção do extrato por via úmida (digestão nítrico-perclórica). Cálcio, $\mathrm{Mg}, \mathrm{Cu}, \mathrm{Fe}, \mathrm{Mn}$ e $\mathrm{Zn}$ foram determinados por espectrometria de absorção atômica; o K por fotometria de chama de emissão; e o P foi determiando colorimetricamente em espectrofotômetro pelo método do vanado-molibdato de amônio.

c) Boro (B): extrato obtido por via seca (incineração em forno microondas) e determinação colorimétrica pelo método da azometina- $\mathrm{H}$, utilizando espectrofotômetro a $420 \mathrm{~nm}$.

\subsection{Avaliação do sistema radicular da braquiária}

A avaliação do sistema radicular foi efetuada no final do experimento, em agosto de 1997, utilizado-se os seguintes métodos: 1) filmagem de raízes no perfil, seguida de digitalização das imagens obtidas, processamento e análise das imagens digitais (Crestana et al., 1994); e 2) coleta de amostras de solo pelo método do monolito 
e posterior separação das raízes (Bohm, 1979; Kopke, 1981). Para isso, em cada uma das 24 parcelas experimentais foi aberta, manualmente, uma trincheira com $100 \times 50 \mathrm{~cm}$ de largura e $60 \mathrm{~cm}$ de profundidade. $O$ método do monolito permitiu a avaliação do sistema radicular através da sua densidade de massa (massa seca de raízes/volume de solo amostrado) e de comprimento (comprimento de raízes/volume de solo amostrado). Por outro lado, com a filmagem pôde-se determinar o comprimento das raízes, como também a distribuição destas no perfil do solo.

\subsubsection{Método auxiliado por processamento de imagens digitais}

Após a abertura da trincheira, o perfil do solo foi lavado com um jato d'água para a remoção de uma camada de solo em torno de $3 \mathrm{~mm}$ de espessura, de forma a promover uma melhor exposição das raízes. Em seguida, foi afixada ao perfil uma moldura de madeira, com dimensões internas de $50 \times 60 \mathrm{~cm}$, dividida por barbante em quadrículas de $10 \times 10 \mathrm{~cm}$, totalizando 30 quadrículas por perfil. A quantidade de raízes expostas em cada quadrícula foi avaliada através de imagens adquiridas com uma câmera de vídeo comum. Assim, no total obteve-se, respectivamente, 30, 120 e 720 imagens por perfil, por tratamento e no experimento como um todo. A figura 4 mostra um esquema do procedimento adotado para a obtenção das imagens no perfil do solo.

A digitalização das imagens foi efetuada utilizando-se uma placa digitalizadora para IBM-PC, com resolução espacial de 512 x 512 "pixels" e 256 tons de cinza por "pixel". As imagens digitalizadas foram processadas no programa SIARCS, desenvolvido pela EMBRAPA/CNPDIA (Crestana et al., 1994), para determinação do comprimento de raizes em cada quadrícula (Figura 5) . O SIARCS possui uma ferramenta que possibilita a subdivisão da imagem original, em função do número de linhas e colunas desejadas. Assim, dividiu-se a imagem de $10 \times 10 \mathrm{~cm}$ em 25 regiões de $2 \times 2 \mathrm{~cm}$, quantificando-se as raízes em cada uma delas (Figura 5f). Este procedimento foi importante para a confecção do gráfico de distribuição de raízes no perfil através da interpolação dos dados. 


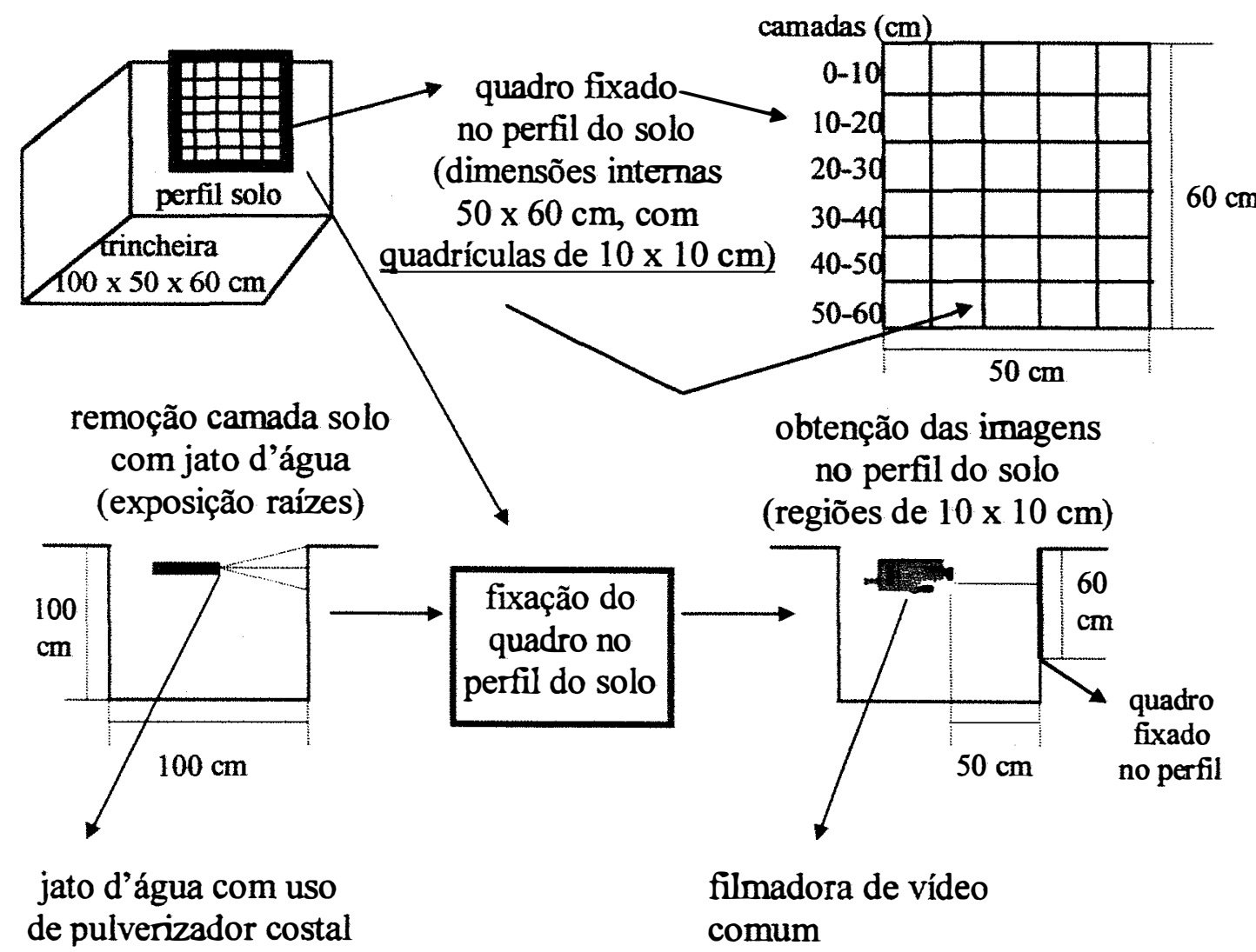

Figura 4. Esquema do procedimento utilizado para a obtenção das imagens de raízes no perfil do solo $(50 \times 60 \mathrm{~cm})$ em quadrículas de $10 \times 10 \mathrm{~cm}$.

\subsubsection{Método do monolito}

Após a filmagem, o perfil foi nivelado novamente com uma pá reta, raspando-se uma fina camada de solo onde as raízes estavam expostas. Na sequência, foram retiradas, via monolito $(10 \times 10 \times 3 \mathrm{~cm})$, duas amostras por cada camada de $0-10$, 10-20, 20-40 e 40-60 cm, resultando em 8 e 32 amostras por perfil e por tratamento, respectivamente. No geral, tomou-se 192 amostras em 24 perfis. As raizes foram separadas do solo através de sua dispersão sob água corrente, com agitação manual e utilização de um sistema de peneiras de malhas 0,5 e $0,2 \mathrm{~mm}$, e colocadas em estufa a 
$60{ }^{\circ} \mathrm{C}$ por 48 horas para a determinação de suas massas secas. Após a pesagem, as raízes separadas na peneira de $0,5 \mathrm{~mm}$ foram distribuídas numa bandeja de vidro com água sobre um "scanner" de mesa para a obtenção das respectivas imagens digitalizadas com resolução de 150 dpi (150 "pixels" por polegada), as quais foram processadas via SIARCS para a determinação do comprimento radicular. As raízes separadas na peneira de $0,2 \mathrm{~mm}$ foram consideradas raizes em decomposição, buscando-se obter correlação de suas massas secas com o ter de carbono do solo. As figuras 6 e 7 apresentam o esquema de amostragem e dos procedimentos adotados na quantificação das raízes pelo método do monolito.

\subsection{Coleta de amostras e análises químicas do solo}

As amostras de solo para a realização das análises químicas, biomassa microbiana e determinação das taxas de mineralização e nitrificação do nitrogênio foram coletadas em fevereiro e agosto de 1997, compreendendo as estações chuvosa e seca, respectivamente. Em cada parcela foram retiradas cinco subamostras (Figura 2) por meio de uma sonda de aço inoxidável (com 4,0 cm de diâmetro interno, nas profundidades de 0-10, 10-20, 20-40 e 40-60 cm, sendo a seguir misturadas para formar uma amostra composta por parcela e por profundidade citada. Após a coleta, as amostras de solo foram secas ao ar e passadas em peneira de $2 \mathrm{~mm}$ para posterior análise dos teores de $\mathrm{Ce}$ $\mathrm{N}$ total, $\mathrm{pH}, \mathrm{Ca}^{2+}, \mathrm{Mg}^{2+}, \mathrm{K}^{+}, \mathrm{Al}^{3+}, \mathrm{P}$ disponível, $\mathrm{H}^{+}+\mathrm{Al}^{3+}, \mathrm{N}-\mathrm{NO}_{3}{ }^{-}$e $\mathrm{N}-\mathrm{NH}_{4}^{+} . \mathrm{A}$ metodologia utilizada foi a descrita por Raij et al. (1987), exceto para C total, $\mathrm{N}$ total, $\mathrm{N}$ $\mathrm{NO}_{3}{ }^{-}$e $\mathrm{N}-\mathrm{NH}_{4}^{+}$.

O C total foi determinado por combustão a seco num analisador LECO CR-412, em amostras secas ao ar, moídas e peneiradas a 100 mesh. O $\mathrm{N}$ total foi analisado através de digestão sulfúrica com sais catalizadores (semimicro-Kjeldahl), determinação do $\mathrm{N}^{-\mathrm{NH}_{4}}{ }^{+}$formado por destilação a vapor e posterior titulação com uma solução padronizada de ácido sulfúrico (Bremner, 1996). O pH foi determinado em solução de $\mathrm{CaCl}_{2}$ 0,01 mol L ${ }^{-1}$, na proporção solo:solução de 1:2,5. Os cátions básicos 
trocáveis e o P disponível foram extraídos com a solução extratora Melich-3 (Melich, 1984). Os teores de $\mathrm{Ca}^{2+}, \mathrm{Mg}^{2+}$ foram determinados em espectrofotômetro de absorção atômica; o $\mathrm{K}^{+}$por espectrometria de chama de emissão; e o $\mathrm{P}$ por colorimetria em um espectrofotômetro a $660 \mathrm{~nm}$, após reação com molibdato de amônio e cloreto de estrôncio.

$\mathrm{O} \mathrm{Al}^{3+}$ trocável foi extrádo com $\mathrm{KCl} 1 \mathrm{~mol} \mathrm{~L}^{-1}$, agitando-se $5 \mathrm{~cm}^{3}$ de terra com $50 \mathrm{~mL}$ da solução por 15 minutos. O extrato obtido ficará em repouso durante 24 horas. Uma alíquota de $25 \mathrm{~mL}$ do líquido sobrenadante foi usada para determinação do $\mathrm{Al}^{3+}$ por titulometria com uma solução padronizada de $\mathrm{NaOH} 0,025 \mathrm{~mol} \mathrm{~L}^{-1}$, usando-se azul de bromotimol como indicador. A acidez potencial $\left(\mathrm{H}^{+}+\mathrm{AP}^{3+}\right)$ foi determinada por titulometria, após a extrafão com solução de acetato de cálcio $2 \mathrm{~mol} \mathrm{~L}^{-1}$ tamponado a pH 7,0.

Os teores de $\mathrm{N}-\mathrm{NH}_{4}^{+}$e N-NO${ }_{3}^{-}$foram determinados em um sistema de fluxo contínuo (FIA) após a extração de $10 \mathrm{~g}$ de amostras de solo fresco com $50 \mathrm{~mL}$ da solução de $\mathrm{KCl} 2 \mathrm{~mol} \mathrm{~L}^{-1}$ (Piccolo et al., 1994).

\subsection{Coleta de amostras e análises físicas do solo}

As amostragem foi realizada na mesma época e nas mesmas trincheiras utilizadas para a avaliação do sistema radicular (item 3.6). Foram analisados os atributos densidade e porosidade do solo (macroporosidade, microporosidade e porosidade total Para isso, foram coletadas, com anéis volumétricos $(4,8 \mathrm{~cm}$ de diâmetro e $3,0 \mathrm{~cm}$ de altura), duas amostras indeformadas por camada de interesse (0-10, 10-20, 20-40 e 40-60 $\mathrm{cm}$ ), totalizando 192 amostras. A densidade do solo foi determinada pelo método do anel volumétrico (Blake \& Hartge, 1986). A porosidade total foi determinada pelo método da saturação das amostras com água em mesa de tensão (Kiehl, 1979). A porosidade total foi subdividida em macroporosidade, englobando os poros que retêm água a uma tensão inferìor a $6 \mathrm{KPa}$ (poros $>0,05 \mathrm{~mm}$ ), e em microporosidade, envolvendo poros que retêm água acima dessa tensão (poros $<0,05 \mathrm{~mm}$ ). 
(a)

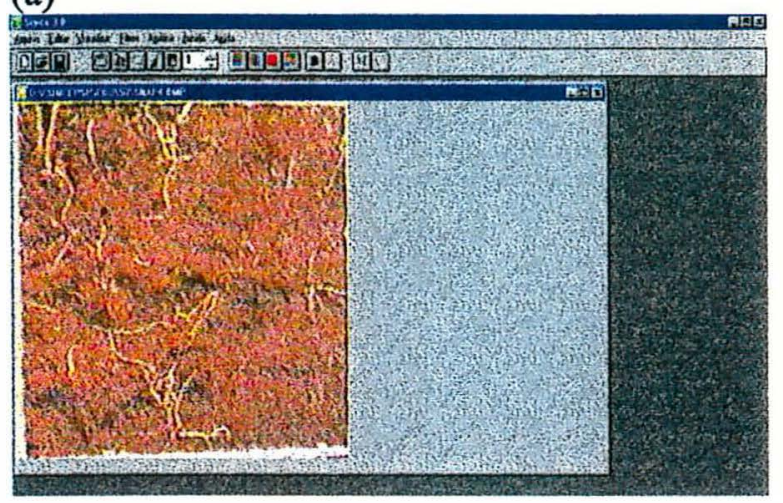

(c)

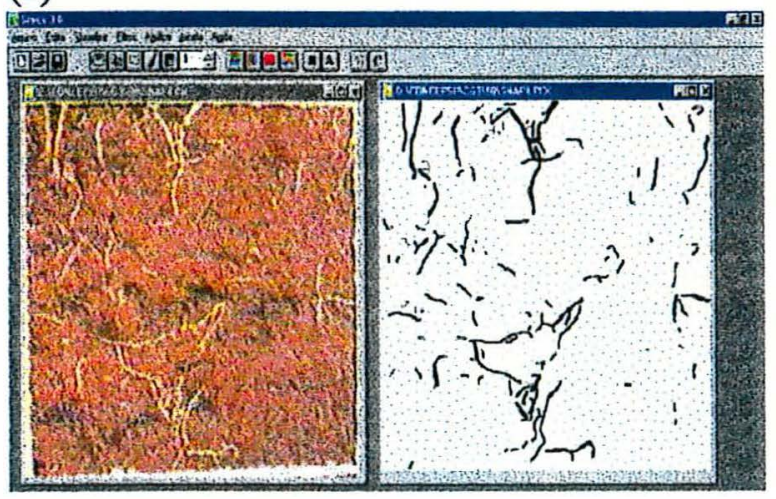

(e)

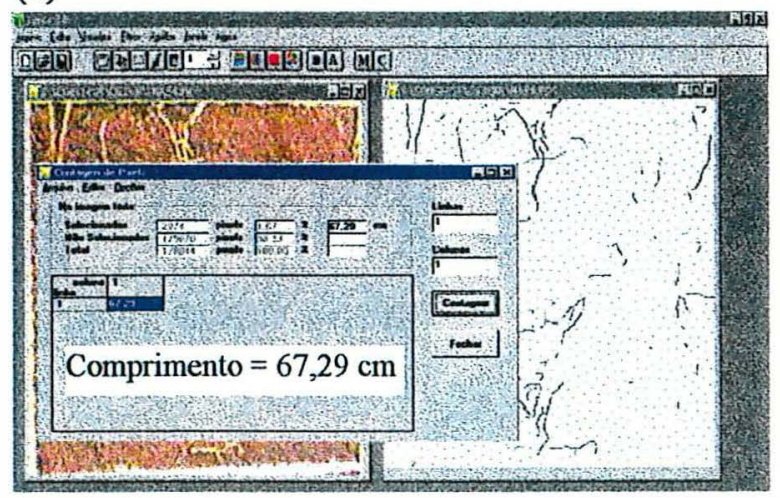

(b)

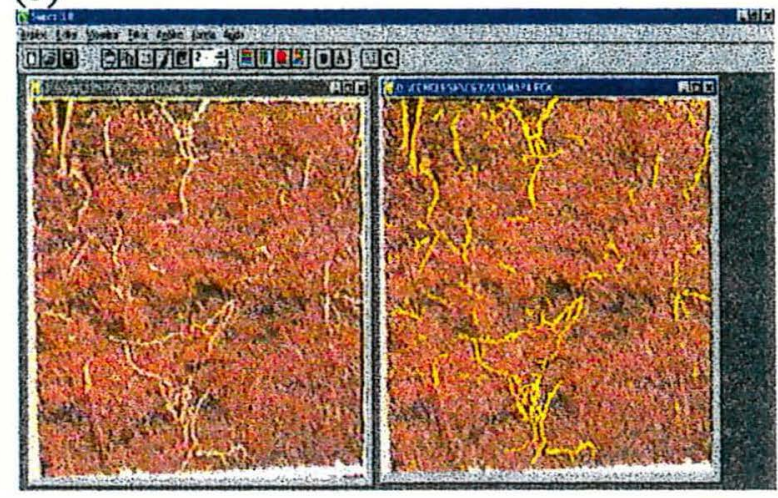

(d)

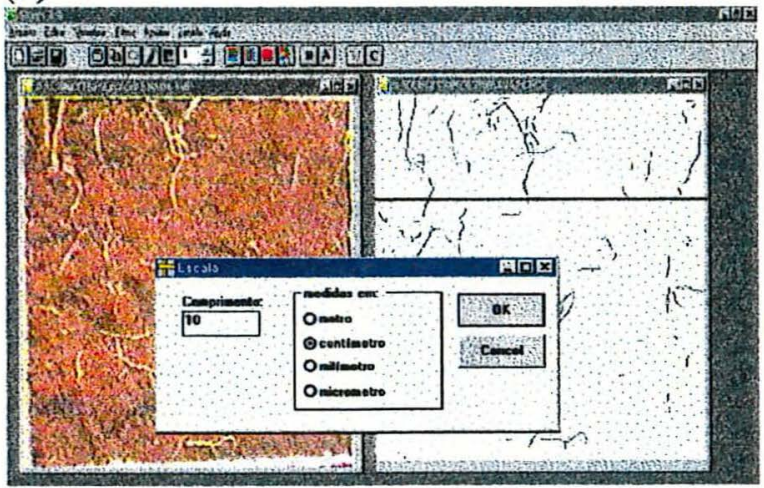

(f)

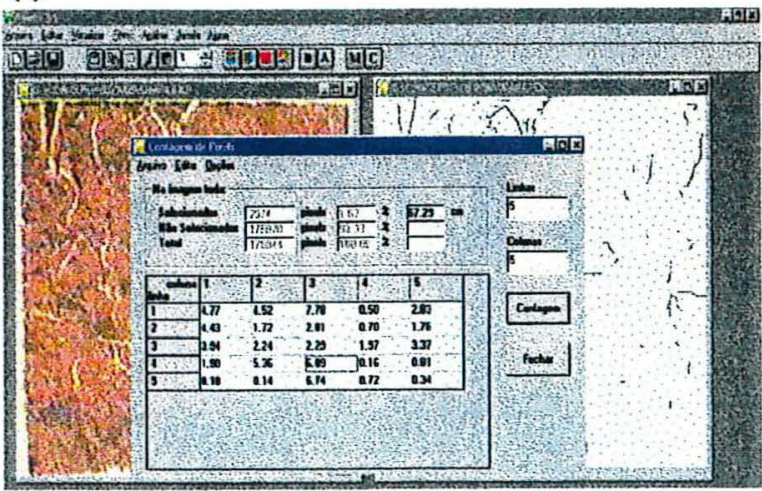

Figura 5. Processamento das imagens filmadas no SIARCS: a) imagem original; b) imagem colorida; c) binarização (preto e branco); d) afinamento para determinação do comprimento e linha referencial de comprimento conhecido; e) determinação do comprimento radicular na quadrícula de $10 \times 10 \mathrm{~cm}$; e f) determinação do comprimento radicular em regiões de $2 \times 2 \mathrm{~cm}$. 

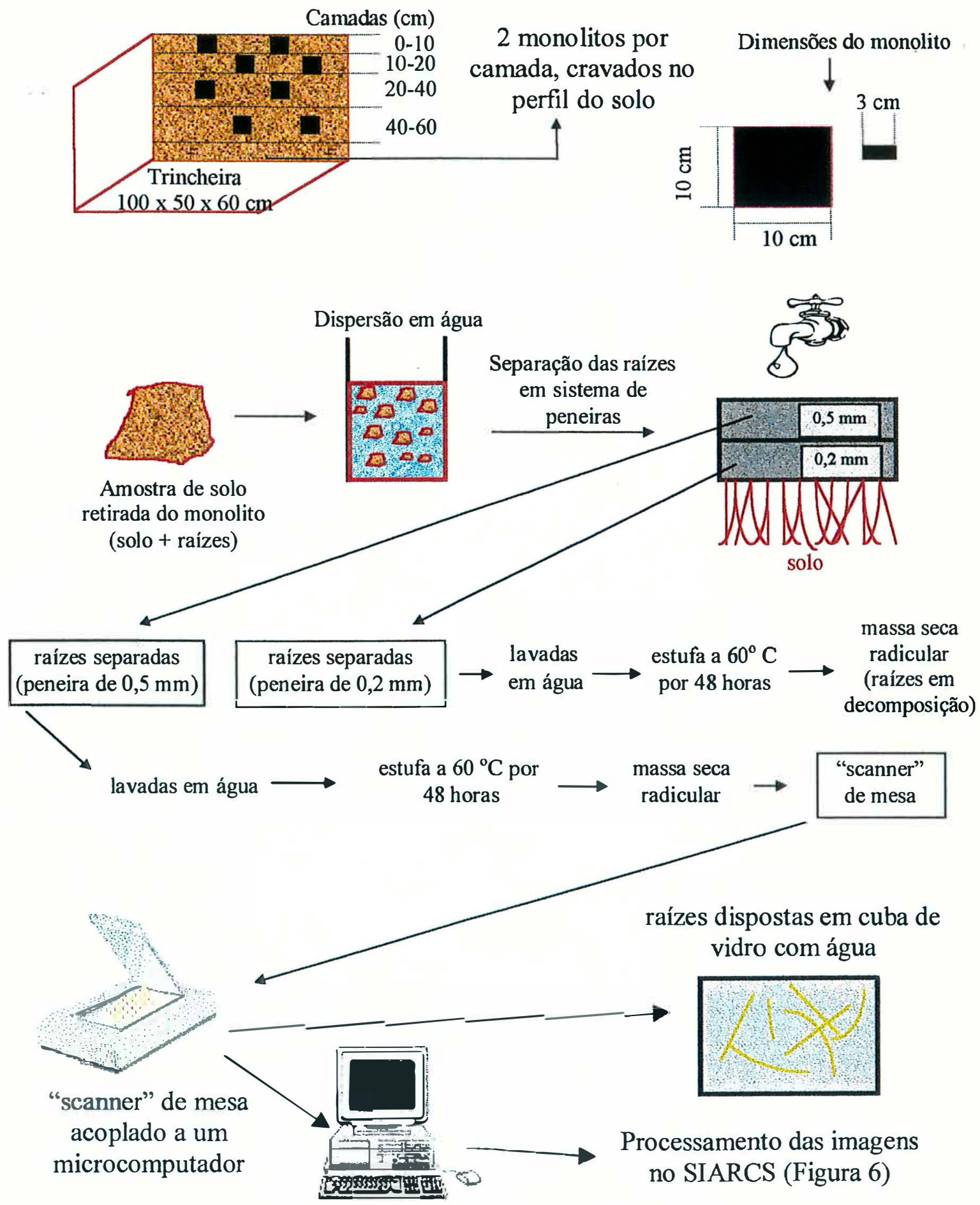

Figura 6. Esquema do procedimento adotado para coleta de amostras de raízes separação do solo e obtenção de imagens digitalizadas via "scanner" de mesa. 

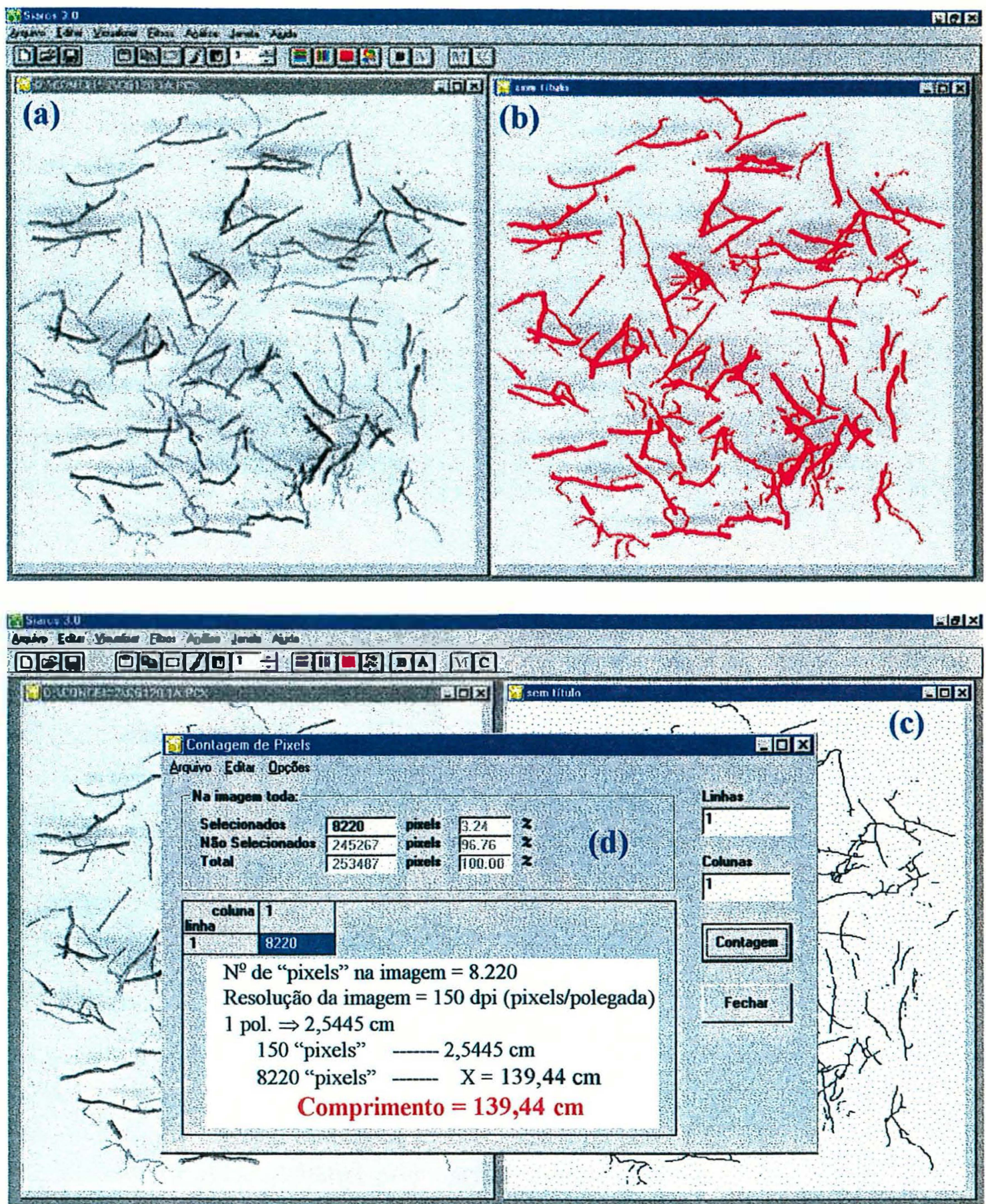

Figura 7. Processamento de imagens digitalizadas obtidas por "scanner" no SIARCS: a) imagem original b) raízes selecionadas; c) raízes afinadas para contagem do número de "pixels"; d) determinação do número de pixels, que foi utilizado para o cáculo do comprimento radicular. 


\subsection{Biomassa microbiana $\mathrm{C}, \mathrm{N}$ e $\mathrm{P}$ do solo}

A biomassa microbiana $\mathrm{C}, \mathrm{N}$ e $\mathrm{P}$ foi estimada pelo método da fumigaçãoextração (Brookes et al., 1982,1985; Vance et al, 1987) nas amostras de solo das camadas de 0-10 e 10-20 cm. No mesmo dia da coleta, as amostras foram peneiradas (malha de $4 \mathrm{~mm}$ ) para retirada do excesso de raízes e armazenadas em câmera fria a $4{ }^{\circ} \mathrm{C}$, onde permaneceram por cerca de 30 a dias, até a análise.

\subsubsection{Biomassa micrbiana C}

Dois dias após a retirada da câmera fria determinou-se a umidade das amostras de solo, ajustando-a, quando necessário, para $50 \%$ da sua capacidade de campo. Duas subamostras de solo úmido, pesando o equivalente a $25 \mathrm{~g}$ de solo seco em estufa a $105^{\circ} \mathrm{C}$, foram colocadas em frascos de vidro de $200 \mathrm{~cm}^{3}$. Uma das subamostras foi fumigada em um dissecador, revestido com papel-toalha umedecido e contendo um pequeno béquer com $25 \mathrm{~mL}$ de clorofórmio $\left(\mathrm{CHCl}_{3}\right)$ livre de álcool e pérolas de vidro. $\mathrm{O}$ dissecador foi evacuado com bomba de vácuo por 5 minutos até o $\mathrm{CHCl}_{3}$ borbulhar. Após 24 horas de fumigação, o bécker foi retirado e o vapor residual de $\mathrm{CHCl}_{3}$ no solo foi removido através de repetidas evacuações e retorno à pressão atmosférica. Para a extração, as subamostras fumigada e não fumigada (controle) foram transferidas para erlenmayer de $250 \mathrm{~cm}^{3}$, adicionando-se $100 \mathrm{~mL}$ de $\mathrm{K}_{2} \mathrm{SO}_{4} 0,5 \mathrm{~mol} \mathrm{~L}^{-1}$. O conjunto foi agitado por 30 minutos e a suspensão resultante foi filtrada (papel de filtro "Whatman $\mathrm{n}^{\mathrm{0}}$ 42”). Ambas extrações foram feitas em triplicata.

O C orgânico foi determinado pela digestão de $8 \mathrm{~mL}$ do extrato com $2 \mathrm{~mL}$ de $\mathrm{K}_{2} \mathrm{Cr}_{2} \mathrm{O}_{7} 0,067 \mathrm{~mol} \mathrm{~L}-1$ e $15 \mathrm{~mL}$ de uma mistura de $\mathrm{H}_{2} \mathrm{SO}_{4}$ e $\mathrm{H}_{3} \mathrm{PO}_{4}$ concentrados na proporção de 2:1 (v/v). Após o aquecimento em banho-maria por 1 hora, adicionou-se $10 \mathrm{~mL}$ de água deionizada e o excesso de dicromato foi determinado por titulação com $\mathrm{Fe}\left(\mathrm{NH}_{4}\right)_{2}\left(\mathrm{SO}_{4}\right)_{2} \cdot 6 \mathrm{H}_{2} 0$ (sulfato ferroso amoniacal) $0,33 \mathrm{~mol} \mathrm{~L}^{-1} \mathrm{em}$ $\mathrm{H}_{2} \mathrm{SO}_{4}, 0,4 \mathrm{~mol} \mathrm{~L}^{-1}$, usando-se fenolftaleína como indicador. A quantidade de dicromato 
consumido foi dada pela diferença entre o excesso titulado no extrato de solo e aquele que sobrou numa digestão em branco de $8 \mathrm{~mL}$ do extrator $\left(\mathrm{K}_{2} \mathrm{SO}_{4} 0,5 \mathrm{~mol} \mathrm{~L}^{-1}\right)$. A biomassa microbiana $C$ foi calculada pela seguinte equação:

\section{Biomassa $\mathrm{C}\left(\mathrm{mg} \mathrm{Kg}{ }^{-1}\right.$ solo seco $)=\left(\mathrm{C}_{\mathrm{F}}-\mathrm{C}_{\mathrm{NF}}\right) / 0,33$}

onde: $\mathrm{C}_{\mathrm{F}}=$ quantidade de carbono ( $\mathrm{mg} \mathrm{Kg}^{-1}$ solo seco) na amostra fumigada $\mathrm{C}_{\mathrm{NF}}=$ quantidade de carbono ( $\mathrm{mg} \mathrm{Kg}^{-1}$ solo seco) na amostra não fumigada $0,33 \Rightarrow$ fator de correção $\left(\mathrm{K}_{\mathrm{EC}}\right)$ que representa a eficiência de extração do carbono (Sparling \& West, 1988).

\subsubsection{Biomassa $\mathbf{N}$}

Do mesmo extrato utilizado para a biomassa $\mathrm{C}$, pipetou-se uma alíquota de $30 \mathrm{~mL}$ em tubo de digestão, ao qual acrescentou-se $1 \mathrm{~mL}$ de $\mathrm{H}_{2} \mathrm{SO}_{4}$ concentrado. Em seguida, o tubo foi colocado em estufa a $60^{\circ} \mathrm{C}$, visando a concentração do extrato o máximo possível. $\mathrm{O} \mathrm{N}$ total no extrato concentrado foi determinado através de digestão

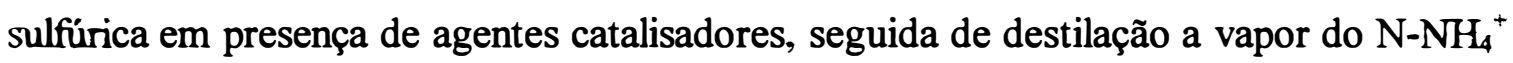
formado no digerido (método semimicro-Kjeldahl) e subsequente titulação do $\mathrm{N}-\mathrm{NH}_{3}$ coletado na solução $\mathrm{H}_{3} \mathrm{BO}_{3}$-indicadores com solução padronizada de $\mathrm{H}_{2} \mathrm{SO}_{4}$ (Bremner * Mulvaney, 1982). A biomassa microbiana $\mathrm{N}$ foi então calculada pela fórmula:

Biomassa $\mathrm{N}\left(\mathrm{mg} \mathrm{Kg}{ }^{-1}\right.$ solo seco $)=\left(\mathrm{N}_{\mathrm{F}}-\mathrm{N}_{\mathrm{NF}}\right) / 0,54$

onde: $\mathrm{N}_{\mathrm{F}}=\mathrm{N}$ total ( $\mathrm{mg} \mathrm{Kg}^{-1}$ solo seco) extraído na amostra fumigada $\mathrm{N}_{\mathrm{NF}}=\mathrm{N}$ total ( $\mathrm{mg} \mathrm{Kg}^{-1}$ solo seco) extraído na amostra não fumigada (controle) $0,54 \Rightarrow$ fator de correção $\left(\mathrm{K}_{\mathrm{EN}}\right)$ que representa a eficiência de extração do $\mathrm{N}$ (Brookes et al., 1985). 


\subsubsection{Biomassa $P$}

A biomassa microbiana $\mathrm{P}$ foi estimada pelo método da fumigaçãoextração do $\mathrm{P}$ inorgânico (Brookes et al., 1982, 1984). Três subamostras de solo úmido (equivalentes a $5 \mathrm{~g}$ de solo seco em estufa a $105^{\circ} \mathrm{C}$ ) foram colocadas em frascos de vidro. Uma delas foi fumigada com $\mathrm{CHCl}_{3}$ por 24 horas, de acordo com o procedimento descrito no 3.9.1. No dia seguinte, a amostra fumigada e uma das não fumigadas foram extraídas com $100 \mathrm{~mL}$ de $\mathrm{NaHCO}_{3} 0,5 \mathrm{~mol} \mathrm{~L}^{-1}$ (pH 8,5) em agitador mecânico por 30 minutos. Uma fração do $\mathrm{P}$ liberado dos microrganismos pelo clorofórmio pode ser adsorvida pelo solo durante a fumigação-extração. Por isso, na terceira subamostra (denominada doravante de não fumigada padrão, NFP ) adicionou-se uma quantidade de $\mathrm{P}$ equivalente a $25 \mathrm{mg} \mathrm{kg}^{-1}$ de solo seco (como $\mathrm{KH}_{2} \mathrm{PO}_{4}$ ) durante a extração, que foi corrigida no cálculo. Após a filtragem, os extratos foram acidificados com aproximadamente $7 \mathrm{~mL}$ de $\mathrm{H}_{2} \mathrm{SO}_{4} 4,5 \mathrm{~mol} \mathrm{~L}^{-1}$ até pH 1,5 e resfriados em geladeira por uma noite.

O P foi medido colorimetricamente em espectrofotômetro a $660 \mathrm{~nm}$, após reação com molibdato de amônio em meio sulfúrico, na presença de ácido ascórbico como agente redutor (Olsen \& Sommers, 1982). Os resultados, expressos com base na massa de solo seco a $105^{\circ} \mathrm{C}$ por 24 horas, foram médias de três réplicas de laboratório para cada repetição de campo.

$\mathrm{O}$ conteúdo de $\mathrm{P}$ microbiano foi calculado de acordo com a fórmula (Brookes et al., 1982):

\section{Biomssa $\mathrm{P}\left(\mathrm{mg} \mathrm{kg}^{-1}\right.$ solo $)=25\left(\mathrm{P}_{\mathrm{F}}-\mathrm{P}_{\mathrm{NF}}\right) / 0,4\left(\mathrm{P}_{\mathrm{NFP}}-\mathrm{P}_{\mathrm{NF}}\right)$}

onde: 25 = quantidade de $\mathrm{P}$ adicionada na amostra não fumigada padrão ( $\mathrm{mg} \mathrm{kg}^{-1}$ solo)

$\mathrm{P}_{\mathrm{F}}=\mathrm{P}$ extraído na amostra fumigada ( $\mathrm{mg} \mathrm{kg}^{-1}$ solo)

$\mathrm{P}_{\mathrm{NF}}=\mathrm{P}$ extraído na amostra não fumigada ( $\mathrm{mg} \mathrm{kg}^{-1}$ solo)

$\mathrm{P}_{\text {NFP }}=\mathrm{P}$ extraído na amostra não fumigada padrão ( $\mathrm{mg} \mathrm{kg}^{-1}$ solo)

$0,4 \Rightarrow$ fator de correção $\left(K_{E P}\right)$, pois apenas $40 \%$ do $P$ microbiano é liberado pelo

$\mathrm{CHCl}_{3}$ e extraído pelo $\mathrm{NaHCO}_{3}$ (Brookes et al., 1982). 


\subsection{Atividade microbiana}

A atividade microbiana foi estimada em laboratório, através da medida do C$\mathrm{CO}_{2}$ liberado no processo de oxidação dos compostos orgânicos no solo. Para isso, amostras de solo úmido (correspondente a $50 \mathrm{~g}$ de solo seco) das camadas 0-10 e 10-20 cm foram colocados em frascos de vidro hermeticamente fechados, contendo um frasco menor com 20 $\mathrm{mL}$ de $\mathrm{NaOH} 1 \mathrm{~mol} \mathrm{~L}^{-1}$ para capturar o $\mathrm{CO}_{2}$. A umidade do solo foi mantida a $60 \%$ da capacidade de campo. A intervalos que variaram de 10 a 15 dias, no período total de 80 dias de incubação, os frascos com $\mathrm{NaOH}$ foram substituídos por outros contendo a mesma solução. Quantificou-se o $\mathrm{C}-\mathrm{CO}_{2}$ despreendido em cada amostra, pela titulação do $\mathrm{NaOH}$ residual (que não reagiu com o $\mathrm{CO}_{2}$ ) com $\mathrm{HCl} 0,5 \mathrm{~mol} \mathrm{~L}^{-1}$, após precipitação do carbonato devido a adição de $2 \mathrm{~mL}$ de sohução saturada de $\mathrm{BaCl}_{2}$.

\subsection{Taxas líquida de mineralização e nitrificação do nitrogênio do solo}

As amostras de solo para as determinaçōes do $\mathrm{N}$ inorgânico e das taxas líquidas de mineralização e nitrificação foram preparadas no mesmo dia da coleta, removendo-se as raízes. Uma subamostra de aproximadamente $10 \mathrm{~g}$ de solo fresco foi extraido com $50 \mathrm{~mL}$ de $\mathrm{KCl} 2 \mathrm{~mol} \mathrm{~L}^{-1}$ para determinar as concentrações de $\mathrm{N}$ inorgânico. Após 24 horas, estes extratos foram filtrados e preservados com fenil acetato de mercúrio a uma concentração final de $0,5 \mathrm{mg} \mathrm{L}^{-1}$. Uma segunda subamostra de $5 \mathrm{~g}$ foi seca até peso constante a $105^{\circ} \mathrm{C}$ para determinação da umidade gravimétrica. Para determinar as taxas líquidas de mineralização e nitrificação, uma terceira subamostra com $50 \mathrm{~g}$ foi incubada em laboratório por 7 dias (Piccolo et al., 1994), quando outro extrato de $\mathrm{KCl} 2$ mol L ${ }^{-1}$ foi obtido, conforme descrito acima.

As concentrafões de $\mathrm{N}-\mathrm{NH}_{4}{ }^{+}$e N-NO${ }_{3}^{-}$no extrato foram analisadas usando um sistema automático de injeção de fluxo contínuo (FIA) (Ruzicka \& Hansen, 1981). O N$\mathrm{NH}_{4}^{+}$foi medido colonimetnicamente pelo método de Solorzano e o N-NO${ }_{3}^{-}$foi determinado por condutivimetria na forma de $\mathrm{N}^{-\mathrm{NO}_{2}}{ }_{2}^{-}$, após a redução com o catalisador cádmio. Os 
limites de deteç̧ão utilizados foram aproximadamente $0,1 \mathrm{mg} \mathrm{L}^{-1}$ para $\mathrm{N}_{-\mathrm{NH}_{4}^{+}}^{+}$e $0,01 \mathrm{mg} \mathrm{L}^{-1}$ para $\mathrm{N}^{-\mathrm{NO}_{3}^{-}}$. A taxa líquida de mineralização do $\mathrm{N}$ foi calculada pela alteração na concentração de $\mathrm{N}-\left(\mathrm{NH}_{4}{ }^{+}+\mathrm{N}^{-\mathrm{NO}_{3}}{ }^{-}\right)$durante a incubação $\left(\mathrm{t}_{T}-\mathrm{t}_{0}\right)$. Da mesma forma, a taxa líquida de nitrificação correspondeu ao teor de $\mathrm{N}-\mathrm{NO}_{3}{ }^{-}$final menos o inicial.

\subsection{Forma de análise dos resulatdos}

Os resultados obtidos foram submetidos à análise de variância (teste F), segundo o esquema de parcelas subdivididas (Cochran \& Cox, 1978), considerando as práticas de recuperação e as profundidades como fator principal e secundário, respectivamente. Para tal, utilizou-se o procedimento ANOVA do programa de análise estatística SAS (SAS Institute, 1987). A comparação das médias foi feita pelo teste de Tukey a $5 \%$, utilizando-se o programa SANEST (Zonta \& Machado, s.d. ${ }^{2}$ ). Também foi realizada a análise de correlação linear simples de Pearson (Procedimento CORRELATION do SAS) entre as diversas variáveis medidas, mostrando-se alguns resultados de interesse para a discussão técnica.

${ }^{2}$ ZONTA, E.P.; MACHADO, A.A. SANEST - Sistema de análise estatística para micromputadores, v. 21, 148p. s.n.t. (mimeografado). 


\section{RESULTADOS E DISCUSSÃO}

\subsection{Resposta da pastagem de braquiária aos tratamentos de recuperação}

\subsubsection{Produção de massa seca da parte aérea}

A produção de massa seca da parte aérea da braquiária (Tabela 2) foi influenciada significativamente $(P<0,01)$ pelos tratamentos de recuperação.

Os tratamentos com aplicação de fertilizantes associados à calagem, com (CGF) ou sem incorporação (CSF), foram significativamente superiores $(P<0,05)$ aos demais, nos dois anos de avaliação (Tabela 2), proporcionando acréscimos acima de 200 \% na produção total, em relação à testemunha. Estes resultados indicam que a produtividade da pastagem estava sendo limitada pela deficiência dos nutrientes adicionados. Outros autores (Arruda et al., 1987; Carvalho et al., 1990; Miranda et al., 199?; Soares Filho et al., 1992) também verificaram que a adubação completa foi a estratégia mais eficiente na recuperação de pastagem de $B$. decumbens em solos de baixa fertilidade. No primeiro ano, a perfórmance do tratamento CSF foi superior ao CGF. Isto sugere que o revolvimento do solo pela incorporação do calcário, neste último, pode ter prejudicado o sistema radicular, bem como o estande das plantas nos primeiros meses em que a operação foi realizada, afetando a absorção dos nutrientes fornecidos na adubação. No ano seguinte, a produção de massa seca nestes dois tratamentos foram comparáveis, de modo a obter-se igualdade para a produção total. A resposta à adição de fertilizantes deve-se não somente ao aumento da disponibilidade de nutrientes, mas também ao incremento na mineralização da matéria orgânica do solo, o que acelera o processo de reciclagem. 
Tabela 2. Produção acumulada de massa seca da parte aérea de $B$. decumbens sob efeito de tratamentos de recuperação no primeiro (10/1995 a 07/1996) e no segundo ano (10/1996 a 07/1997) de avaliação. Médias de quatro tratamentos e sete cortes por ano.

\begin{tabular}{lccc}
\hline \multirow{2}{*}{ Tratamentos } & \multicolumn{2}{c}{ Produção acumulada por ano } & $\begin{array}{c}\text { Produção total } \\
n^{\circ}\end{array}$ \\
\cline { 2 - 4 } & $1^{\circ}$ ano & $2^{0}$ ano & $1^{\circ}$ ano $+2^{0}$ ano \\
\hline Testemunha (T) & $1,31 \mathrm{~d}^{(1)}$ & $2,42 \mathrm{~b}$ & $3,73 \mathrm{c}$ \\
Gradagem (G) & $2,54 \mathrm{bc}$ & $3,48 \mathrm{~b}$ & $6,02 \mathrm{~b}$ \\
Calcário sem incorporação (CS) & $1,39 \mathrm{~cd}$ & $2,48 \mathrm{~b}$ & $3,87 \mathrm{c}$ \\
Calcário incorporado com grade (CG) & $1,52 \mathrm{~cd}$ & $2,89 \mathrm{~b}$ & $4,41 \mathrm{bc}$ \\
CS + fertilizantes (CSF) & $4,69 \mathrm{a}$ & $6,99 \mathrm{a}$ & $11,68 \mathrm{a}$ \\
CG + fertilizantes (CGF) & $3,48 \mathrm{~b}$ & $8,05 \mathrm{a}$ & $11,53 \mathrm{a}$ \\
C.V. $(\%)$ & 20,43 & 14,10 & 13,51 \\
\hline
\end{tabular}

(1) Médias seguidas de mesma letra, em cada coluna, não diferem estatisticamente pelo teste de Tukey a $5 \%$.

Contrariando os resultados obtidos em outros trabalhos (Arruda et al., 1987; Carvalho et al. 1990; Soares Filho et al., 1992), o tratamento apenas com gradagem aumentou significativamente a produção de massa seca, no primeiro ano, igualando-se à testemunha no ano subseqüente (Tabela 2 ).

A gradagem em pastagens degradadas tem por objetivos quebrar uma possivel camada compactada pelo pisoteio dos animais e incorporar a massa vegetal, visando acelerar a mineralização dos nutrientes contidos na matéria orgânica (principalmente $\mathrm{N}, \mathrm{S}$ e $\mathrm{P}$ ), tomando-os disponíveis à planta forrageira. $\mathrm{O}$ resultado efetivo dessa prática irá depender de vários fatores, dentre os quais, a velocidade de recuperação do sistema radicular da pastagem e o balanço entre os processos de mineralização-imobilização, que ocorrem simultaneamente no solo. Por outro lado, é de se esperar que o impacto positivo do revolvimento do solo, quando ocorre, seja de curta duração, uma vez que o material incorporado é normalmente pobre em nutrientes. Ainda que ocorra um balanço líquido a favor da mineralização, a quantidade de nutrientes liberados não deverá atender às exigências da forrageira a longo prazo. Assim, Arruda et 
al. (1987) verificaram que diversos tratamentos fisico-mecânicos, incluindo gradagem, não afetaram a recuperação de uma pastagem degradada de $B$. decumbens em solo argiloso de tabuleiro no Sul da Bahia. Resultados semelhantes, sobre o efeito da gradagem, foram apresentados por Carvalho et al. (1990) e Soares Filho et al. (1992), em experimentos conduzidos em solos de baixa fertilidade .

$O$ resultado positivo da gradagem observado no presente trabalho pode estar associado à textura arenosa do solo, a despeito dos baixos teores de nutrientes no mesmo. A textura do solo é um dos fatores que determinam a velocidade de decomposição da matéria orgânica, sendo que em solos argilosos a mineralização é mais lenta devido à formação de complexos argilo-húmicos, os quais dificultam a ação dos microrganismos quimiorganotróficos (Sanchez, 1981). Assim, é possível que a redução de produtividade verificada em outros trabalhos com a gradagem, principalmente nos primeiros meses (Carvalho et al., 1990; Soares Filho et al., 1992), possa ser explicada, em parte, pela baixa taxa de decomposição da matéria orgânica, de forma que o crecimento das plantas foi prejudicado. No caso de solos arenosos, como o do presente estudo, não só a mineralização da matéria orgânica é acelerada como também seu acúmulo é dificultado.

A falta de resposta da braquiária aos tratamentos com calcário sem fertilizantes, tanto aplicado na superfície (CS) como incorporado com grade (CG), resultou, provavelmente, do desbalanço entre os nutrientes na solução do solo, de modo que o acúmulo de massa seca foi limitado por aqueles presentes em quantidades insuficientes ao requerimento das plantas, especialmente N, P e K. Esta hipótese pode ser facilmente comprovada para o $\mathrm{K}$, através dos resulatdos da análise química do solo (Tabela 5), cujos teores trocáveis foram inferiores aos outros tratamentos até $20 \mathrm{~cm}$ de profundidade, alcançando níveis indetectáveis a partir desta camada. Tal resultado evidencia a ocorrência de lixiviação de $\mathrm{K}^{+}$neste solo de drenagem muito rápida devido à sua substituição pelo $\mathrm{Ca}^{+}$e/ou $\mathrm{Mg}^{2+}$ nos sítios de troca, sendo que o $\mathrm{NO}_{3}{ }^{-}$, proveniente da mineralização da matéria orgânica, pode ter sido o ânion acompanhante nessa movimentação. Raij (1991) abordou a possibilidade de efeitos depressivos da calagem em 
doses elevadas sobre a produção de culturas, relacionados às deficiências de $\mathrm{K}, \mathrm{Zn}, \mathrm{B}$ e Mn, quando as adubações são inexistentes ou inadequadas. Além desses aspectos, resposta positiva à calagem, como prática isolada, é fato muito raro em gramíneas forrageiras e, quando ocorre, está geralmente associada com o suprimento das necessidades de Ca e Mg (Pereira, 1986). Por outro lado, ao aumentar o pH e reduzir o Al trocável do solo, a calagem favorece o desenvolvimento do sistema radicular das culturas e aumenta a disponibilidade dos nutrientes adicionados nos fertilizantes, melhorando asssim a eficiência da adubação, conforme verificado por Paulino et al (1994).

A $B$. decumbens é considerada uma das forrageiras mais tolerantes à acidez do solo, sendo inserida por Werner et al.(1996) no grupo das menos exigentes em satuarção por bases: apenas $40 \%$ para formação e manutenção da pastagem. No entanto, a literatura registra resultados contraditórios a respeito do efeito da calagem para $B$. decumbens, encontrando-se desde ausência de resposta a doses de 0,5 a 4,5 $\mathrm{t} \mathrm{ha}^{-1}$ (Cantarutti et al., 1983; Sanzonowicz \& Goedart, 1986), até aumento médio de $103 \%$ na produção de massa seca com $5 \mathrm{t} \mathrm{ha}^{-1}$ de calcário (Salinas \& Gualdrón, 1988). Tais variações devem estar relacionadas com as diferentes condições em que são realizados os experimentos, tais como tipo e textura do solo, doses e fontes dos fertilizantes aplicados, níveis iniciais de acidez e teores de $\mathrm{Ca}, \mathrm{Mg}$ e $\mathrm{K}$, dentre outros. Outros autores (Carvalho et al., 1992; Carriel et al., 1995; Sanzonowicz et al., 1987) também relataram efeito positivo do calcário na produção dessa gramínea, o que é normalmente atribuído à adição de $\mathrm{Ca}$ e $\mathrm{Mg}$, aumento da disponibilidade de $\mathrm{N}$ e $\mathrm{P}$, além da redução da acidifiacção causada pelo adubo nitrogenado.

Nota-se que, para todos os tratamentos, as maiores produções foram obtidas no segundo ano, o que pode estar ligado à maior precipitação pluvial no período abril-julho, em relação ao ano anterior conforme pode-se observar na Figura 2. A produção de forragem das gramíneas tropicais é altamente dependente da disponibilidade de água no solo, estando diretamente relacionada com a distribuição de chuvas durante o ano (Smith \& Stephens, 1976; Sonego, 1988). 


\subsubsection{Distribuição do sistema radicular}

Os resultados de avaliação do sistema radicular da pastagem de braquiána pelos métodos do monolito e da filmagem do perfil do solo, em função dos tratamentos de recuperação e das profundidades de amostragem, estão representados nas Figuras 9 e 10 , respectivamente.

A boa correlação encontrada entre as medidas de comprimento e massa total de raizes (Figura 11a), amostradas pelo método do monolito, sugere que ambas podem ser usadas com sucesso no estudo do sistema radicular de pastagens. Contudo, a determinação do comprimento, expresso por unidade de volume de solo (densidade de comprimento) (Figuras 9a e 10), discriminou melhor os efeitos dos tratamentos, obtendose também menores valores de coeficiente de variação (C.V.), em comparação com a densidade de massa (Figura $9 b, c, d$ ). A questão é que a presença de pequena quantidade de raízes grossas, porém menos eficientes na absorção de água e nutrientes, numa determinada amostra, altera sobremaneira a massa total. Com a medida do comprimento este fator é controlado, obtendo-se resultados mais consistentes.

Por outro lado, a medida da massa de raizes é importante, por exemplo, para avaliar a contribuição destas no acúmulo de matéria orgânica do solo. Conforme mostrado na Figura 11b, houve correlação $(\mathrm{N}=96 ; \mathrm{P}<0,01)$ entre teor de carbono total do solo e massa total de raízes $(r=0,85)$, o mesmo acontecendo com a massa de raízes vivas $(r=0,85)$ e em decomposição $(r=0,84)$. Quando a análise de correlação foi realizada, considerando-se o efeito dos tratamentos $(n=16)$, os respectivos coeficientes foram sempre superiores a $0,94(\mathrm{P}<0,01)$, indicando que além das raizes, outros fatores influenciaram na alteração do conteúdo de carbono.

$\mathrm{O}$ desenvolvimento das raizes, avaliado pelas densidades de comprimento (Figura 9a) e de massa (Figura 9b,c,d) foi afetado pela interação entre tratamentos e profundidades $(\mathrm{P}<0,01)$. Independentemente dos tratamentos, mais de $75 \%$ das raízes concentraram-se na camada de $0-20 \mathrm{~cm}$ (cerca de $53 \%$ na camada $0-10$ ), refletindo as melhores condições químicas até esta profundidade (Tabelas 4 e 5). 


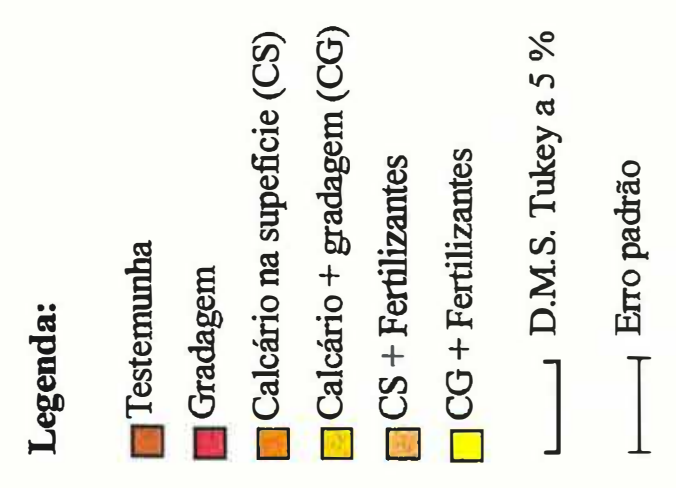

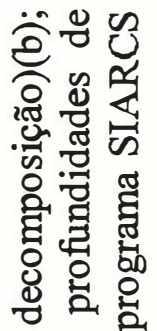

동 웜 웅

o 0 .

的 음

+
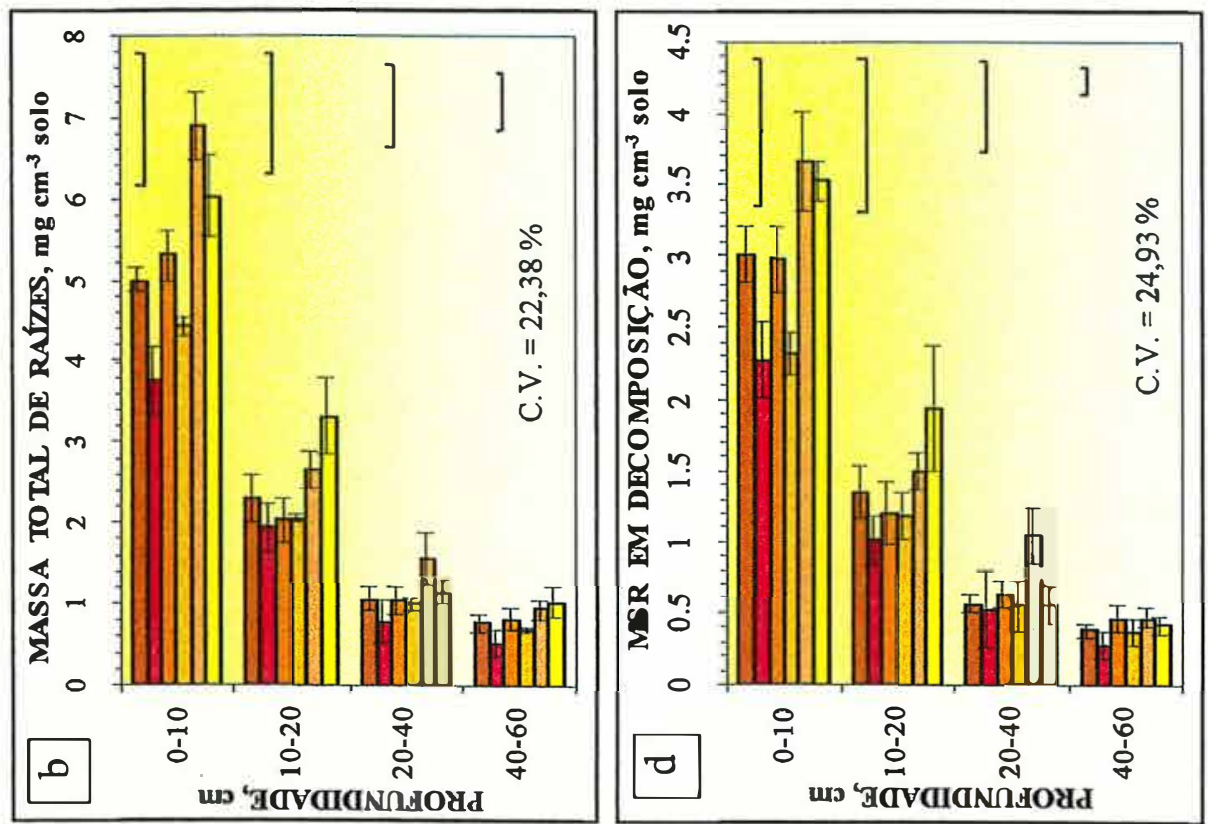

ช 잉 . 疍 \& 幽造

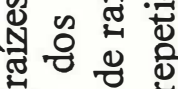

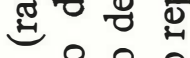

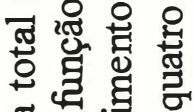
ঠु

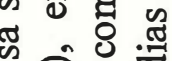
มิ घ 0

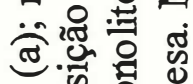

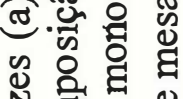
칭 영 임 언 잉 잉

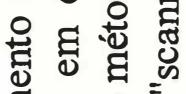
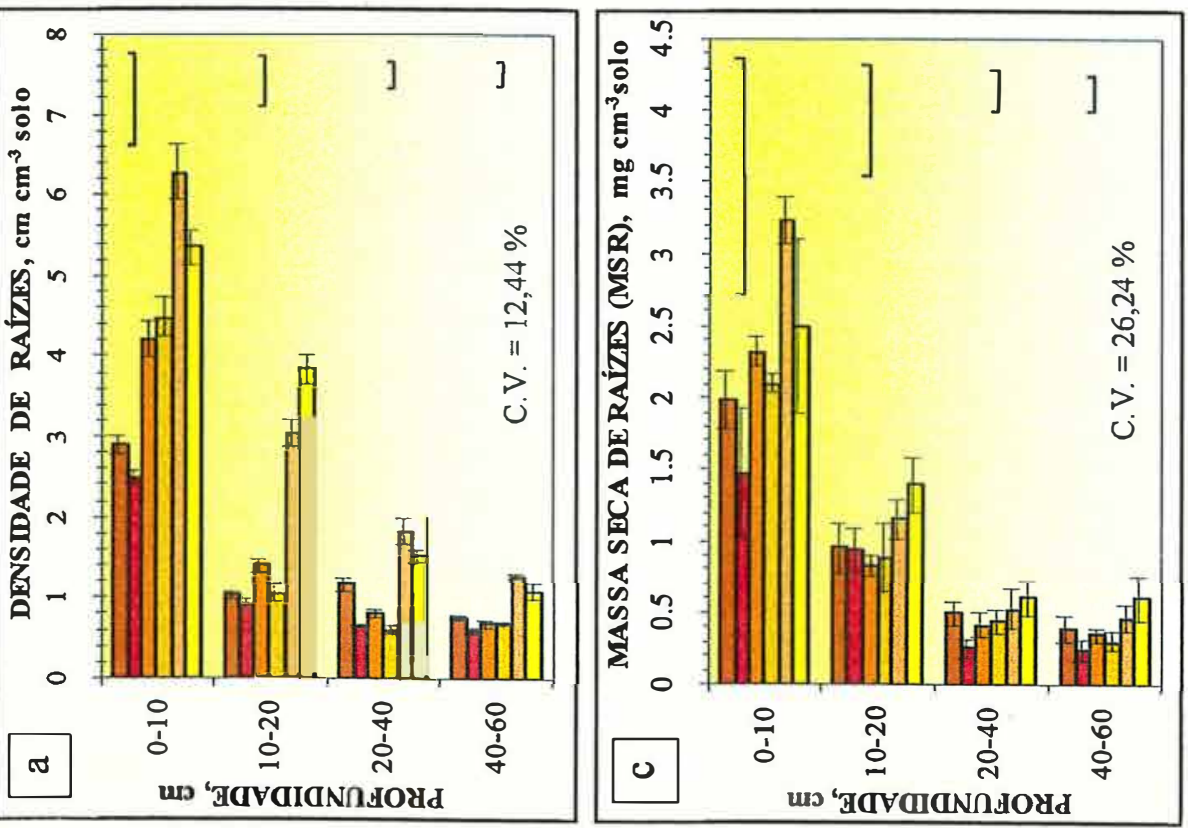

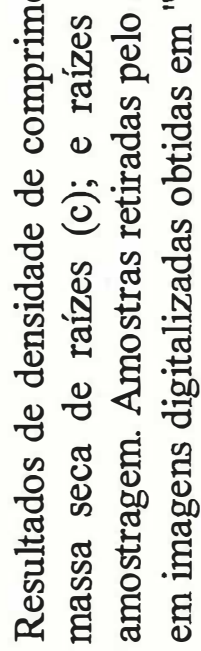
i

볼

造 
(a) Testemunha

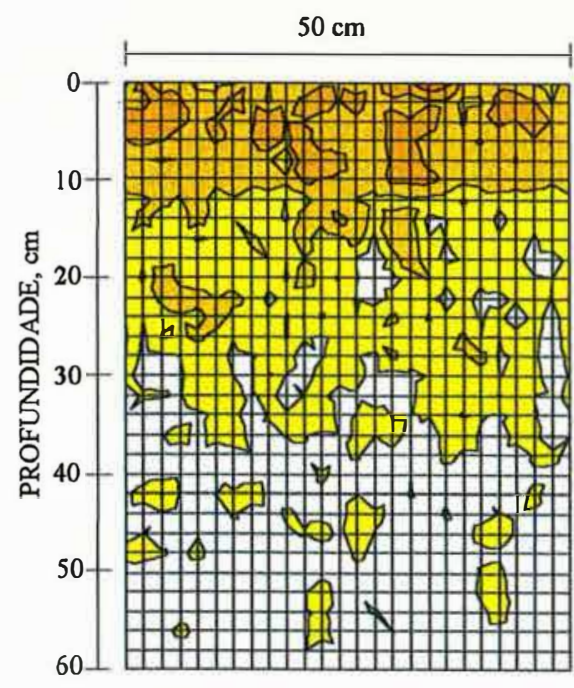

(d) Calcário + gradagem (CG)

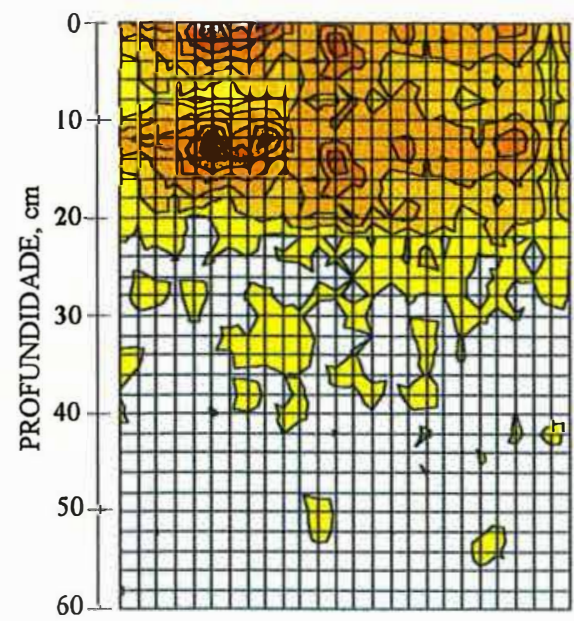

(b) Gradagem

(c) Calcário na superfície (CS)
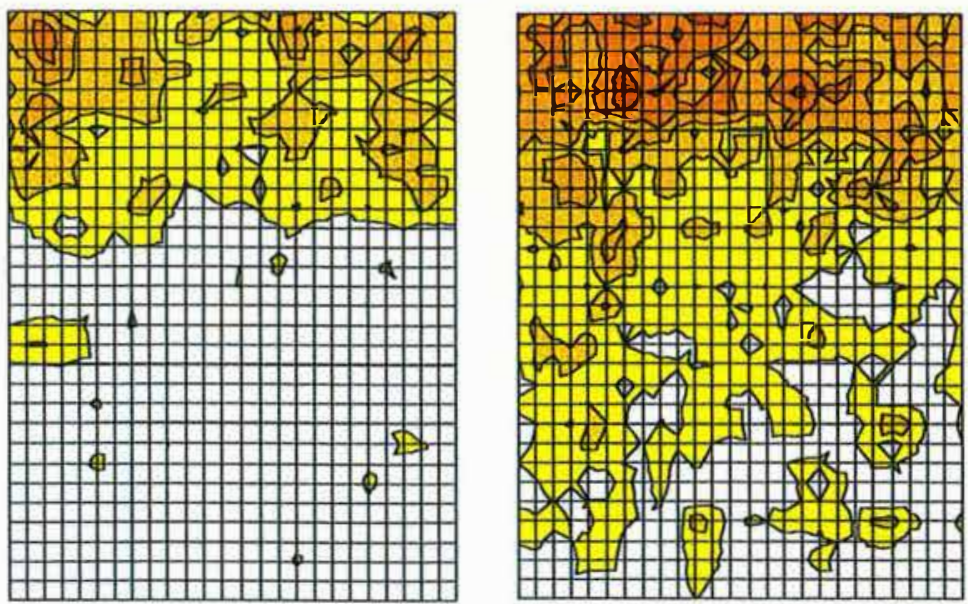

(e) CS + fertilizanets

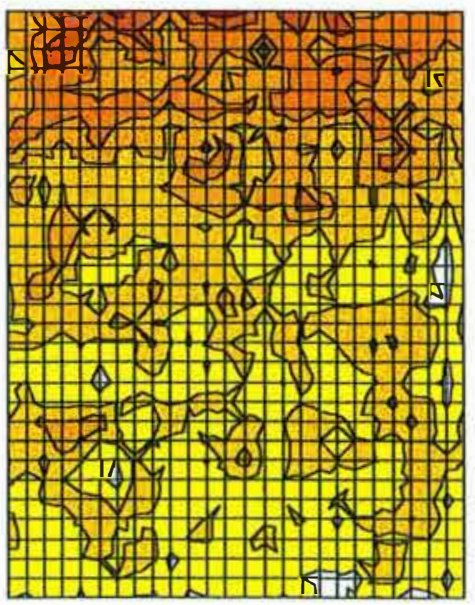

(f) CG + fertilizantes

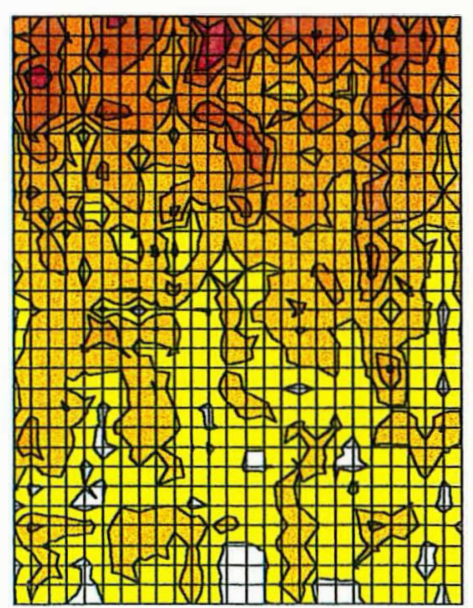

Legenda: Comprimento de raízes $\left(\mathrm{cm} 4,0 \mathrm{~cm}^{-2}\right.$ solo)
$\square 0-1,5$
$1,5-3,0$
$\square 3,0-4,5$
4,5-6,0
$6,0-7,5$
7,5-9,0
$>9,0$

Figura 10. Representação gráfica da distribuição do sistema radicular da pastagem de $B$. decumbens no perfil do solo $(50 \times 60 \mathrm{~cm})$, em função dos tratamentos de recuperação. Gráficos construídos com resultados de comprimento de raízes (média de quatro repetições) calculados pelo programa SIARCS em regiões de $2 \times 2 \mathrm{~cm}$, a partir de imagens obtidas por filmagem em regiões de $10 \times 10 \mathrm{~cm}$. 
Comparando-se os tratamentos, aqueles combinados com fertilizantes (CSF e CGF) apresentaram melhor distribuição de raízes em profundidade (Figura 10), cujas diferenças em relação aos restantes foram mais pronunciadas na camada de 10-20 cm (Figura 9a).

Segundo Brown \& Scott (1984), os fatores que mais frequentemente determinam o crescimento e a distribuição do sistema radicular são aqueles relacionados com as características físicas e químicas dos solos, tais como densidade do solo, aeração, teor de água, $\mathrm{pH}$, disponibilidade de nutrientes e presença de elementos tóxicos. Os resultados de densidade do solo, porosidade total e distribuição de poros realizados no presente trabalho (Figura 8) indicaram niveis não prejudiciais à aeração e ao crescimento de raízes, segundo a literatura (Baver, et al., 1972; Kiehl, 1979; Schuurnanm, 1965), conforme discutido no ítem 4.2.1. Por exemplo, Schuurmann (1965), baseado em trabalhos realizados por vários autores, concluiu que a densidade do solo crítica ao crescimento radicular situa-se na faixa de 1,7 e $1,5 \mathrm{~kg} \mathrm{dm}^{-3}$ para solos arenosos e argilosos, respectivamente. No presente trabalho, tratando-se de areia quartzosa, a densidade do solo variou de 1,44 a $1,62 \mathrm{~kg} \mathrm{dm}^{-3}$, portanto inferiores ao limite crítico relatado por Schuurmann (1965).

Sendo assim, pode-se afirmar que as condições químicas existentes originalmente no solo causaram severas restrições ao desenvolvimento do sistema radicular da braquiária, especialmente nas camadas subsuperficiais, de modo que a aplicação de corretivo e fertilizantes proporcionaram alterações significativas e positivas no comprimento e distribuição das raízes (Figuras 9 e 10). Tais restrições estão relacionadas, provavelmente, com saturação por alumínio (>50\% abaixo de $10 \mathrm{~cm}$ de profundidade) e baixos teores de nutrientes (Tabelas 1 e 4).

Em solos ácidos de baixa fertilidade, a exemplo do utilizado neste experimento, o crescimento das raízes é limitado pela toxicidade de $\mathrm{Al}$ e $\mathrm{Mn}$ e/ou deficiência de nutrientes, tais como Ca, P, N e K (Foy, 1984). A redução do desenvolvimento do sistema radicular tem como consequências diminuições significativas da absorção de água e nutrientes das camadas subsuperficiais do solo, tornando as plantas 
mais suscetíveis à deficiência hídrica e nutricional durante a ocorrência de períodos de estiagem (Foy, 1984; Mengel \& Kirkby, 1982; Ritchey et al., 1980). A imobilidade do cálcio no floema das plantas impede sua translocação da parte aérea para as extremidades das raizes (Mengel \& Kirkby, 1982), de forma que a presença deste elemento no meio é essencial para que as raízes se desenvolvam nele. Carvalho \& Raij (1997), trabalhando com amostras de subsolos ácidos contendo teores de $\mathrm{Ca}^{2+}$ trocáveis inferiores a $3 \mathrm{mmol}_{\mathrm{c}}$ $\mathrm{dm}^{-3}$, demonstraram que a aplicação de gesso, sulfato e carbonato de cálcio (em doses equivalentes a 10 mmol $_{\mathrm{c}} \mathrm{dm}^{-3}$ de Ca) propiciaram acréscimos do comprimento radicular do milho, os quais variaram de 65 a $190 \%$.

O requerimento externo de cálcio é bastante variável entre espécies, sendo as Brachiarias consideradas eficientes na sua aquisição (Rao et al., 1996). Mesmo assim, a resposta de braquiárias à calagem relatada em vários trabalhos (Carvalho et al., 1992; Carriel et al., 1995; Sanzonowicz et al., 1987) pode ser devida, em parte, à melhor distribuição do seu sistema radicular, com reflexos positivos na absorção de água e nutrientes.

A densidade de comprimento radicular foi correlacionada negativamente com a satuarção por $\mathrm{Al}^{3+}$ trocável do solo $(\mathrm{r}=-0.87 ; \mathrm{n}=96 ; \mathrm{P}<0,01)$ e positivamente com a saturação por bases (Figura 11c,d), tomando evidente a influência desses dois fatores sobre a distribuição do sistema radicular da braquiária, nas condicões do presente estudo. Embora a $B$. decumbens tenha demonstrado maior persistência em solos ácidos do que $B$. brizantha e $B$. ruziziensis, Rao et al. (1996) mostraram resultados de um experimento conduzido pelo CIAT (Colômbia) no qual as densidades de comprimento das raízes destas três espécies decresceram de maneira semelhante com o aumento do $\mathrm{Al}$ trocável no solo, indicando que as diferenças de adaptação não podem ser atribuídas à toxicidade devida ao alumínio. Embora não tenha avaliado o sistema radicular, Cruz et al. (1994), em experimento de calagem conduzido em casa de vegetação, encontraram correlação negativa entre teor de alumínio trocável e produção relativa de três gramíneas forrageiras, incluindo o capim Andropogon gayanus, que é classificado na literatura como tolerante à acidez e pouco exigente em fertilidade do solo. 

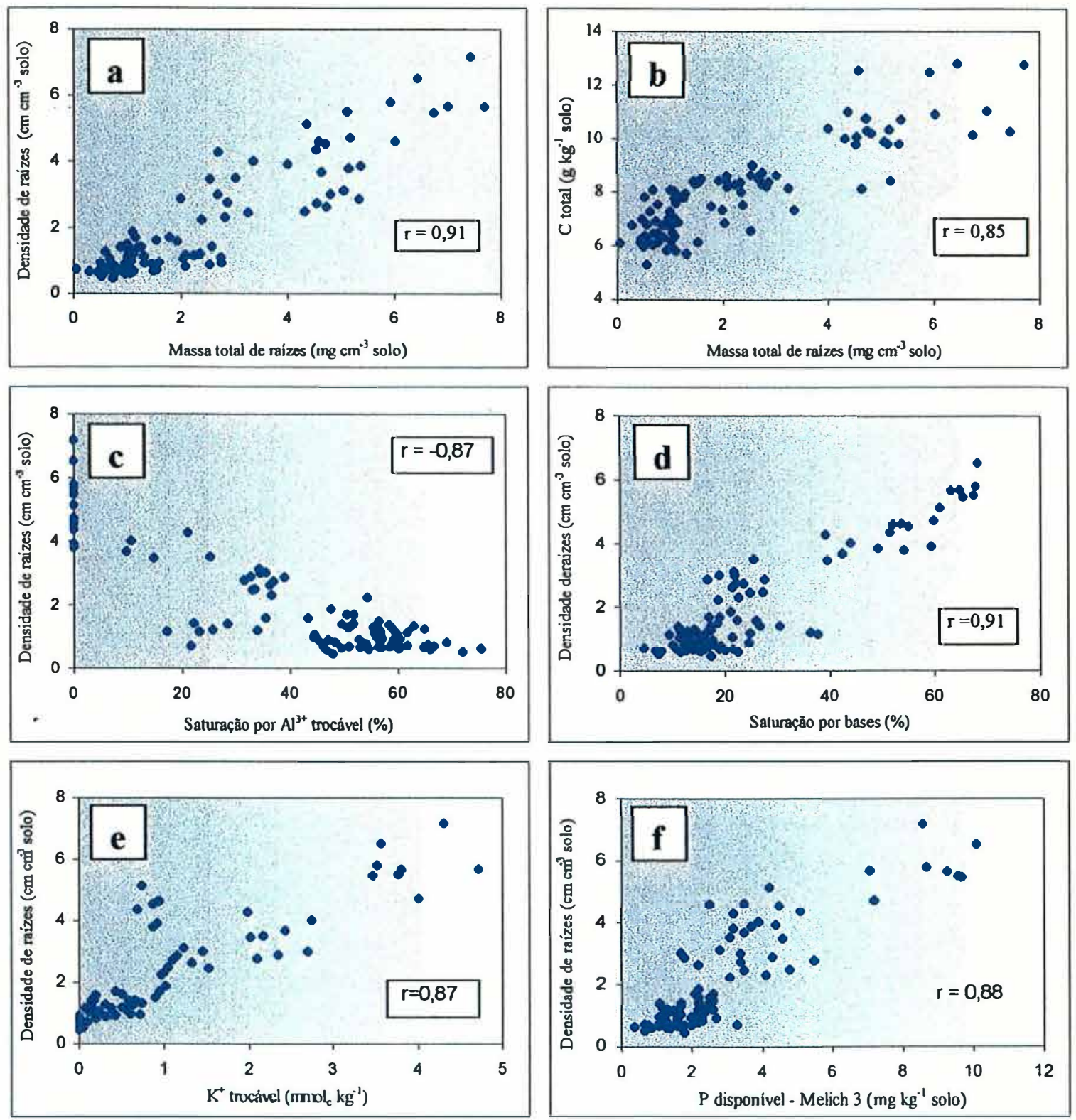

Figura 11. Relações entre: a) densidade de comprimento e densidade de massa total de raízes; b) $\mathrm{C}$ total e densidade de massa total de raízes; c) densidade de comprimento de raízes e satuarção por $\mathrm{Al}^{3+}$; d) densidade de comprimento de raízes e saturação por bases; e) densidade de comprimento e raízes e $\mathrm{K}^{+}$trocável; f) densidade de comprimento de raízes e $\mathbf{P}$ disponível. Os valores de $r$ correspondem aos coeficientes de correlação de Pearson $(\mathrm{N}=96 ; \mathrm{P}<0,01)$. 
A quantidade de raízes não diferiu entre os tratamentos CSF (calcário aplicado em cobertura + fertilizantes) e CGF (calcário incorporado com grade + fertilizantes), mas foi superior à encontrada nos demais (Figura 9). Esta diferença pode ser melhor visualizada nos gráficos de distribuição das raízes no perfil do solo, construídos com imagens digitalizadas obtidas por filmagem nas trincheiras, em quadrículas de $10 \times 10 \mathrm{~cm}$ (Figura 10). Estes resultados tomam evidente o efeito benéfico da adubação no desenvolvimento do sistema radicular da braquiária, em função do aumento da disponibilidade de nutrientes. Os elevados coeficientes de correlação obtidos entre a densidade de comprimento de raizes e os teores de $\mathrm{K}$ trocável (Figura 11e) e $\mathrm{P}$ disponível (Figura 11f) suportam esta hipótese. Baseando-se em resultados de diversas publiacações, Marshner (1986) destacou que a distribuição de raízes em solos pode ser modificada pela adição de fertilizantes, sendo que a densidade de raízes aumenta marcadamente em zonas de maior concentração de nutrientes, especialmente $\mathrm{N}$ e $\mathrm{P}$. Da mesma forma Bono \& Macedo (1996) demonstraram que o uso de práticas mecânicas (gradagem ou subsolagem) e químicas (calagem + adubação) associadas estimulou o crescimento de raízes de $B$. decumbens em profundidade.

O efeito positivo da gradagem por sí só sobre a produção de massa seca da parte aérea da pastagem, conforme apresentado no ítem anterior, não foi verificado para as raízes. A distribuição do sistema radicular neste tratamento, avaliada pelas densidades de massa (raizes vivas, em decomposição e massa total) e comprimento, não diferiu estatisticamente da testemunha, embora tenha havido uma tendência de decréscimo em todas as profundidades (Figuras 9). Contudo, através da observação visual do perfil do solo, verificou-se menor presença de raízes nas parcelas que foram tratadas apenas com gradagem, em comparação com as demais. O processamento (digitalização e determinação do comprimento por unidade de área) das imagens de raízes obtidas por filmagem no campo, em quadrículas de $10 \times 10 \mathrm{~cm}$ (Figura 10), confirmaram as observações visuais.

Dentre os vários trabalhos sobre recuperação de pastagens degradadas encontrados na literatura, raros são aqueles que incluem as raízes na sua avaliação (Bono 
\& Macedo, 1996; Soares Filho et al. 1992), provavelmente, devido à dificuldade de amostragem e separação das mesmas do solo. Em experimento onde estudou a recuperação de uma pastagem de $B$. decumbens, Soares Fillho et al. (1992) venificararn que a gradagem reduziu a quantidade de raízes, acentuando ainda mais o estado de degradacão da pastagem Quando esta estratégia foi associada à adubação (sem inchuir nitrogênio), a quantidade de raízes foi idêntica à testemunha, mas superior ao tratamento apenas com gradagem. Para explicar o fato, os autores sugeriram que o efeito prejudicial da gradagem foi mascarado pela influência benéfica da adubação, de forma que a possível mineralização da matéria orgânica juntamente com a maior disponibilidade de nutrientes favoreceu a recuperação do sistema radicular. Por outro lado, a adubação completa sem revolvimento do solo aumentou a massa de raizes nos dois anos em que estas foram avaliadas.

$\mathrm{Na}$ ausência de fertilizantes, os tratamentos com calcário em cobertura (CS) ou incorporado com grade (CG) tiveram comportamentos simlares na amostragem de raízes pelo método do monolito (Figura 9). Ambos proporcionaram acréscimos na densidade de comprimento radicular em cerca de $50 \%$ na camada $0-10 \mathrm{~cm}$, em comparafão com a testemunha, porém em magnitudes duas vezes inferiores às dos tratamentos com adubação. Quanto à densidade de massa (Figura 9b,c,d), não foi detectado efeito significativo destes dois tratamentos. Todavia, os gráficos de distribuição de raizes pelo método da filmagem no perfil (Figura 10) mostraram, mais uma vez, uma tendência prejudicial da gradagem para as raízes, de modo a observar-se melhor distribuição destas onde o calcário não foi incorporado (CS). $\mathrm{O}$ efeito positivo da calagem, na ausência de adubação, sobre o crescimento radicular da braquiána pode estar associado com a neutralização do alumínio trocável (Tabela 4), uma vez que essas duas variáveis foram negativamente correlacionadas (Figura 11c). 


\subsubsection{Teores totais de macro e micronutrientes na massa seca da parte aérea}

Os teores totais de macro e micronutrientes determinados na massa seca da parte aérea da braquiánia encontram-se na Tabela 3.

De modo geral, as concentração de nutrientes foi superior na estação chuvosa (Tabela 3), porém as duas épocas de amostragem gurdaram proporções semelhantes entre os tratamentos. A maior concentração de nutrientes no período das chuvas pode ser atribuída à maior disponibilidade no solo em função de vários fatores, dentre os quais pode-se citar: a) maior teor de água no solo, com reflexos diretos na absorção, através das formas de contato nutriente-raiz (fluxo de massa, difusão e interceptação radicular), e na mineralização da matéria orgânica que, por sua vez, pode fornecer nutrientes à solução do solo (especialmente $\mathrm{N}, \mathrm{S}$ e B); b) melhor desenvolvimento e atividade do sistema radicular, resultando em exploração de maior volume de solo; c) aceleração do processo fotossintético com conseqüente aumento da demanda por nutrientes do solo, além da translocação de carboidratos para as raízes, que os utilizam como fonte de energia para o processo de absorção. Estas diferenças de absorção de nutrientes, em função das épocas de chuva e seca, são também consideradas na determinação dos seus respectivos níveis críticos internos (Salinas \& Gualdrón, 1988).

Os maiores teores de $\mathrm{N}$ na forragem foram observados nos tratamentos que receberam fertilizantes (CSF e CGF), com valores máximos de 16,2 e 17,2 $\mathrm{g} \mathrm{kg}^{-1}$ na estação chuvosa (Tabela 3), enquanto entre os demais tratamentos não houve variação significativa. Na ausência de adubação, os teores de $\mathrm{N}$ na forragem variaram de 8,3 (tratamentos CS e CG na estação seca) a $11,5 \mathrm{~g} \mathrm{~kg}^{-1}$ (tratamento apenas com gradagem na estação úmida). Estes valores estão bem próximos daqueles apresentados por Carvalho et al. (1991), estudando o efeito da aplicação de doses de $\mathrm{N}$ e $\mathrm{K}$ sobre a produção de $B$. decumbens estabelecida em latossolo vermelho escuro álico: 17 a $21 \mathrm{~g}$ $\mathrm{kg}^{-1}$ na maior dose (400 kg ha' ${ }^{-1}$ ano) e 8 a $14 \mathrm{~g} \mathrm{~kg}^{-1}$ na ausência de adubação nitrogenada. 
Tabela 3. Teores totais de macro e micronutrientes na massa seca da parte aérea da pastagem de $B$. decumbens submetida aos tratamentos: sem tratamento (T); gradagem (G); calcário aplicado na superfície (CS); calcário incorporado com grade (CG); CS + fertilizantes (CSF); e CG + fertilizantes (CGF).

\begin{tabular}{|c|c|c|c|c|c|c|}
\hline \multirow[b]{2}{*}{ Teor de nutrientes } & \multicolumn{6}{|c|}{ Tratamentos de recuperação } \\
\hline & $\mathrm{T}$ & $\mathrm{G}$ & $\mathrm{CS}$ & CG & $\mathrm{CSF}$ & CGF \\
\hline & \multicolumn{6}{|c|}{ Estaçäo chuvosa } \\
\hline $\mathrm{C}$ total, $g \mathrm{~kg}^{-1}$ & $406,4 \mathrm{a}^{(1)}$ & $412,0 \mathrm{a}$ & $401,9 \mathrm{a}$ & $405,5 \mathrm{a}$ & $425,9 \mathrm{a}$ & $420,8 \mathrm{a}$ \\
\hline $\mathrm{N}$ total, $g \mathrm{~kg}^{-1}$ & $9,7 \mathrm{~b}$ & $11,5 \mathrm{~b}$ & $9,9 \mathrm{~b}$ & $10,5 \mathrm{~b}$ & $16,2 \mathrm{a}$ & $17,2 \mathrm{a}$ \\
\hline $\mathrm{P}, g \mathrm{~kg}^{-1}$ & $\overline{1,4 \mathrm{a}}$ & $1,2 \mathrm{a}$ & $1,0 \mathrm{a}$ & $1,1 \mathrm{a}$ & $1,4 \mathrm{a}$ & $1,4 \mathrm{a}$ \\
\hline $\mathrm{K}, \mathrm{g} \mathrm{kg}^{-1}$ & $6,8 \mathrm{c}$ & $8,0 \mathrm{bc}$ & $6,1 \mathrm{c}$ & $6,9 \mathrm{c}$ & $11,3 \mathrm{a}$ & $10,7 \mathrm{ab}$ \\
\hline $\mathrm{Ca}, g \mathrm{~kg}^{-1}$ & $1,7 \mathrm{bc}$ & $1,5 \mathrm{bc}$ & $2,0 \mathrm{ab}$ & $2,3 \mathrm{a}$ & $1,4 \mathrm{c}$ & $1,5 \mathrm{bc}$ \\
\hline $\mathrm{Mg}, g \mathrm{~kg}^{-1}$ & $1,7 \mathrm{bc}$ & $1,3 \mathrm{c}$ & $2,0 a b$ & $2,2 \mathrm{a}$ & $1,4 \mathrm{c}$ & $1,4 \mathrm{c}$ \\
\hline $\mathrm{S}, \mathrm{g} \mathrm{kg}^{-1}$ & $1,0 \mathrm{a}$ & $0,8 \mathrm{a}$ & $1,0 \mathrm{a}$ & $1,0 \mathrm{a}$ & $1,0 \mathrm{a}$ & $0,9 \mathrm{a}$ \\
\hline $\mathrm{B}, m g k g^{-1}$ & $23,0 \mathrm{a}$ & $18,9 \mathrm{a}$ & 22,1 a & $24,9 \mathrm{a}$ & $22,7 \mathrm{a}$ & $24,8 \mathrm{a}$ \\
\hline $\mathrm{Cu}, m g k g^{-1}$ & $3,2 \mathrm{bc}$ & $3,9 a b$ & $3,0 \mathrm{c}$ & $3,0 \mathrm{c}$ & $4,3 \mathrm{a}$ & $4,4 \mathrm{a}$ \\
\hline $\mathrm{Fe}, m g k^{-1}$ & $64,5 \mathrm{a}$ & $61,7 \mathrm{a}$ & $61,4 \mathrm{a}$ & $63,2 \mathrm{a}$ & 49,9 a & $48,8 \mathrm{a}$ \\
\hline $\mathrm{Mn}, m g k g^{-1}$ & 58,3 a & $52,0 \mathrm{a}$ & $41,9 \mathrm{abc}$ & $44,8 \mathrm{ab}$ & $23,4 \mathrm{c}$ & $28,3 \mathrm{bc}$ \\
\hline $\mathrm{Zn}, m g \mathrm{~kg}^{-1}$ & $16,6 \mathrm{a}$ & $16,4 \mathrm{a}$ & $16,0 \mathrm{a}$ & $16,1 \mathrm{a}$ & $17,9 \mathrm{a}$ & $17,6 \mathrm{a}$ \\
\hline Relação C:N & 41,9 a & $35,8 \mathrm{a}$ & $40,6 \mathrm{a}$ & $38,6 \mathrm{a}$ & $26,3 \mathrm{~b}$ & $24,5 \mathrm{~b}$ \\
\hline Relação N:S & $9,7 \mathrm{~b}$ & $14,4 \mathrm{ab}$ & $9,9 \mathrm{~b}$ & $10,5 \mathrm{~b}$ & $16,2 \mathrm{a}$ & $19,1 \mathrm{a}$ \\
\hline \multirow[t]{2}{*}{ Relação K:(Ca+Mg) } & $2,0 \mathrm{c}$ & $2,9 \mathrm{~b}$ & $1,5 \mathrm{~cd}$ & $1,3 \mathrm{~d}$ & $4,0 \mathrm{a}$ & $3,7 \mathrm{a}$ \\
\hline & \multicolumn{6}{|c|}{ Estacão seca } \\
\hline $\mathrm{C}$ total, $\mathrm{g} \mathrm{kg}^{-1}$ & $414,0 \mathrm{a}$ & $410,6 \mathrm{a}$ & $400,0 \mathrm{a}$ & $405,6 \mathrm{a}$ & $413,2 \mathrm{a}$ & $403,4 \mathrm{a}$ \\
\hline $\mathrm{N}$ total, $g \mathrm{~kg}^{-1}$ & 8,9 bc & $9,0 \mathrm{bc}$ & $8,3 \mathrm{c}$ & $8,3 \mathrm{c}$ & $10,6 \mathrm{a}$ & $9,9 \mathrm{ab}$ \\
\hline $\mathrm{P}, g \mathrm{~kg}^{-1}$ & $1,0 \mathrm{a}$ & $0,9 \mathrm{a}$ & $0,7 \mathrm{a}$ & $0,7 \mathrm{a}$ & $0,9 \mathrm{a}$ & $0,8 \mathrm{a}$ \\
\hline $\mathrm{K}, \mathrm{g} \mathrm{kg}^{-I}$ & $6,3 \mathrm{bc}$ & $7,5 \mathrm{ab}$ & $4,4 \mathrm{~d}$ & $5,6 \mathrm{dc}$ & $8,2 \mathrm{a}$ & $8,2 \mathrm{a}$ \\
\hline $\mathrm{Ca}, g k^{-1}$ & $2,9 \mathrm{a}$ & $2,7 \mathrm{ab}$ & $3,2 \mathrm{a}$ & $2,7 \mathrm{ab}$ & $2,2 b$ & $2,1 \mathrm{~b}$ \\
\hline $\mathrm{Mg}, \mathrm{g} \mathrm{kg}^{-1}$ & $1,8 \mathrm{bc}$ & $1,5 \mathrm{c}$ & $2,2 \mathrm{ab}$ & $2,3 \mathrm{a}$ & $1,6 \mathrm{bc}$ & $1,4 \mathrm{c}$ \\
\hline $\mathrm{S}, \mathrm{g} \mathrm{kg^{-1 }}$ & $1,0 \mathrm{a}$ & $0,7 \mathrm{bc}$ & $0,9 a b$ & $1,0 \mathrm{a}$ & $0,7 \mathrm{c}$ & $0,6 \mathrm{c}$ \\
\hline $\mathrm{B}, \mathrm{mg} \mathrm{kg}^{-1}$ & $16,9 \mathrm{a}$ & $17,4 \mathrm{a}$ & $17,9 \mathrm{a}$ & $16,2 \mathrm{a}$ & $17,4 \mathrm{a}$ & $17,4 \mathrm{a}$ \\
\hline $\mathrm{Cu}, m g k^{-1}$ & $2,8 \mathrm{a}$ & $2,5 \mathrm{a}$ & $2,3 \mathrm{a}$ & $2,3 \mathrm{a}$ & $2,3 \mathrm{a}$ & $1,7 \mathrm{a}$ \\
\hline $\mathrm{Fe}, m g \mathrm{~kg}^{-l}$ & $111,7 \mathrm{a}$ & $126,6 \mathrm{a}$ & $134,6 \mathrm{a}$ & $135,4 \mathrm{a}$ & 94,1 a & 82,9 a \\
\hline $\mathrm{Mn}, m g \mathrm{~kg}^{-1}$ & 66,3 a & $67,5 \mathrm{a}$ & $55,2 \mathrm{ab}$ & $41,0 \mathrm{ab}$ & $35,6 \mathrm{~b}$ & $34,4 \mathrm{~b}$ \\
\hline $\mathrm{Zn}, m g \mathrm{~kg}^{-I}$ & $17,6 \mathrm{a}$ & $17,3 \mathrm{a}$ & $17,7 \mathrm{a}$ & $16,7 \mathrm{a}$ & $16,0 \mathrm{a}$ & $16,0 \mathrm{a}$ \\
\hline Relação C:N & $46,5 \mathrm{ab}$ & $45,6 \mathrm{ab}$ & $48,2 \mathrm{ab}$ & 48,9 a & $39,0 \mathrm{~b}$ & $40,8 \mathrm{ab}$ \\
\hline Relação N:S & 8,9 bc & $12,9 \mathrm{ab}$ & $9,2 \mathrm{bc}$ & $8,3 \mathrm{c}$ & $15,1 \mathrm{a}$ & $16,5 \mathrm{a}$ \\
\hline Relação K:(Ca+Mg) & $1,3 \mathrm{~b}$ & $1,8 \mathrm{a}$ & $0,8 \mathrm{~b}$ & $1,1 \mathrm{~b}$ & $2,2 \mathrm{a}$ & $1,8 \mathrm{a}$ \\
\hline
\end{tabular}

\footnotetext{
${ }^{775}$ Médias seguidas da mesma letra em cada linha não diferem estatisticamente pelo teste de Tukey a $5 \%$.
} 
Na Figura 12 estão represantadas as relações obtidas entre a produção total de massa seca da braquiária (Tabela 2) e as médias (estações chuvosa e seca) das concentrações de $\mathrm{N}, \mathrm{K}$ e relação $\mathrm{K} /(\mathrm{Ca}+\mathrm{Mg})$ mostradas na Tabela 3. Nota-se que a produção foi altamente correlacionada com os teores de $\mathrm{N}$ na planta $\left(\mathrm{r}^{2}=0,99\right)$, o mesmo acontecendo com o $\mathrm{K}\left(r^{2}=0,92\right)$, indicando que o acúmulo de massa seca foi altamente dependente da absorção desses nutrientes.

Nas duas épocas de amostragem, os teores de $\mathrm{K}$ na planta alcançaram níveis mais elevados nos tratamentos fertilizados (Tabela 3), refletindo seus teores no solo (Tabela 5). Os valores encontrados nos tratamentos CSF (calcário em cobertura + fertilizantes) e CGF (calcário incorporado com grade + fertilizantes) foram, respectivamente: 11,3 e $10,7 \mathrm{~g} \mathrm{~kg}^{-1}$ na estação chuvosa e 8,2 para ambos na amostragem referente à estação seca. Nos outros tratamentos, incluindo a testemunha, os teores de $\mathrm{K}$ variaram de 4,4 (tratamento CS na estação seca) a $6,9 \mathrm{~g} \mathrm{~kg}^{-1}$ (tratamento CG na estação chuvosa), ficando abaixo do nível crítico interno de $\mathrm{K}$ igual a $8,3 \mathrm{~g} \mathrm{~kg}^{-1}$ para $B$. decumbens (Salinas \& Gualdrón, 1988).

Contraniando as expectativas e os resultados obtidos por outros autores (Carriel et al., 1995; Carvalho et al., 1992; Paulino et al., 1994), os teores de Ca e Mg na planta não aumentaram em todos os tratamentos onde o calcário dolomítico foi aplicado (Tabela 3), a despeito da maior disponibilidade no solo, como pode ser observado na Tabela 5. De modo geral, os teores de Ca variaram de 1,4 a $3,2 \mathrm{~g} \mathrm{~kg}^{-1}$ e, com exceção deste último valor (Tabela 3), estão abaixo da concentração crítica de Ca para $B$. decumbens, que é de $3,7 \mathrm{~g} \mathrm{~kg}^{-1}$ na época chuvosa e $3,0 \mathrm{~g} \mathrm{~kg}^{-1}$ na época das secas, segundo Salinas \& Gualdrón (1988). Considerando todos os tratamentos e as duas épocas de amostragem, o $\mathrm{Mg}$ apresentou tendência similar ao $\mathrm{Ca}$ e seus teores situaramse na faixa de 1,3 a $2,3 \mathrm{~g} \mathrm{~kg}^{-1}$, os quais são inferiores aos determinados por Carvalho et al. (1991) e Carriel et al. (1995) em experimentos de calagem conduzidos em casa de vegetação. Os menores valores corresponderam aos tratamentos com gradagem $(G)$ e com fertilizantes associados à aplicação de calcário em cobertura (CSF) ou incorporado com grade (CGF), os quais proporcionaram as maiores produções de foragem. 
Os baixos teores de $\mathrm{Ca}$ e $\mathrm{Mg}$ na massa seca da parte aérea da braquiária observados no presente trabalho devem estar ligados com a interação entre os íons na solução do solo. Khasawneh (1971) relatou que a absorção de um determinado íon pelas raízes depende não só da sua atividade na solução, mas também da atividadae de outros íons e da relação que existe eles na solução e na fase sólida do solo. Por exemplo, a

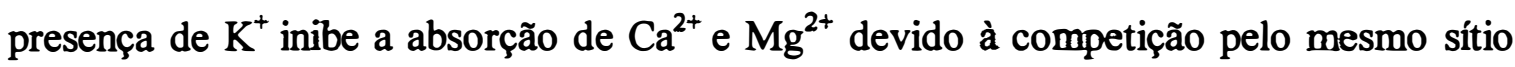
ativo na raíz (Malavolta et al., 1997). No caso das gramíneas forrageiras, este efeito inibitório pode ser mais acentuado em função da baixa CTC de suas raízes, que as tornam mais eficientes na absorção de cátions monovalentes, principalmente $\mathrm{K}^{+}$, em detrimento dos divalentes (Rao et al., 1996). As correlações negativas obtidas entre os teores de $\mathrm{Ke}$ $\mathrm{Ca}$ na planta (Figura 12d), bem como entre $\mathrm{K}$ e $\mathrm{Ca}+\mathrm{Mg}$ (Figura 12e), confirmam as afirmações acima. Por outro lado, o aumento de produção de forragem foi relacionado com o acréscimo da relação $\mathrm{K}:(\mathrm{Ca}+\mathrm{Mg})$, indicando que a menor absorção de cátions divalentes não afetou a produção.

Büll (1986) estudando a influência de diferentes relações $\mathrm{K}: \mathrm{Ca}+\mathrm{Mg}$ do solo (1:50 a 1:5) na produção de massa seca e na absorção de $\mathrm{K}$ em relação a $\mathrm{Ca}+\mathrm{Mg}$ por capim colonião (Panicum maximum Jacq.) e soja perene (Glycine wightii, Willd), verificaram que as duas espécies apresentaram aumentos nos valores da relação $\mathrm{K}: \mathrm{Ca}+\mathrm{Mg}$ ) na planta, proporcionais à elevação dessas relações no solo. Os autores sugeriram ainda que quanto maior o valor dessa relação no solo maior será o desenvolvimento das gramíneas.

Os baixos teores de $\mathrm{Ca}$ nos tratamentos com calcário, aplicado em cobertura ou incorporado com grade, mas sem fertilizantes, mesmo com os acréscimos dos teores trocáveis no solo (Tabela 5), refletem, provavelmente, o estado geral de deficiência dos demais nutrientes.

$\mathrm{O}$ teor de $\mathrm{P}$ não foi alterado significativamente por qualquer dos tratamentos (Tabela 3) e encontram-se próximos do nível crítico determinado para a $B$. decumbens em condições de campo: 0,8 (CIAT, 1978) e $1,2 \mathrm{~g} \mathrm{~kg}^{-1}$ de massa seca (Salinas \& Gualdrón, 1988). 

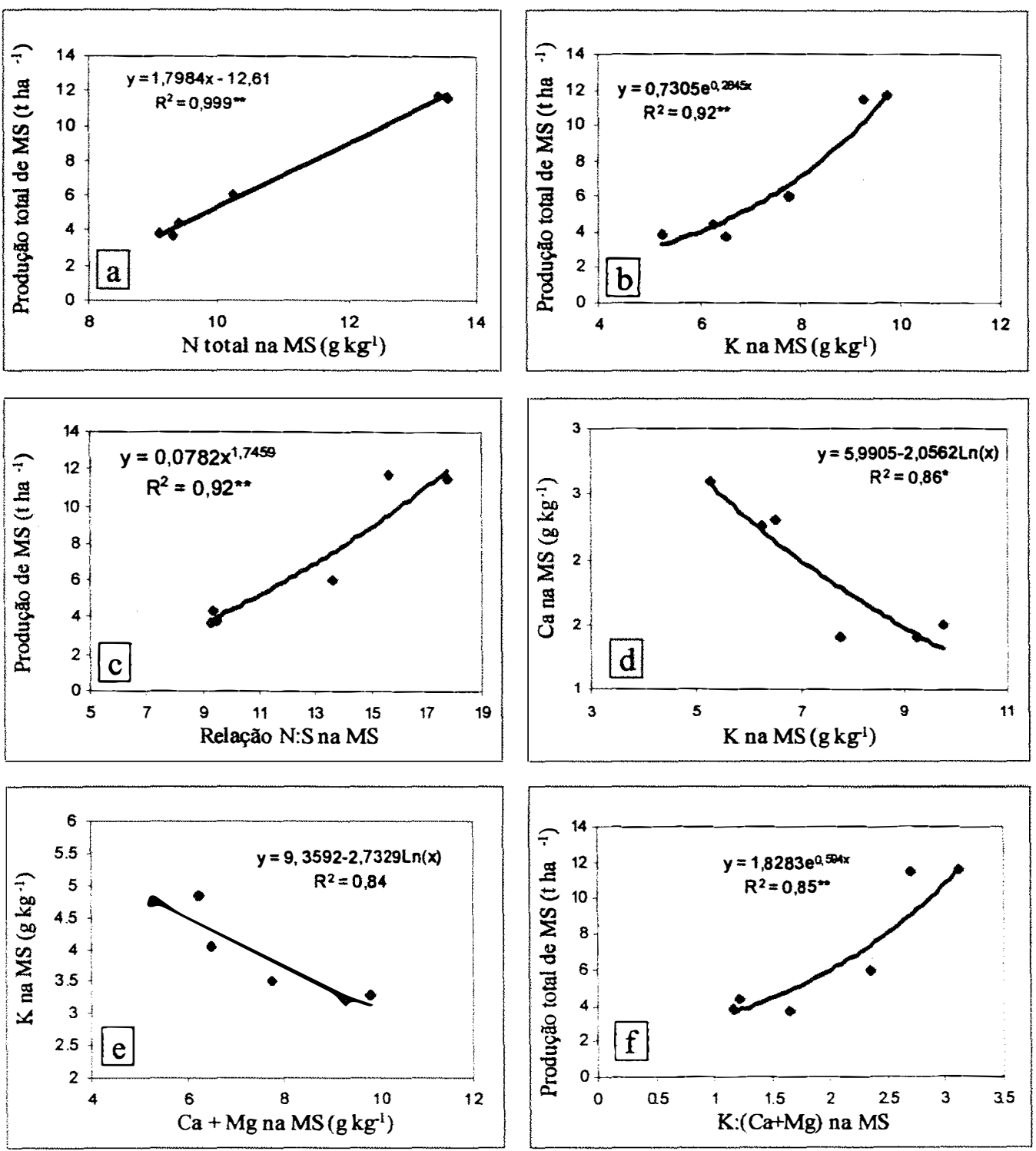

Figura 12. Relações entre: a) produção total de massa seca (MS) da parte aérea da braquiánia e teor de $\mathrm{N}$ na MS; b) produção de MS e teor de $\mathrm{K}$ na MS; c); produção de $\mathrm{MS}$ e relação $\mathrm{N}: \mathrm{S}$ na $\mathrm{MS}$; d) $\mathrm{K}$ e Ca na $\mathrm{MS}$; e) $\mathrm{K}$ e C+Mg na MS; e) produção de MS e K:(Ca+Mg) na MS. 
$\mathrm{O}$ teor de $\mathrm{S}$, que não variou entre os tratamentos na estação chuvosa, diminuiu nos tratamentos adubados (CSF e CGF) na estação seca, o que deve estar relacionado com o efeito de diluição (Jarrel \& Baverly, 1981), em função da maior produção de massa seca de forragem e/ou redução da disponibilidade no solo devido à menor mineralização da matéria orgânica. Os valores encontrados estão abaixo do requerimento crítico de $1,6 \mathrm{~g} \mathrm{~kg}^{-1}$, citado por Rao et al. (1996). Contudo, a relação N:S tem sido usada, preferencialmente ao teor isolado de $\mathrm{S}$ total, para avaliar o estado nutricional e o rendimento das forrageiras (Spencer et al., 1977; Monteiro \& Carriel, 1987), uma vez que essa relação mantêm-se constante nos diferentes estádios de desenvolvimento da planta (Spencer et al., 1977). No presente trabalho, a produção da braquiána foi correlacionada positivamente com a relação N:S (Figura 12c), a qual variou de 8,8 a 19,1 , sendo os maiores valores associados aos tratamentos com fertilizantes (CSF e CGF). De acordo com Tisdale (1977), as plantas apresentam crescimento adequado quando a relação $\mathrm{N}: \mathrm{S}$ da forragem está entre 14:1 e 16:1.

Com relação aos micronutrientes, os teores de $\mathrm{B}, \mathrm{Fe}$ e $\mathrm{Zn}$ não variaram significativamente entre os tratamentos, porém, com exceção do $\mathrm{B}$, os valores encontrados estão abaixo daqueles exigidos pelas gramíneas forrageiras, de acordo com Malavolta et al. (1997). Contudo, os valores apresentados por aqueles autores são muito generalizados para permitir alguma conclusão, uma vez que as concentrações críticas de nutrientes nas plantas, observados na literatura (CIAT, 1978; Fonseca et al, 1992; Salinas $\&$ Gualdrón, 1988) diferem entre espécies dentro do mesmo gênero e cultivares dentro da mesma espécie. Além disso, o nível crítico de um determinado nutriente na parte aérea pode ser influenciada por vários fatores, tais como: características do solo, época de amostragem, método analítico utilizado, dose de outros nutrientes aplicados, dentre outros (Salinas \& Gualdrón, 1988; Hoffman, et al., 1995; Fonseca et al., 1992).

Os menores teores de $\mathrm{Mn}$ foram observados nos tratamentos CSF e CGF, não havendo diferença significativa entre os mesmos. Como a produção de forragem foi mais elevada nestes tratamentos, é possível que tenha ocorrido um efeito de diluição pelo maior crescimento das plantas, tanto que na estação seca, época de menor crescimento 
das plantas, a sua concentração foi mais elevada, comparada com a estação chuvosa. $O$ $\mathrm{Cu}$, por outro lado, apresentou tendência oposta à do $\mathrm{Mn}$, ou seja, sua concentração na parte aérea foi mais elevada nos tratamentos com fertilizantes, onde ele foi incluído. Faquim et al. (1995), avaliando o estado nutricional de B. brizantha e Andropogon gayanus através da diagnose por subtração, mostraram resultados semelhantes, em que o teor de Mn decresceu no tratamento completo (calcário + macro e micronutrienets) e aumentou naqueles tratamentos que mais limitaram o crescimento das plantas $(-\mathrm{N},-\mathrm{P}$ e $\mathrm{K}$ ), caracterizando o efeito de diluição; enquanto o teor de $\mathrm{Cu}$ foi maior no tratamento completo.

\subsection{Efeitos dos tratamentos sobre os atributos do solo}

\subsubsection{Atributos físicos}

Os resultados de densidade e distribuição de poros no perfil do solo estão representados na Figura 13.

Considerando todos os tratamentos e profundidades analisadas, os valores de densidade do solo e o volume total de poros variaram de 1,44 a $1,62 \mathrm{~kg} \mathrm{dm}^{-3}$ e 0,37 a $0.43 \mathrm{~m}^{3} \mathrm{~m}^{-3}$, respectivamente, sendo comparáveis àqueles determinados por outros autores em areias quartzosas sob pastagens (Campos, 1998; Dadalto, 1983; DeMaria et al., 1998). Em média, a densidade dos solos arenosos varia de 1,2 a $1,8 \mathrm{~kg} \mathrm{dm}^{-3}$, enquanto a porosidade total situa-se na faixa de 35 a $50 \%\left(0,35\right.$ a $\left.0,50 \mathrm{~m}^{3} \mathrm{~m}^{-3}\right)$, dependendo da profundidade e do conteúdo de matéria orgânica (Baver et al., 1972; Kiehl, 1979).

De modo geral, observa-se que a densidade tendeu a aumentar na camada de 10-20 cm, voltando a decrescer a 40-60 cm, acontecendo o oposto com o volume de macroporos (poros $>0,05 \mathrm{~mm}$ ) e a porosidade total $(P t)$. Tal fato evidencia a presença de uma leve compactação nesta zona do perfil, que não parece ter sido provocada diretamente pelo pisoteio do gado, uma vez que este efeito é normalmente restrito à 
superficie do solo (Carvalho, 1976). Sendo assim, o aumento da densidadade do solo $\left(D_{s}\right)$ na camada 10-20 cm deveu-se, provavelmente, à obstrução dos poros por partículas sólidas eluviadas, que caracteriza o processo pedogenético de adensamento.

A ocorrência de camadas subsuperficiais adensadas em solos cultivados de diferentes texturas, inclusive sob pastagens, têm sido relatada por vários autores (Marun et al., 1996; Costa et al., 1998; Dadalto, 1983) e, frequentemente, é atribuída à queda do teor de matéria orgânica do solo. No caso de pastagens degradadas, este processo pode ser agravado devido à redução da cobertura do solo, o que favorece a dispersão das partículas na sua superfície pelo impacto das gotas de chuva.

Isolando-se os efeitos dos tratamentos, não houve diferença significativa entre as camadas 0-10 e 40-60 cm com relação à densidade do solo e à porosidade total. Uma possível explicação é que em solos sob pastagens de gramíneas, a manutenção da qualidade física na camada superficial é o resultado do balanço entre o efeito benéfico do sistema radicular e o maléfico do pisoteio animal. Assim, o volume de macroporos foi superior na camada de 40-60 cm, a qual sofre pouca influência das pressões exercidas na superfície do solo, quer seja por implementos agrícolas ou tráfico de máquinas e animais (Baver et al., 1972; Kiehl, 1979, Marun et al., 1996).

Os atributos físicos do solo avaliados neste trabalho (Figura 8) foram afetados significativamente $(\mathrm{P}<0,05)$ pela interação tratamentos $\mathrm{x}$ profundidades. A aplicação de calcário mais fertilizantes (CSF e CGF) proporcionaram acréscimos significativos na porosidade total do solo e na proporção de macroporos na camada de 0 $10 \mathrm{~cm}$, o que está associado, provavelmente, ao melhor desenvolvimento do sistema radicular nestes tratamentos (Figuras 9 e 10), em função da melhoria das condições químicas previamente adversas (Tabela 1). A melhor perfórmance foi do tratamento CSF (calcário sem incorporação + fertilizantes): a $D s$ passou de 1,58 (parcela sem tratamento) para $1,44 \mathrm{~kg} \mathrm{dm}^{-3}$, enquanto a $P t$ e a macroporosidade foi elevada de 0,37 e $0,13 \mathrm{~m}^{3} \mathrm{~m}^{-3}$ para 0,43 e $0,17 \mathrm{~m}^{3} \mathrm{~m}^{-3}$, respectivamente. 


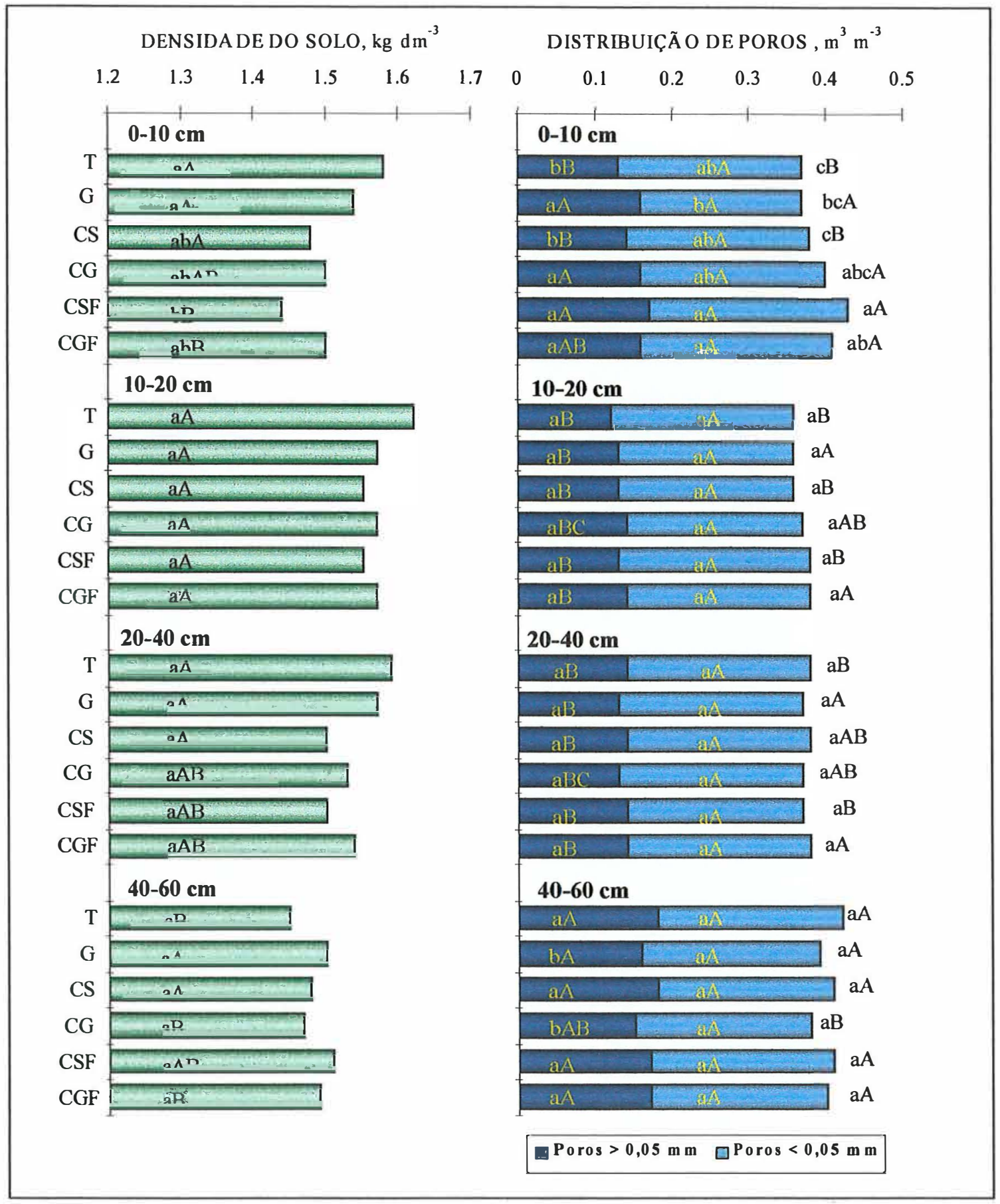

Figura 13. Densidade e distribuição de poros do solo, nas camadas $0-10,10-20,20-40$ e 40-60 cm, sob pastagem de $B$. decumbens submetida aos tratamentos de recuperação: testemunha (T); gradagem (G); calcário aplicado na superfície do solo (CS); calcário + gradagem (CG); CS + fertilizantes (CSF); e CG + fertilizantes (CGF). As médias seguidas de mesma letra minúscula, dentro de cada profundidade, e maiúscula, dentro de cada tratamento, não diferem entre sí pelo teste de Tukey a5 \%. 
Os efeitos positivos das raízes das grammeas na recuperação da qualidade fisica dos solos podem ser atribuídos, em parte, à sua ação direta através da criação de canais (bioporos) e aproximação das partículas, além da deposição de exsudatos orgânicos que também podem atuar na estabilização dos agregados e ainda são utilizados como substratos pelos microrganismos para a produção de polissacarídeos (Oades, 1993). Nos solos arenosos, a porosidade é normalmente inferior àqueles com maior teor de argila, devido à disposição hexagonal e à baixa agregação de suas partículas (Baver et al., 1979; Kiehl, 1979). Assim, a presença de matéria orgânica é de fundamental importância nestes solos, pois além de dificultar o arranjo piramidal das partículas, é por sí só um material poroso. Oades (1993) relatou que a formação e a estabilização da estrutura de solos arenosos é altamente dependente dos fatores bióticos, uma vez que não há efeito dos ciclos de secamento-umedecimento e a capacidade de expansão-contração desses solos é praticamente nula.

Como era de se esperar, a gradagem (G) aumentou a proporção de macroporos na camada superficial, que passou de 0,13 para $0,16 \mathrm{dm}^{3} \mathrm{dm}^{-3}$, porém sem alterar o volume total de poros. O efeito do tratamento CG (calcário incorporado com grade) também deve ter sido devido ao revolvimento do solo, pois a aplicação de calcário em cobertura (CS) não resultou em alterações significativas dos atributos físicos estudados.

Vale ressaltar que os atributos físicos avaliados neste trabalho estão relacionados indiretamente com o crescimento das plantas, através do seus efeitos sobre o movimento e retenção de água, aeração, temperatura e resistência mecânica, os quais afetam diretamente a produtividade das culturas (Letey, 1985). A proporção de macroporos em relação à porosidade total variou de 33 a $43 \%$, considerando todos os tratamentos, e estão bem próximas dos $33 \%$ relatados por Kiehl (1979) como suficientes para garantir boa difusão de oxigênio, permeabilidade e retenção de água. Mesmo nas camadas mais densas (10-20 e 20-40 cm), a porosidade de aeração (poros $>0,05 \mathrm{~mm}$ ) encontra-se acima de $0,10 \mathrm{~m}^{3} \mathrm{~m}^{-3}$, considerada limitante para o desenvolvimento das raízes (Baver et al., 1972; Kiehl, 1979). 


\subsubsection{Atributos químicos}

Os resultados de $\mathrm{pH}, \mathrm{Al}^{3+}$ trocável, acidez potencial, saturação por $\mathrm{Al}^{3+} \mathrm{e}$ $\mathrm{P}$ disponível no solo, determinados em quatro profundidades e duas épocas de amostragem, encontram-se na Tabela 4. Na Tabela 5 são apresentados os teores de cátions básicos trocáveis $\left(\mathrm{Ca}^{2+}, \mathrm{Mg}^{2+}, \mathrm{K}^{+}\right), \mathrm{CTC}$ e saturação por bases $(\mathrm{V} \%)$.

Os quatro tratamentos com calcário ( $\mathrm{CS}, \mathrm{CG}, \mathrm{CSF}, \mathrm{CGF}$ ), independentemente do modo de aplicação ou da presença dos fertilizantes, afetaram de modo similar a reação do solo na camada superficial $(0-10 \mathrm{~cm}), 20$ meses após a sua aplicação (fevereiro de 1997), aumentando o $\mathrm{pH}$ de 4,4 (tratamento testemunha) para 5,2 , em média, neutralizando o $\mathrm{Al}^{3+}$ trocável e reduzindo a acidez potencial em cerca de $32 \%$ (Tabela 4). Na camada de 10-20 cm, o aumento do $\mathrm{pH}$ foi pouco pronunciado e significativo apenas para o tratamento com calcário incorporado mais fertilizantes (CGF). Mesmo assim, com exceção do tratamento apenas com calcário, aplicado em cobertura (CS), houve redução significativa do $\mathrm{Al}^{3+}$ trocável, acompanhada de decréscimo da saturação por $\mathrm{Al}^{3+} \mathrm{e}$, em menor magnitude, da acidez potencial. Nas camadas mais profundas $(20-40$ e $40-60 \mathrm{~cm})$ o $\mathrm{pH}$ não foi influenciado pelos tratamentos e, conseqüentemente, os valores de Al trocável e acidez potencial também permaneceram inalterados, em relação à testemunha. A diminuição da porcentagem de saturação por $\mathrm{Al}^{3+}$ nestas duas camadas, portanto, foi devido ao aumento do teor $\mathrm{Ca}^{2+}$ trocável (Tabela 5). Na segunda amostragem (agosto de 1997), correspondente à 26 meses após a aplicação dos corretivos, as tendências foram mantidas, porém, nos tratamentos com incorporação do calcário (CG e CGF) o pH foi um pouco maior nos primeiros $20 \mathrm{~cm}$, em relação à amostragem anterior, indicando uma possível reação do calcário residual, com reflexos também na redução do $\mathrm{Al}^{3+}$ trocável.

A gradagem (G), como já era esperado, não afetou qualquer das variáveis discutidas acima, igualando-se à testemunha (Tabela 4). Nestes tratamentos, a acidez potencial manteve-se constante com a profundidade, em torno de $39 \mathrm{mmol}_{\mathrm{c}} \mathrm{kg}^{-1}$, o pH foi mais elevado na camada $0-10 \mathrm{~cm}$, não havendo diferença entre as demais profundidades, 
Tabela 4. Valores de $\mathrm{pH}, \mathrm{Al}^{3+}$ trocável, $\mathrm{H}^{+}+\mathrm{Al}^{3+}$, saturação por $\mathrm{Al}^{3+}$ e $\mathrm{P}$ disponível no solo sob pastagem degradada de B. decumbens, submetida aos tratamentos: sem tratamento $(\mathrm{T})$; gradagem $(\mathrm{G})$; calcário aplicado na superfície (CS); calcário incorporado com grade (CG); CS + fertilizantes (CSF); e CG + fertilizantes (CGF).

\begin{tabular}{|c|c|c|c|c|c|c|c|c|}
\hline \multirow{3}{*}{ Tratamentos } & \multicolumn{8}{|c|}{ Epocas de amostragem } \\
\hline & \multicolumn{4}{|c|}{ Estação chuvosa (fevereiro de 1997) } & \multicolumn{4}{|c|}{ Estação seca (agosto de 1997) } \\
\hline & $0-10 \mathrm{~cm}$ & $10-20 \mathrm{~cm}$ & $2040 \mathrm{~cm}$ & $4060 \mathrm{~cm}$ & $0-10 \mathrm{~cm}$ & $10-20 \mathrm{~cm}$ & $20-40 \mathrm{~cm}$ & $40-60 \mathrm{~cm}$ \\
\hline & \multicolumn{8}{|c|}{$\mathrm{pH} \mathrm{em} \mathrm{CaCl}_{2} 0,01 \mathrm{~mol} L^{-I}$} \\
\hline $\mathbf{T}$ & $4,42 b^{(1)}$ & $4,03 \mathrm{bcB}$ & $3,98 \mathrm{~B}$ & $3,94 \mathrm{~B}$ & $4,24 \mathrm{dA}$ & $3,98 \mathrm{cB}$ & $4,09 \mathrm{AB}$ & $3,98 \mathrm{~B}$ \\
\hline G & $4,27 \mathrm{bA}$ & $3,93 \mathrm{cB}$ & $3,94 \mathrm{~B}$ & $3,93 \mathrm{~B}$ & $4,12 \mathrm{dA}$ & $4,09 \mathrm{bcA}$ & $4,07 \mathrm{~A}$ & $3,99 \mathrm{~A}$ \\
\hline CS & $5,19 \mathrm{aA}$ & $4,16 \mathrm{abcB}$ & $3,95 \mathrm{BC}$ & $3,95 \mathrm{C}$ & $5,12 \mathrm{cA}$ & $4,23 \mathrm{bcB}$ & $4,06 \mathrm{BC}$ & $3,99 \mathrm{C}$ \\
\hline CG & $5,20 \mathrm{aA}$ & 4,19 abB & 4,09 BC & $3,96 \mathrm{C}$ & $5,24 \mathrm{bcA}$ & $4,33 \mathrm{abB}$ & $4,08 \mathrm{C}$ & $3,99 \mathrm{C}$ \\
\hline CSF & $5,38 \mathrm{aA}$ & $4,20 \mathrm{abB}$ & $4,09 \mathrm{~B}$ & $4,02 \mathrm{~B}$ & $5,42 \mathrm{abA}$ & $4,20 \mathrm{bcB}$ & $4,04 \mathrm{~B}$ & $3,98 \mathrm{~B}$ \\
\hline \multirow[t]{2}{*}{ CGF } & $5,16 \mathrm{aA}$ & $4,34 \mathrm{aB}$ & $4,02 \mathrm{C}$ & $3,97 \mathrm{C}$ & 5,55 aA & $4,49 \mathrm{aB}$ & $4,08 \mathrm{C}$ & $3,99 \mathrm{C}$ \\
\hline & \multicolumn{8}{|c|}{$A \ell^{3+}$ trocável, mmol $_{c} \mathrm{~kg}^{-1}$} \\
\hline $\mathbf{T}$ & $5,7 \mathrm{aC}$ & $8,3 \mathrm{abB}$ & $8,8 \mathrm{abcB}$ & $10,6 \mathrm{abA}$ & $5,4 \mathrm{aC}$ & $8,2 \mathrm{aAB}$ & $7,3 \mathrm{~B}$ & $9,3 \mathrm{~A}$ \\
\hline $\mathbf{G}$ & $6,3 \mathrm{aB}$ & $9,3 \mathrm{aA}$ & 9,4 abA & $10,4 \mathrm{abA}$ & $6,2 \mathrm{aC}$ & $7,3 \mathrm{aBC}$ & $8,1 \mathrm{AB}$ & $9,2 \mathrm{~A}$ \\
\hline CS & 0,0 & $6,5 \mathrm{bcB}$ & $10,1 \mathrm{aA}$ & $10,7 \mathrm{abA}$ & 0,0 & $4,7 \mathrm{boC}$ & $8,2 \mathrm{~B}$ & $10,3 \mathrm{~A}$ \\
\hline CG & 0,0 & $6,7 \mathrm{cB}$ & $8,1 \mathrm{bcB}$ & $10,9 \mathrm{aA}$ & 0,0 & $5,0 \mathrm{bC}$ & $8,2 \mathrm{~B}$ & $10,3 \mathrm{~A}$ \\
\hline CSF & 0,0 & $6,2 \mathrm{cB}$ & $7,8 \mathrm{cA}$ & $9,0 \mathrm{bA}$ & 0,0 & $5,2 \mathrm{bB}$ & $8,2 \mathrm{~A}$ & $9,6 \mathrm{~A}$ \\
\hline \multirow[t]{2}{*}{ CGF } & 0,0 & $5,1 \propto C$ & $8,0 \mathrm{cB}$ & $9,6 \mathrm{abA}$ & 0,0 & $3,0 \mathrm{cB}$ & $7,8 \mathrm{~A}$ & $8,9 \mathrm{~A}$ \\
\hline & \multicolumn{8}{|c|}{ Acidez potencial $\left(\mathrm{H}^{+}+A \boldsymbol{l}^{3+}\right)$, mmol $_{c} \mathrm{~kg}^{-1}$} \\
\hline $\mathbf{T}$ & $38,1 \mathrm{a}$ & $37,1 \mathrm{a}$ & 39,6 & 40,3 & $39,1 \mathrm{a}$ & $38,0 \mathrm{a}$ & 38,8 & 39,8 \\
\hline G & $37,8 \mathrm{a}$ & $36,6 \mathrm{abc}$ & 40,6 & 40,6 & $35,3 \mathrm{ab}$ & $34,6 a b$ & 35,8 & 37,3 \\
\hline CS & $23,6 \mathrm{bB}$ & $37,6 \mathrm{abA}$ & $40,8 \mathrm{~A}$ & $41,3 \mathrm{~A}$ & $28,3 \mathrm{bcB}$ & $32,6 \mathrm{bcB}$ & $35,6 \mathrm{AB}$ & $40,8 \mathrm{~A}$ \\
\hline CG & $26,8 \mathrm{bB}$ & $32,3 \mathrm{bcB}$ & $38,8 \mathrm{~A}$ & $39,8 \mathrm{~A}$ & $23,3 \mathrm{cB}$ & $26,3 \mathrm{cB}$ & $35,3 \mathrm{~A}$ & $40,1 \mathrm{~A}$ \\
\hline CSF & $26,1 \mathrm{bC}$ & $36,6 \mathrm{abcB}$ & $39,3 \mathrm{AB}$ & $40,1 \mathrm{~A}$ & $21,8 \propto C$ & $30,3 \mathrm{aB}$ & $34,5 \mathrm{~B}$ & $40,3 \mathrm{~A}$ \\
\hline \multirow[t]{2}{*}{ CGF } & $27,4 \mathrm{bB}$ & $31,1 \mathrm{cB}$ & $38,1 \mathrm{~A}$ & $38,3 \mathrm{~A}$ & $22,8 \mathrm{cB}$ & $26,3 \mathrm{cB}$ & $35,6 \mathrm{~A}$ & $36,3 \mathrm{~A}$ \\
\hline & \multicolumn{8}{|c|}{ Saturação por $A l^{3+}(m), \%$} \\
\hline $\mathbf{T}$ & $39,6 \mathrm{aD}$ & $54,5 \mathrm{aC}$ & $63,3 \mathrm{aB}$ & 79,3 aA & $40,9 \mathrm{aC}$ & $61,0 \mathrm{aB}$ & $62,8 \mathrm{aB}$ & 78,4 aA \\
\hline $\mathbf{G}$ & $38,7 \mathrm{aD}$ & $57,6 \mathrm{aC}$ & $65,5 \mathrm{aB}$ & $76,9 \mathrm{aA}$ & $43,1 \mathrm{aC}$ & $53,9 \mathrm{aB}$ & $63,0 \mathrm{aAB}$ & $74,2 \mathrm{aA}$ \\
\hline CS & 0,0 & 36,2 bC & $54,6 \mathrm{bB}$ & $67,6 \mathrm{bA}$ & 0,0 & $37,1 \mathrm{bC}$ & $58,6 \mathrm{abB}$ & $70,1 \mathrm{abA}$ \\
\hline CG & 0,0 & $36,7 \mathrm{bC}$ & $51,6 \mathrm{bB}$ & $59,8 \mathrm{cA}$ & 0,0 & $24,8 \mathrm{cC}$ & $53,9 \mathrm{bB}$ & $67,3 \mathrm{bA}$ \\
\hline CSF & 0,0 & $34,8 \mathrm{bC}$ & $42,0 \mathrm{cB}$ & $47,6 \mathrm{dA}$ & 0,0 & $30,7 \mathrm{bB}$ & $55,9 \mathrm{abA}$ & $61,3 \mathrm{cA}$ \\
\hline \multirow[t]{2}{*}{ CGF } & 0,0 & $19,8 \mathrm{cC}$ & $39,4 \mathrm{cB}$ & $51,2 \mathrm{dA}$ & 0,0 & $15,5 \mathrm{~dB}$ & $48,3 \mathrm{bA}$ & $59,3 \mathrm{cA}$ \\
\hline & \multicolumn{8}{|c|}{$P$ disponivel, $m g \mathrm{~kg}^{-1}$} \\
\hline $\mathbf{T}$ & $2,5 \mathrm{~d}$ & $2,5 b c$ & $1,9 \mathrm{a}$ & 1,6 & $2,1 \mathrm{dA}$ & $1,7 \mathrm{bA}$ & $1,4 \mathrm{bA}$ & $0,7 \mathrm{~b}$ \\
\hline G & $4,3 \mathrm{cA}$ & $1,5 \mathrm{cdB}$ & $0,9 \mathrm{bB}$ & 1,5 & $4,0 \mathrm{bcA}$ & $1,7 \mathrm{~b}$ & $1,4 \mathrm{~b}$ & $1,3 \mathrm{~b}$ \\
\hline CS & $3,0 \mathrm{dA}$ & $1,4 \mathrm{~dB}$ & $1,3 \mathrm{bB}$ & $1,1 \mathrm{~B}$ & 3,2 cdA & $2,4 \mathrm{bA}$ & $1,5 \mathrm{ab}$ & $1,3 \mathrm{~b}$ \\
\hline CG & $3,0 \mathrm{dA}$ & $2,0 \mathrm{cdB}$ & 1,9 abB & $1,6 \mathrm{~B}$ & $4,6 \mathrm{bA}$ & $2,6 \mathrm{~b}$ & $1,7 \mathrm{aC}$ & $1,5 \mathrm{abC}$ \\
\hline CSF & $7,0 \mathrm{bA}$ & $3,4 \mathrm{abB}$ & $2,6 \mathrm{aB}$ & $1,3 \mathrm{C}$ & $9,2 \mathrm{aA}$ & 4,1 a & $2,6 \mathrm{aC}$ & $1,5 \mathrm{abD}$ \\
\hline CGF & $9,1 \mathrm{aA}$ & $4,0 \mathrm{aB}$ & $1,8 \mathrm{abC}$ & $1,5 \mathrm{C}$ & $8,4 \mathrm{aA}$ & $3,8 \mathrm{a}$ & $2,0 \mathrm{abC}$ & $2,5 \mathrm{aC}$ \\
\hline
\end{tabular}

(1) Médias seguidas da mesma letra, minúscula em cada coluna e maiúscula na mesma linha, dentro de cada atributo avaliado numa mesma época, não diferem estatisticamente entre sí pelo teste de Tukey a $5 \%$. 
cujos valores estiveram ao redor de 4,0, portanto muito baixos. Independente dos tratamentos, a porcentagem de saturação por $\mathrm{Al}^{3+}$ aumentou com o aumento da profundidade do solo e o valor máximo encontrado foi $79 \%$ na camada de $0-60 \mathrm{~cm}$ do tratamento testemunha, evidenciando o caráter álico deste solo (Tabela 4).

Todos os tratamentos que incluíram a aplicação de calcário (CS, CG, CSF, CGF) resultaram em aumento da saturação por bases do solo até $60 \mathrm{~cm}$ de profundidade (Tabela 5), porém em magnitudes diferentes, refletindo os acréscimos dos teores de $\mathrm{Ca}^{2+}$, principalmente, $\mathrm{Mg}^{2+}$ e a redução do $\mathrm{Al}^{3+}$ trocável. Vinte meses após a aplicação do calcário (fevereiro de 1997), a saturação por bases, na camada 0-10 cm, passou de 19 (tratamento testemunha) para $56 \%$, em média, nas parcelas que receberam calcário, não havendo diferença quanto ao tipo de aplicação (incorporado ou cobertura) ou da presença de fertilizantes. Abaixo de $10 \mathrm{~cm}$ de profundidade, contudo, estas diferenças começaram a aparecer.

De modo geral, a aplicação de calcário na presença dos fertilizantes

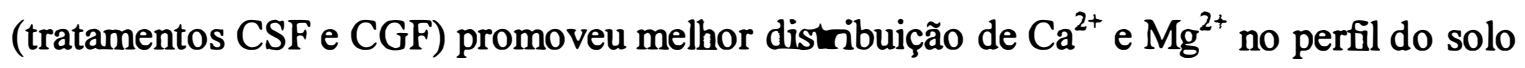
(Tabela 5) do que quando este corretivo foi aplicado isoladamente (tratamentos CS e CG). Este fato sugere que a presença de ânios adicionados nos fertilizantes $\left(\mathrm{Cl}^{-}\right.$e $\left.\mathrm{SO}_{4}{ }^{2-}\right)$ pode ter contribuído efetivamente para o movimento descendente destes cátions. De acordo com Raij (1988), a lixiviação de cátions básicos é mais acelerada pelos ânions $\mathrm{Cl}^{-}$ e $\mathrm{NO}_{3}{ }^{-}$do que pelo $\mathrm{SO}_{4}{ }^{2-}$. Ritchey et al. (1980) observaram que os solos de vários experimentos de campo, conduzidos na região do cerrado, amostrados após 3 a 4 anos da aplicação de superfosfato simples, mostraram aumentos no $\mathrm{pH}$ e nos teores de $\mathrm{Ca}$ e $\mathrm{Mg}$ do subsolo e diminuição dos teores e das saturações por $\mathrm{Al}$ na profundidade de até $90 \mathrm{~cm}$. O efeito do superfosfato simples foi atribuído à presença do gesso $\left(\mathrm{CaSO}_{4} \cdot 2 \mathrm{H}_{2} 0\right)$.

Comparando-se os tratamentos CSF e CGF, a diferença significativa em favor do segundo, com relação ao aumento da saturação por bases, só foi verificada na camada de 10-20 cm. Assim, pode-se inferir que, por tratar-se de um solo arenoso, de fácil drenagem e baixa CTC, a incorporação do calcário parece ter influenciado mais na dissolução deste material, em função do maior contato com as partículas, do que na 
Tabela 5. Teores de $\mathrm{Ca}^{2+}, \mathrm{Mg}^{2+}, \mathrm{K}^{+}, \mathrm{CTC}$ e saturação por bases no solo sob pastagem de B. decumbens, submetida aos tratamentos: sem tratamento $(\mathrm{T})$; gradagem $(\mathrm{G})$; calcário aplicado na superfície (CS); calcário incorporado com grade (CG); $\mathrm{CS}+$ fertilizantes (CSF); e CG + fertilizantes (CGF).

\begin{tabular}{|c|c|c|c|c|c|c|c|c|}
\hline \multirow{3}{*}{ Tratamentos } & \multicolumn{8}{|c|}{ Epocas de amostragem } \\
\hline & \multicolumn{4}{|c|}{ Estação chuvosa (fevereiro de 1997) } & \multicolumn{4}{|c|}{ Estação seca (agosto de 1997) } \\
\hline & $0-10 \mathrm{~cm}$ & $10-20 \mathrm{~cm}$ & $20-40 \mathrm{~cm}$ & $4060 \mathrm{~cm}$ & $0-10 \mathrm{~cm}$ & $10-20 \mathrm{~cm}$ & $20-40 \mathrm{~cm}$ & $40-60 \mathrm{~cm}$ \\
\hline & \multicolumn{8}{|c|}{$\mathrm{Ca}^{2+}$ trocável, mmol $\mathrm{kg}^{-1}$} \\
\hline $\mathbf{T}$ & $4,5 \mathrm{cA}(1)$ & $4,0 \mathrm{cA}$ & $3,1 \mathrm{cAB}$ & $1,6 \mathrm{cB}$ & $4,4 \mathrm{cA}$ & $3,8 \mathrm{cAB}$ & $2,6 \mathrm{cBC}$ & $1,5 \mathrm{bC}$ \\
\hline $\mathbf{G}$ & $6,3 \mathrm{cA}$ & $5,0 \mathrm{cAB}$ & $3,6 \mathrm{cB}$ & $2,1 \mathrm{cB}$ & $5,3 \mathrm{cA}$ & $4,5 \mathrm{cB}$ & 3,4 bcBC & $2,3 \mathrm{bC}$ \\
\hline CS & $15,8 \mathrm{bA}$ & $8,4 \mathrm{bB}$ & $7,0 \mathrm{bB}$ & $4,3 \mathrm{bC}$ & $15,5 \mathrm{bA}$ & $5,2 \mathrm{bcB}$ & $4,4 \mathrm{bB}$ & $3,9 \mathrm{aB}$ \\
\hline CG & $19,3 \mathrm{aA}$ & $7,5 \mathrm{bB}$ & $6,1 \mathrm{bC}$ & $6,5 \mathrm{aC}$ & $15,0 \mathrm{bA}$ & $9,7 \mathrm{aB}$ & $5,5 \mathrm{abC}$ & $4,3 \mathrm{aC}$ \\
\hline CSF & $20,5 \mathrm{aA}$ & $7,0 \mathrm{bB}$ & $8,1 \mathrm{aB}$ & $8,3 \mathrm{aB}$ & $21,0 \mathrm{aA}$ & $6,6 \mathrm{bB}$ & $4,0 \mathrm{bC}$ & $3,4 \mathrm{aC}$ \\
\hline \multirow[t]{2}{*}{ CGF } & $20,9 \mathrm{aA}$ & $13,5 \mathrm{aB}$ & $9,8 \mathrm{aC}$ & $7,8 \mathrm{aD}$ & $19,4 \mathrm{aA}$ & $8,3 \mathrm{aB}$ & $5,9 \mathrm{aB}$ & $4,1 \mathrm{aC}$ \\
\hline & \multicolumn{8}{|c|}{$\mathrm{Mg}^{2+}$ trocável, numol $\mathrm{kg}^{-1}$} \\
\hline $\mathbf{T}$ & $3,5 \mathrm{dA}$ & $2,8 \mathrm{cB}$ & $1,9 \mathrm{abC}$ & $1,2 \mathrm{D}$ & $2,8 \mathrm{cA}$ & $1,3 \mathrm{cB}$ & $1,6 \mathrm{~B}$ & $1,0 \mathrm{abcB}$ \\
\hline $\mathbf{G}$ & $2,8 \mathrm{dA}$ & $1,4 \mathrm{~dB}$ & $1,2 \mathrm{bB}$ & $0,9 \mathrm{~B}$ & $2,2 \mathrm{cA}$ & $1,5 \mathrm{cAB}$ & $1,3 \mathrm{~B}$ & $0,9 a b c B$ \\
\hline CS & $11,0 \mathrm{cA}$ & $2,7 \mathrm{cB}$ & $1,4 \mathrm{abC}$ & $0,8 \mathrm{C}$ & $10,9 \mathrm{bA}$ & $2,6 \mathrm{bB}$ & $1,4 \mathrm{C}$ & $0,5 \mathrm{cD}$ \\
\hline CG & $12,9 \mathrm{bA}$ & $3,9 \mathrm{bB}$ & $1,5 \mathrm{abC}$ & $0,8 \mathrm{C}$ & $11,0 \mathrm{bA}$ & $5,4 \mathrm{aB}$ & $1,5 \mathrm{C}$ & $0,7 \mathrm{bcD}$ \\
\hline CSF & $14,3 \mathrm{aA}$ & $2,8 \mathrm{cB}$ & $1,9 \mathrm{abC}$ & $1,5 \mathrm{C}$ & $13,0 \mathrm{aA}$ & $2,8 \mathrm{bB}$ & $1,5 \mathrm{C}$ & $2,0 \mathrm{abC}$ \\
\hline \multirow[t]{2}{*}{ CGF } & $12,5 \mathrm{aA}$ & $5,4 \mathrm{aB}$ & $2,1 \mathrm{aC}$ & $1,1 \mathrm{D}$ & $12,3 \mathrm{aA}$ & $5,8 \mathrm{aB}$ & $1,9 \mathrm{C}$ & $1,6 \mathrm{aC}$ \\
\hline & \multicolumn{8}{|c|}{$K^{+}$trocável, mmol ${ }_{c} \mathrm{~kg}^{-1}$} \\
\hline $\mathbf{T}$ & $0,7 \mathrm{bA}$ & $0,3 \mathrm{bB}$ & $0,1 \mathrm{bB}$ & 0,0 & $0,6 \mathrm{bcA}$ & $0,2 \mathrm{bB}$ & $0,1 \mathrm{bC}$ & $0,1 \mathrm{C}$ \\
\hline $\mathbf{G}$ & $0,9 \mathrm{bA}$ & $0,4 \mathrm{bB}$ & $0,2 \mathrm{bB}$ & $0,1 \mathrm{aC}$ & $0,7 \mathrm{bA}$ & $0,2 \mathrm{bB}$ & $0,1 \mathrm{bB}$ & 0,0 \\
\hline CS & $0,4 \mathrm{c}$ & $0,2 \mathrm{~b}$ & 0,0 & 0,0 & 0,4 bc & $0,2 \mathrm{~b}$ & 0,0 & 0,0 \\
\hline CG & $0,3 \mathrm{c}$ & $0,1 \mathrm{~b}$ & 0,0 & 0,0 & $0,3 \mathrm{c}$ & $0,1 \mathrm{~b}$ & 0,0 & 0,0 \\
\hline CSF & $3,4 \mathrm{aA}$ & $1,8 \mathrm{aB}$ & $0,8 \mathrm{aC}$ & $0,1 \mathrm{aD}$ & $2,9 \mathrm{aA}$ & $2,3 \mathrm{aA}$ & $1,0 \mathrm{aB}$ & $0,5 \mathrm{aB}$ \\
\hline \multirow[t]{2}{*}{ CGF } & $3,0 \mathrm{aA}$ & $1,8 \mathrm{aB}$ & $0,4 \mathrm{aC}$ & $0,3 \mathrm{aC}$ & $2,6 \mathrm{aA}$ & $2,3 \mathrm{aA}$ & $0,6 \mathrm{aB}$ & $0,4 \mathrm{aB}$ \\
\hline & \multicolumn{8}{|c|}{$C T C$, mmol $_{c} \mathrm{~kg}^{-1}$} \\
\hline $\mathbf{T}$ & $46,8 \mathrm{c}$ & $44,2 \mathrm{~b}$ & $44,7 \mathrm{~b}$ & $43,1 \mathrm{c}$ & $46,9 \mathrm{~b}$ & 43,3 & 43,1 & 42,4 \\
\hline $\mathbf{G}$ & $47,8 \mathrm{bcA}$ & $43,4 \mathrm{bB}$ & $45,6 \mathrm{bAB}$ & $43,7 \mathrm{cAB}$ & $43,5 b c$ & 40,8 & 40,6 & 40,5 \\
\hline CS & $50,8 \mathrm{~b}$ & $49,0 \mathrm{a}$ & $49,2 \mathrm{ab}$ & 46,4 bc & $55,1 \mathrm{aA}$ & $40,7 \mathrm{~B}$ & $41,4 \mathrm{~B}$ & $45,2 \mathrm{~B}$ \\
\hline CG & $59,3 \mathrm{aA}$ & $43,8 \mathrm{bB}$ & $46,4 \mathrm{bB}$ & $47,1 \mathrm{abB}$ & $49,6 \mathrm{bA}$ & $41,5 \mathrm{~B}$ & $42,3 \mathrm{~B}$ & $45,1 \mathrm{~B}$ \\
\hline CSF & $64,3 \mathrm{aA}$ & $48,2 \mathrm{aB}$ & $50,1 \mathrm{aB}$ & $50,0 \mathrm{aB}$ & $58,7 \mathrm{aA}$ & $42,0 \mathrm{~B}$ & $41,0 \mathrm{~B}$ & $46,2 \mathrm{~B}$ \\
\hline \multirow[t]{2}{*}{ CGF } & $63,8 \mathrm{aA}$ & $51,8 \mathrm{aB}$ & $50,4 \mathrm{aB}$ & $47,5 \mathrm{abB}$ & 57,1 aA & $42,7 \mathrm{~B}$ & $44,0 \mathrm{~B}$ & $42,4 \mathrm{~B}$ \\
\hline & \multicolumn{8}{|c|}{ Saturação por bases (V), \% } \\
\hline$T$ & $18,6 \mathrm{bA}$ & $16,1 \mathrm{cB}$ & $11,4 \mathrm{cB}$ & $6,4 \mathrm{dC}$ & $16,6 \mathrm{cA}$ & $11,3 \mathrm{cB}$ & $12,2 \mathrm{cB}$ & $6,0 \mathrm{bC}$ \\
\hline $\mathbf{G}$ & $20,9 \mathrm{bA}$ & $15,7 \mathrm{cB}$ & $10,9 \mathrm{cC}$ & $7,2 \mathrm{cdC}$ & $18,9 \mathrm{cA}$ & $15,3 \mathrm{bcA}$ & $11,7 \mathrm{cB}$ & 7,9 bC \\
\hline CS & $53,5 \mathrm{aA}$ & $23,3 \mathrm{bB}$ & $17,1 \mathrm{bC}$ & $11,0 \mathrm{bD}$ & $48,6 \mathrm{bA}$ & $19,9 \mathrm{bB}$ & $14,0 \mathrm{bcB}$ & $9,7 \mathrm{abc}$ \\
\hline CG & $54,8 \mathrm{aA}$ & $26,2 \mathrm{bB}$ & $16,4 \mathrm{bC}$ & $15,6 \mathrm{abC}$ & $53,0 \mathrm{bA}$ & $36,6 \mathrm{aB}$ & $16,5 \mathrm{abC}$ & $11,1 \mathrm{abC}$ \\
\hline CSF & 59,4 aA & $24,1 \mathrm{bB}$ & $21,5 \mathrm{aB}$ & $19,8 \mathrm{aB}$ & $62,9 \mathrm{aA}$ & $27,9 \mathrm{bB}$ & $15,8 \mathrm{abC}$ & $12,8 \mathrm{abC}$ \\
\hline CGF & 57,0 aA & $39,9 \mathrm{aB}$ & $24,4 \mathrm{aC}$ & $19,3 \mathrm{aD}$ & 60,1 aA & $38,4 \mathrm{aB}$ & $19,0 \mathrm{aC}$ & $14,4 \mathrm{aD}$ \\
\hline
\end{tabular}

Th Médias seguidas da mesma letra minúscula em cada coluna e maiúscula na mesma linha dentro de cada atributo avaliado, numa mesma época, não diferem estatisticamente entre sí pelo teste de Tukey a $5 \%$. 
movimentação dos cátions $\left(\mathrm{Ca}^{2+} \mathrm{e} \mathrm{Mg}^{2+}\right)$ dissolvidos. Pode-se observar (Tabela 5) que na segunda amostragem (agosto de 1997) os teores de $\mathrm{Ca}^{2+}$ trocável nos tratamentos adubados (CSF e CGF) foram inferiores àqueles determinados seis meses antes (fevereiro), indicando uma possível lixiviação para camadas ainda mais profundas.

As perdas de $\mathrm{Ca}$ e $\mathrm{Mg}$, adicionados pela calagem, foram avaliadas por Raij et al. (1982), em experimento de campo conduzido por cinco anos em um latossolo vermelho amarelo cultivado com milho, que recebeu $90 \mathrm{~kg} \mathrm{ha}^{-1}$ de $\mathrm{N}$ como sulfato de amônio e $90 \mathrm{~kg} \mathrm{ha}^{-1}$ de $\mathrm{P}_{2} \mathrm{O}_{5}$ como superfosfato simples. Os autores constataram perdas anuais de Ca+Mg de 2, 5, 9 e 12 mmol $_{\mathrm{c}} \mathrm{dm}^{-3}$ de solo, nas doses de 0, 3, 6 e $9 \mathrm{t} \mathrm{ha}^{-1}$ de calcário, aplicado no início do experimento.

A calagem é uma prática já consagrada para aumentar o $\mathrm{pH}$ e comigir a acidez na camada arável do solo. No caso de subsolos ácidos, diversos autores demonstraram que a calagem em doses elevadas também pode reduzir a acidez nas camadas subsuperficiais (Quaggio, 1982, 1985, 1992; Raij et al., 1982; Souza \& Ritchey, 1986). Souza \& Ritchey (1986) demonstraram que foi possível reduzir a acidez de um latossolo vermelho escuro argiloso a uma profundidade de até $60 \mathrm{~cm}$ com calcánio. Para tanto, porém, foram necessários oito anos e doses superiores a 7,5 tha ${ }^{-1}$. Os mesmos autores ressaltaram, no entanto, que para solos de textura média e arenosa o tempo para esta correção é menor.

De acordo com os resultados apresentados por Quaggio et al. $(1982,1985)$ e Raij et al. (1982), é possível que o tempo para que o efeito da calagem seja manifestado, em profundidade, não seja tão longo. Quaggio et al. (1982), em um experimento conduzido em latossolo roxo distrófico de cerrado, verificaram que a aplicação de 6 t.ha $^{-1}$ de calcário elevou os teores de $\mathrm{Ca}+\mathrm{Mg}$ e o $\mathrm{pH}$ em água, a $50 \mathrm{~cm}$ de profundidade, após 30 meses. Em outro experimento, num Cambissolo álico, Quaggio et al. (1985) observaram que em 12 meses, 12 t.ha ${ }^{-1}$ de calcário elevaram os teores de $\mathrm{Ca}+\mathrm{Mg}$ em cerca de 15,0 mmolc. $_{\text {. }} \mathrm{dm}^{-3}$ a uma profundidade de $50 \mathrm{~cm}$.

No caso de pastagens, experimentos como os de Carvalho et al. (1992) e Werner (1979) têm demonstrado que a aplicação de calcário em cobertura pode ser eficiente para corrigir a acidez e elevar os teores de $\mathrm{Ca}$ e $\mathrm{Mg}$ do solo, pelo menos nas 
camadas mais superficiais. Porém, a magnitude desses efeitos irá depender das doses de calcário aplicadas, textura do solo, granulometria do calcário, umidade do solo, dentre outros fatores (Quaggio et al. 1982, 1985; Raij et al, 1982; Carvalho et al., 1992)

Com relação ao $\mathrm{K}$, observa-se que a fertilização (tratamentos CSF e CGF), incluindo este elemento, resultou em aumento de seu teor trocável no perfil do solo em relação à testemunha, atingindo cerca de $5 \%$ da CTC na camada superficial. Por outro lado, na ausência dos fertilizantes, a aplicação de calcário parece ter provocado a lixiviação do $\mathrm{K}$, cujos teores trocáveis nestes tratamentos foram inferiores ao existente originalmente no solo (testemunha) e indetectáveis a partir de $20 \mathrm{~cm}$ de profundidade.

$\mathrm{O}$ teor de $\mathrm{P}$ disponível, na camada $0-10 \mathrm{~cm}$, aumentou com a aplicação dos fertilizantes, incluindo este elemento, passando de $2 \mathrm{mg} \mathrm{kg}^{-1}$ (testemunha) para 8 e 9 $\mathrm{mg} \mathrm{kg}{ }^{-1}$, nos tratamentos CSF e CGF, respectivamente (Tabela 4). Nas camadas inferiores, a diferença nos teores de $\mathrm{P}$ a favor dos tratamentos adubados pode ser atribuida à reciclagem de nutrientes, em função do maior desenvolvimento do sistema radicular, conforme demonstrado no ítem 4.1.2. (Figuras 9 e 10). O aumento de $2 \mathrm{mg} \mathrm{kg}^{-1}$ no teor de $\mathrm{P}$ no tratamento com gradagem, na camada superficial, pode ter sido devido à mineralização dos resíduos orgânicos incorporados ao solo.

$\mathrm{Na}$ Tabela 6 encontram-se os resultados dos teores de $\mathrm{C}$ e $\mathrm{N}$ totais e a relação $\mathrm{C}: \mathrm{N}$ do solo. Estes resultados referem-se à amostragem realizada em fevereiro de 1997, vinte meses após o início do experimento, pois os valores encontrados na segunda amostragem, agosto de 1997, foram praticamente idênticos aos mostrados na Tabela 6, não se justificando, portanto, a sua apresentação. $\mathrm{O}$ teor médio de $\mathrm{N}$ total $\left(0,65 \mathrm{~g} \mathrm{~kg}^{-1}\right)$ encontrado na parcela sem tratamento, nos $20 \mathrm{~cm}$ superficiais, é comparável aos verificados por Cantarutti (1996) e Feigl et al. (1995) em solos sob pastagens no Sul da Bahia e Amazônia, respectivamente.

Como já era esperado, os teores de carbono e nitrogênio total decresceram com o aumento da profundidade do solo, refletindo a redução da densidade de raízes, as quais, conforme demonstrado no ítem 4.1.2, concentraram-se em mais de $75 \%$ nos primeiros $20 \mathrm{~cm}$ do perfil. Além das raízes, os resíduos provenientes da parte aérea das 
gramíneas (serrapilheira) constituem importante fonte de matéria orgânica para o solo, mesmo em áreas pastejadas, de acordo com as estimativas feitas por Cadish et al. (1994) e Cantarutti (1996). Cantarutti (1996) verificou elevada reciclagem da serrapilheira em pastagem de $B$. humidicola no Sul da Bahia, sendo estimada entre 15 e $18 \mathrm{t} \mathrm{ha}^{-1}$ de massa seca por ano, com tempo médiode residência (turnover time) de 35 a 40 dias.

A influência dos tratamentos sobre o teor de carbono total do solo ocorreu apenas na camada de $0-10 \mathrm{~cm}$, enquanto o $\mathrm{N}$ total foi afetado até $40 \mathrm{~cm}$ de profundidade Tabela 6). As diferenças foram pequenas, mas efetivas e até surpreendentes, em se tratando da natureza arenosa do solo (de difícil acúmulo de matéria orgânica), e dão indicações importantes da sustentabilidade do sistema a médio e longo prazo.

Os maiores teores de carbono e nitrogênio, 12,3 e $0,93 \mathrm{~g} \mathrm{~kg}^{-1}$ solo, respectivamente, foram encontrados no tratamento onde o calcário foi aplicado em cobertura, associado à fertilização com macro e micronutrientes (CSF), caracterizando um aumento de $26 \%$ no teor de carbono e $36 \%$ no teor de $\mathrm{N}$ total, em relação ao tratamento testemunha. Tais resultados sugerem que o uso de corretivos e fertilizantes em pastagens, como em outras culturas (Sanchez et al., 1989), podem elevar o teor de matéria orgânica do solo, conforme já verificado por Corsi \& Nussio (1993). Isso acontece porque o aumento da disponibilidade dos nutrientes, adicionados nos insumos, proporciona acréscimos da produção, com reflexos diretos na quantidade de resíduos reciclados. Contudo, o conteúdo de matéria orgânica do solo é função da entrada de fontes de carbono e da taxa de decomposição, a qual é influenciada por fatores climáticos e edáficos, além da qualidade do próprio resíduo (relação $\mathrm{C}: \mathrm{N}$, teor de lignina e polifenóis, etc) (Sanchez, 1981). É de se esperar, portanto, diferenças de magnitude para cada situação.

Os menores teores de $\mathrm{C}$ e $\mathrm{N}$ nos tratamentos com gradagem ( $\mathrm{G}, \mathrm{CG}$ e CGF) comparados com aqueles onde esta prática não foi utilizada (CS e CSF), indicam que o revolvimento do solo teve efeito negativo no que se refere ao acúmulo e/ou manutenção da matéria orgânica no solo, por duas possíveis razões: aceleração da taxa de 
Tabela 6. Teores de $\mathrm{C}$ e $\mathrm{N}$ totais e relação $\mathrm{C}: \mathrm{N}$ no solo sob pastagem de $B$. decumbens, submetida aos tratamentos: sem tratamento $(T)$; gradagem $(\mathrm{G})$; calcário aplicado na superfície (CS); calcário incorporado com grade (CG); CS + fertilizantes (CSF); e CG + fertilizantes (CGF).

\begin{tabular}{|c|c|c|c|c|}
\hline \multirow[t]{2}{*}{ Tratamentos } & \multicolumn{4}{|c|}{ Profundidade $(\mathrm{cm})$} \\
\hline & $0-10$ & $10-20$ & $20-40$ & $40-60$ \\
\hline & \multicolumn{4}{|c|}{ C total, $\mathrm{g} \mathrm{gg}^{-1}$ solo } \\
\hline $\mathrm{T}$ & $9,8 \mathrm{cdA}^{(1)}$ & $8,5 \mathrm{~B}$ & $7,5 \mathrm{~B}$ & $6,5 \mathrm{C}$ \\
\hline G & $9,1 \mathrm{dA}$ & $7,4 \mathrm{~B}$ & $7,6 \mathrm{BC}$ & $6,5 \mathrm{C}$ \\
\hline $\mathrm{CS}$ & $11,1 \mathrm{abA}$ & $8,4 \mathrm{~B}$ & $7,4 \mathrm{~B}$ & $6,3 \mathrm{C}$ \\
\hline CG & $10,5 \mathrm{bcA}$ & $8,3 \mathrm{~B}$ & $7,1 \mathrm{C}$ & $5,9 \mathrm{D}$ \\
\hline $\mathrm{CSF}$ & $12,3 \mathrm{aA}$ & $8,2 \mathrm{~B}$ & $7,5 \mathrm{BC}$ & $6,5 \mathrm{C}$ \\
\hline \multirow[t]{2}{*}{ CGF } & $10,4 \mathrm{bcA}$ & $8,2 \mathrm{~B}$ & $6,7 \mathrm{C}$ & $6,1 \mathrm{C}$ \\
\hline & \multicolumn{4}{|c|}{ N total, $\mathrm{g} \mathrm{kg}^{-1}$ solo } \\
\hline $\mathrm{T}$ & $0,70 \mathrm{cA}$ & $0,58 \mathrm{aB}$ & $0,52 \mathrm{abC}$ & $0,41 \mathrm{D}$ \\
\hline G & $0,60 \mathrm{dA}$ & $0,47 \mathrm{bB}$ & $0,48 \mathrm{bB}$ & $0,40 \mathrm{C}$ \\
\hline $\mathrm{CS}$ & $0,79 \mathrm{bA}$ & $0,60 \mathrm{aB}$ & $0,49 \mathrm{abC}$ & $0,42 \mathrm{D}$ \\
\hline CG & $0,73 \mathrm{bcA}$ & $0,64 \mathrm{aB}$ & $0,51 \mathrm{abC}$ & $0,46 \mathrm{D}$ \\
\hline CSF & $0,93 \mathrm{aA}$ & $0,64 \mathrm{aB}$ & $0,56 \mathrm{aC}$ & $0,47 \mathrm{D}$ \\
\hline \multirow[t]{2}{*}{$\mathrm{CGF}$} & $0,74 \mathrm{bcA}$ & $0,63 \mathrm{aB}$ & $0,53 \mathrm{abC}$ & $0,42 \mathrm{D}$ \\
\hline & \multicolumn{4}{|c|}{ Relação C:N } \\
\hline $\mathrm{T}$ & 14,0 & 14,7 & 15,2 & 15,9 \\
\hline G & 15,2 & 15,7 & 15,8 & 15,8 \\
\hline CS & 14,0 & 14,0 & 15,1 & 15,8 \\
\hline CG & 14,4 & 13,0 & 13,9 & 12,8 \\
\hline CSF & 13,2 & 12,8 & 13,4 & 13,8 \\
\hline CGF & 14,0 & 13,0 & 12,6 & 14,5 \\
\hline
\end{tabular}

$7 \pi$ Médias seguidas da mesma letra, minúscula na mesma coluna e maiúscula na mesma linha dentro de cada atributo avaliado, não diferem estatisticamente entre sí pelo teste de Tukey a $5 \%$. 
mineralização e prejuízo do desenvolvimento radicular, principalmente nos primeiros meses após a operação. A gradagem como prática isolada provocou a redução do $\mathrm{N}$ total até $40 \mathrm{~cm}$ de profundidade, indicando claramente que o efeito positivo sobre a produção de forragem, observado no primeiro ano do experimento, foi causado pela mineralização dos nutrientes contidos na matéria orgânica, particularmente nitrogênio. Sendo assim, este aumento de produção não deve ser interpretado como recuperação da pastagem, uma vez que o efeito positivo da mineralização da matéria orgânica é efêmero. $\mathrm{Na}$ verdade, o que ocorre é uma degradação do solo, que irá refletir negativamente na produção do pasto a médio prazo, agravando ainda mais a situação original. Oliveira (1997) fez considerações pertinentes sobre esse assunto.

Não houve efeito da interação entre tratamentos e profundidades para a relação $\mathrm{C}: \mathrm{N}$, mas as médias dos tratamentos foram significativas e indicaram valor mais elevado (16) para o tratamento com gradagem (G) e mais baixo (13) para os tratamentos com adubação (CSF e CGF).

\subsubsection{Atributos microbiológicos do solo}

\subsubsection{Biomassa microbiana $\mathrm{C}, \mathrm{N}$ e $\mathrm{P}$ do solo}

Os resultados do teor de água no solo e da biomassa microbiana $\mathrm{C}, \mathrm{N}$ (com suas respectivas porcentagens em relação ao $\mathrm{C}$ e $\mathrm{N}$ totais, entre parênteses) e $\mathrm{P}$, determinados na estação chuvosa e seca, são mostrados na Tabela 7.

Em termos gerais, a biomassa microbiana $\mathrm{C}, \mathrm{N}$ e $\mathrm{P}$ foi mais elevada na estação chuvosa, observando-se maior amplitude de variação para a biomassa $\mathrm{C}$, cujas quantidades foram aproximadamente duas vezes inferiores na estação seca, independente dos tratamentos e da profundidade. Este comportamento sazonal da biomassa microbiana tem sido registrado na literatura em solos sob pastagens (He et al., 1997; Luizão et al., 1992; Perrot et al., 1992; Tate et al., 1991). O aumento da biomassa microbiana no período das chuvas é resultante da maior disponibilidade de resíduos orgânicos, 
Tabela 7. Resultados de biomassa teor de água e microbiana $\mathrm{C}, \mathrm{N}$ (com suas respectivas porcentagens em relação ao $\mathrm{C}$ e $\mathrm{N}$ totais, entre parênteses) e $\mathrm{P}$ no solo sob $B$. decumens, sumetida aos tratamentos: sem tratamento $(T)$; gradagem $(\mathrm{G})$; calcário aplicado na superfície (CS); calcário incorporado com grade (CG); $\mathrm{CS}+$ fertilizantes (CSF); e CG + fertilizantes (CGF).

\begin{tabular}{|c|c|c|c|c|}
\hline \multirow{3}{*}{ Tratamentos } & \multicolumn{4}{|c|}{ Épocas de amostragem } \\
\hline & \multicolumn{2}{|c|}{ Estação chuvosa } & \multicolumn{2}{|c|}{ Estação seca } \\
\hline & $0-10 \mathrm{~cm}$ & $10-20 \mathrm{~cm}$ & $0-10 \mathrm{~cm}$ & $10-20 \mathrm{~cm}$ \\
\hline & \multicolumn{4}{|c|}{ Teor de água no solo $\left(\mathrm{g} \mathrm{kg}^{-1}\right)$} \\
\hline $\mathbf{T}$ & $129,7 b c^{(1)}$ & 130,2 & 57,4 & 80,6 \\
\hline $\mathbf{G}$ & $126,9 \mathrm{bc}$ & 143,8 & 54,9 & 71,5 \\
\hline CS & $148,2 \mathrm{ab}$ & 123,2 & 73,6 & 96,6 \\
\hline $\mathbf{C G}$ & 172,5 aA & $143,4 \mathrm{~B}$ & 77,4 & 90,7 \\
\hline CSF & $113,1 \mathrm{bc}$ & 117,0 & 69,6 & 71,9 \\
\hline \multirow[t]{2}{*}{ CGF } & $104,6 \mathrm{c}$ & 120,4 & 78,7 & 83,2 \\
\hline & \multicolumn{4}{|c|}{ Biomassa C (mg kg solo $\operatorname{seco}^{-1}$ ) } \\
\hline $\mathbf{T}$ & $165(1,7) \mathrm{bA}$ & $153(1,6) \mathrm{bA}$ & $91(0,9) \mathrm{bA}$ & $63(0,8) \mathrm{cB}$ \\
\hline $\mathbf{G}$ & $159(1,8) \mathrm{bA}$ & $79(1,1) \mathrm{cB}$ & $82(0,9) \mathrm{bA}$ & $59(0,8) \mathrm{cA}$ \\
\hline CS & $209(1,9) \mathrm{aA}$ & $130(1,6) \mathrm{abB}$ & $100(0,9) \mathrm{abA}$ & $75(0,9)$ bcB \\
\hline CG & $173(1,7) \mathrm{bA}$ & $106(1,3) \mathrm{bB}$ & $91(0,9) \mathrm{bA}$ & $76(0,9) \mathrm{bcB}$ \\
\hline CSF & $227(1,9) \mathrm{aA}$ & $157(1,9) \mathrm{aB}$ & $115(1,0) \mathrm{aA}$ & $109(1,3) \mathrm{aA}$ \\
\hline \multirow[t]{2}{*}{ CGF } & $221(2,2) \mathrm{aA}$ & $118(1,5) b B$ & $103(1,1) \mathrm{abA}$ & $85(1,0)$ bB \\
\hline & \multicolumn{4}{|c|}{ Biomasa $N$ (mg kg solo seco-1) } \\
\hline $\mathbf{T}$ & $24(3,4) \mathrm{cA}$ & $22(3,8) \mathrm{cB}$ & $19(2,7) \mathrm{cA}$ & $13(2,2) \mathrm{eB}$ \\
\hline $\mathbf{G}$ & $27(4,5) \mathrm{cA}$ & $20(4,2) \mathrm{cB}$ & $14(2,3) \mathrm{dA}$ & $15(3,2)$ deA \\
\hline CS & $36(4,6) \mathrm{bA}$ & $30(5,0) b B$ & $20(2,5) \mathrm{cA}$ & $17(2,9) \mathrm{cdB}$ \\
\hline CG & $34(4,7) \mathrm{bA}$ & $20(3,1) \mathrm{cB}$ & $22(3,0) \mathrm{abA}$ & $19(2,9) \mathrm{bcB}$ \\
\hline CSF & $45(4,8)$ aA & $38(5,9) \mathrm{aB}$ & $22(2,3) \mathrm{abA}$ & $20(3,3) \mathrm{abA}$ \\
\hline \multirow[t]{2}{*}{ CGF } & $37(5,1) \mathrm{bA}$ & $23(3,7) \mathrm{cB}$ & $23(3,2) a A$ & $22(3,5) \mathrm{aA}$ \\
\hline & \multicolumn{4}{|c|}{ Biomassa microbiana $P$ ( $m g$ kg solo seco $\left.{ }^{-1}\right)$} \\
\hline $\mathbf{T}$ & $7 \mathrm{cA}$ & $6 \mathrm{cA}$ & $5 \mathrm{cA}$ & $5 \mathrm{bA}$ \\
\hline $\mathbf{G}$ & $6 \mathrm{cA}$ & $5 \mathrm{cB}$ & $6 \mathrm{cA}$ & $4 \mathrm{bB}$ \\
\hline CS & $12 \mathrm{bA}$ & $8 \mathrm{abB}$ & $10 \mathrm{bA}$ & $6 \mathrm{bB}$ \\
\hline CG & $11 \mathrm{bA}$ & $6 \mathrm{bB}$ & $9 \mathrm{bA}$ & $5 \mathrm{bB}$ \\
\hline CSF & $16 \mathrm{aA}$ & $10 \mathrm{aB}$ & $13 \mathrm{aA}$ & $9 \mathrm{aB}$ \\
\hline CGF & $15 \mathrm{aA}$ & $10 \mathrm{aB}$ & $13 \mathrm{aA}$ & $9 \mathrm{aB}$ \\
\hline
\end{tabular}

(1) Médias seguidas de mesma letra, minúscula na mesma coluna e maiúscula na mesma linha, dentro de cada atributo avaliado numa mesma época, não diferem estatisticamente pelo teste de Tukey a $5 \%$. 
principalmente exsudatos de raizes, em função do maior crescimento das plantas. Os maiores valores de biomassa $\mathrm{C}, \mathrm{N}$ e $\mathrm{P}$ nos $10 \mathrm{~cm}$ superficiais também refletem a maior disponibilidade de nutrientes e de substrato orgânico nesta camada do solo.

Os valores de biomassa $\mathrm{C}$ variaram de 82 a $227 \mathrm{mg} \mathrm{kg}^{-1}$, nos primeiros $10 \mathrm{~cm}$, e de 75 a $157 \mathrm{mg} \mathrm{kg}^{-1}$ na camada de $10-20 \mathrm{~cm}$. Enquanto a biomassa $\mathrm{N}$ variou de 25 a $46 \mathrm{mg} \mathrm{kg}^{-1}$ solo, na camada de 0-10 cm, e de 20 a $39 \mathrm{mg} \mathrm{kg}^{-1}$ na camada de 10-20 cm. Esses valores estão abaixo daqueles apresentados por Bonde et al. (1991) e Geraldes et al. (1995) para latossolos não sob pastagens não adubadas na Amazônia, porém com teores mais elevados de carbono total. Por outro lado, Campos (1998), trabalhando com o mesmo tipo de solo utilizado no presente trabalho, cultivado com pastagem de $B$. decumbens não degradada, encontrou valores entre 160 e $250 \mathrm{mg} \mathrm{kg}^{-1}$ de solo para biomassa $\mathrm{C}$ e 18 a $24 \mathrm{mg} \mathrm{kg}^{-1}$ para biomassa $\mathrm{N}$, na camada de $0-10 \mathrm{~cm}$.

Em termos relativos, o $\mathrm{C}$ na biomassa microbiana variou entre 0,8 a $2,2 \%$ do $\mathrm{C}$ total do solo, sendo que as menores proporções foram observadas na estação seca. Segundo Lynch \& Panting (1980), a redução da biomassa microbiana na estação seca está diretamente relacionada com a qualidade do substrato. De acordo com estes autores, na época chuvosa, a biomassa microbiana é sustentada, principalmente, pelos exsudatos radiculares facilmente oxidáveis, que compõem cerca de $60 \%$ de sua massa seca. $\mathrm{Na}$ estação seca, a atividade radicular é drasticamente reduzida, de modo que o substrato passa a ser constituído de resíduos mais complexos, limitando o crescimento microbiano.

O aumento da biomassa microbiana $\mathrm{C}$ (cerca de $35 \%$ na estação chuvosa) nos tratamentos que receberam fertilizantes (CSF e CGF) pode ser atribuído à melhoria das condições químicas do solo (Tabelas 4 e 5), além do maior crescimento e desenvolvimento do sistema radicular da braquiária (Figuras 9 e 10), gerando maior quantidade de resíduos de melhor qualidade. A influência benéfica da aplicação de fertilizantes sobre a biomassa microbiana foi constatada por outros autores (Bolan et al., 1996; Goyal et al., 1992). Por outro lado, os efeitos da gradagem na mineralização da matéria orgânica do solo e prejuizo do desenvolvimento radicular da braquiária, como já 
foi discutido anteriormente, tiveram reflexos negativos na biomassa microbiana $C$, principalmente na camada de $10-20 \mathrm{~cm}$, a qual é menos influenciada pela serrapilheira.

Todos os tratamentos que receberam calcário (CS e CG) ou calcário mais fertilizantes (CSF e CGF) promoveram o aumento da biomassa $\mathrm{N}$, especialmente na camada superficial, o que deve estar associado à maior atividade microbiana devido à redução da toxicidade do $\mathrm{Al}^{3+}$, aumento do $\mathrm{pH}$ e disponibilidade de nutrientes. $\mathrm{O}$ tratamento com aplicação de calcário em cobertura mais fertilizantes (CSF) apresentou os maiores valores de biomassa $\mathrm{N}$ na estação chuvosa, caracterizando acréscimos de 87 e $73 \%$ nas camadas de $0-10$ e $10-20 \mathrm{~cm}$, respectivamente, em relação ao tratamento testemunha. Na estação seca, as diferenças permaneceram, porém em menor magnitude, possivelmente em decorrência da menor disponibilidade de substrato orgânico e do nitrogênio na solução do solo.

A porcentagem do $\mathrm{N}$ total na biomassa microbiana (valores entre parênteses) nas parcelas sem tratamento variou de 2,2 a 3,8 \% e são semelhantes às verificadas por Geraldes et al. (1995) e Bonde et al. (1991), em pastagens de diferentes idades na Amazônia. Estas proporções, contudo, são inferiores às observados por Campos (1998), em pastagem de Brachiaria decumbens estabelecida na mesma região e com o mesmo tipo de solo do presente trabalho, embora os valores absolutos sejam comparáveis. Nas parcelas que receberam tratamenton as proporções do $\mathrm{N}$ total imobilizado na biomassa foram claramente aumentadas, chegando a atingir 5,9 \% no tratamento CSF, indicando uma elevada imobilização do $\mathrm{N}$ mineral adicionado ao solo. A biomassa $\mathrm{N}$ constitui um importante compartimento de reserva deste nutriente em solos sob pastagens (Geraldes et al., 1995; Bristow e Jarvis, 1991). Jackson et al. (1989), em estudo com ${ }^{15} \mathrm{~N}$, verificaram que a biomassa imobilizou $\mathrm{NH}_{4}^{+}$e $\mathrm{NO}_{3}^{-}$mais rapidamente do que a pastagem.

As alterações sazonais na biomassa $\mathrm{N}$ refletem a disponibilidade do substrato e podem influenciar a produção ou a taxa de transferência do $\mathrm{N}$ entre outros componentes do sistema, com conseqüente efeitos sobre as perdas por lixiviação ou desnitrificação (Bristow e Jarvis, 1991). No entanto, têm-se verificado que em solos sob 
pastagem de gramíneas, a imobilização do $\mathrm{N}$ na biomassa microbiana pode reduzir a ciclagem deste elemento em virtude da alta relação $\mathrm{C}: \mathrm{N}$ dos resíduos produzidos (Cantarutti, 1996; Robbins et al., 1989), diminuindo assim a sua disponibilidade para a forrageira (Robertson et al., 1993a,b; 1994).

Independente dos tratamentos, das profundidades e da época de amostragem, a biomassa microbiana $\mathrm{P}$ foi sempre maior do que o teor de $\mathrm{P}$ disponível do solo, sugerindo que o fluxo de $\mathrm{P}$ através da biomassa microbiana poderia contribuir, em parte, para o fornecimento deste nutriente às plantas forrageiras. Alguns autores (Perrot et al., 1992; He et al., 1997) têm verificado que a biomassa microbiana $P$, à semelhança da biomassa C e N, apresenta um padrão de variação sazonal. He et al. (1997) relatou que a maior imobilização do $\mathrm{P}$ na biomassa microbiana durante o período chuvoso e quente é devido ao aumento da atividade microbiana pela maior disponibilidade de substrato, enquanto no período seco a menor difusão do $\mathrm{P}$ na solução do solo parece ser o fator mais limitante.

De modo geral, a biomassa $\mathrm{P}$ variou de 5 a $16 \mathrm{mg} \mathrm{kg}^{-1}$ de solo, sendo os maiores valores associados aos tratamentos que receberam fertilizantes (CSF e CGF), incluindo este elemento. Brookes et al. (1984), utilizando o mesmo método empregado neste trabalho, encontraram valores entre 6 a $106 \mathrm{mg} \mathrm{kg}^{-1}$, em solos de clima temperado com maiores teores de $\mathrm{P}$ disponível. Os valores encontrados no presente trabalho estão mais próximos daqueles determinados por Brito (1998), em solos sob pastagem de 2 a 25 anos, que variaram de 7 a $16 \mathrm{mg} \mathrm{kg}^{-1}$.

Comparando-se com a testemunha, a biomassa $P$ aumentou significativamente nos tratamentos com aplicação de calcário na ausência de fertilizantes , independentemente do método de incorporação, o que pode estar relacionado com o aumento da atividade microbiana em decorrência da elevação do $\mathrm{pH}$. Nos tratamentos com calcário mais aplicação de fertilizantes, a biomassa $\mathrm{P}$ praticamente dobrou.Vários autores têm reportado que a aplicação de fertilizante fosfatado em pastagens acarreta em imobilização deste elemento na biomassa microbiana (Guerra et al., 1995; He et al., 1997; Perrot et al., 1992). O P imobilizado na biomassa microbiana fica protegido das reações 
de adsorção em solos com mineralogia predominantemente oxídica, podendo constituir um importante reservatório deste nutriente para a pastagem, através de sua reciclagem no sistema.

\subsubsection{Atividade microbiana}

De modo geral, a atividade microbiana, avaliada pela quantidade de $\mathrm{C}-\mathrm{CO}_{2}$ despreendido no processo de oxidação dos compostos orgânicos, foi mais intensa na camada de 0-10 $\mathrm{cm}$ (Figura 14) refletindo a maior disponibilidade de substrato na camada superficial, tanto proveniente das raizes como da liteira, confirmando os resultados obtidos por outros autores (Della Bruna et all, 1991; Fialho et al., 1991).

As maiores quantidades de $\mathrm{C}-\mathrm{CO}_{2}$ despreendido, nas duas profundidades estudadas, foram observadas no tratamento com aplicação de calcário em cobertura associado à fertilização com macro e micronutrientes (CSF), o que pode ser atribuído ao maior teor de carbono e nitrogênio no solo (Tabela 6), além da melhoria da melhoria da fertilidade do solo, caracterizada pelo aumento do $\mathrm{pH}$ e disponibilidade de nutrientes e redução do $\mathrm{Al}$ tóxico. Em solos ácidos, a mineralização é mais lenta porque fica restrita aos grupos de microrganismos mais tolerantes (Tsai et al., 1992).

A quantidade acumulada de $\mathrm{C}-\mathrm{CO}_{2}$, despreendido em 80 dias de incubação, considerando as duas profundidades de amostragem, apresentou a seguinte ordem decrescente entre os tratamentos: $\mathrm{CSF}>\mathrm{CGF}=\mathrm{CS}>\mathrm{CG}>\mathrm{T}>\mathrm{G}$. Estas diferenças foram mais acentuadas a partir do $22^{\circ}$ dia de incubação devido, provavelmente, à maior disponibilidade de carbono nos tratamentos que receberam adubação, associado ao maior desenvolvimento do sistema radicular, conforme mostrado nas Figuras 9 e 10. Nota-se que as quantidades de $\mathrm{C}-\mathrm{CO}_{2}$ produzidas nas amostras dos tratamentos que incluíram gradagem foram sempre inferiores aos seus pares, ou seja: $\mathrm{G}<\mathrm{T}, \mathrm{CG}<\mathrm{CS}$ e $\mathrm{CGF}<\mathrm{CSF}$, indicando claramente que a gradagem provocou a mineralização da matéria e a redução da densidade de raízes nos primeiros meses após a operação, resultando em menor produção de resíduos utilizados como substrato pelos microrganismos. 

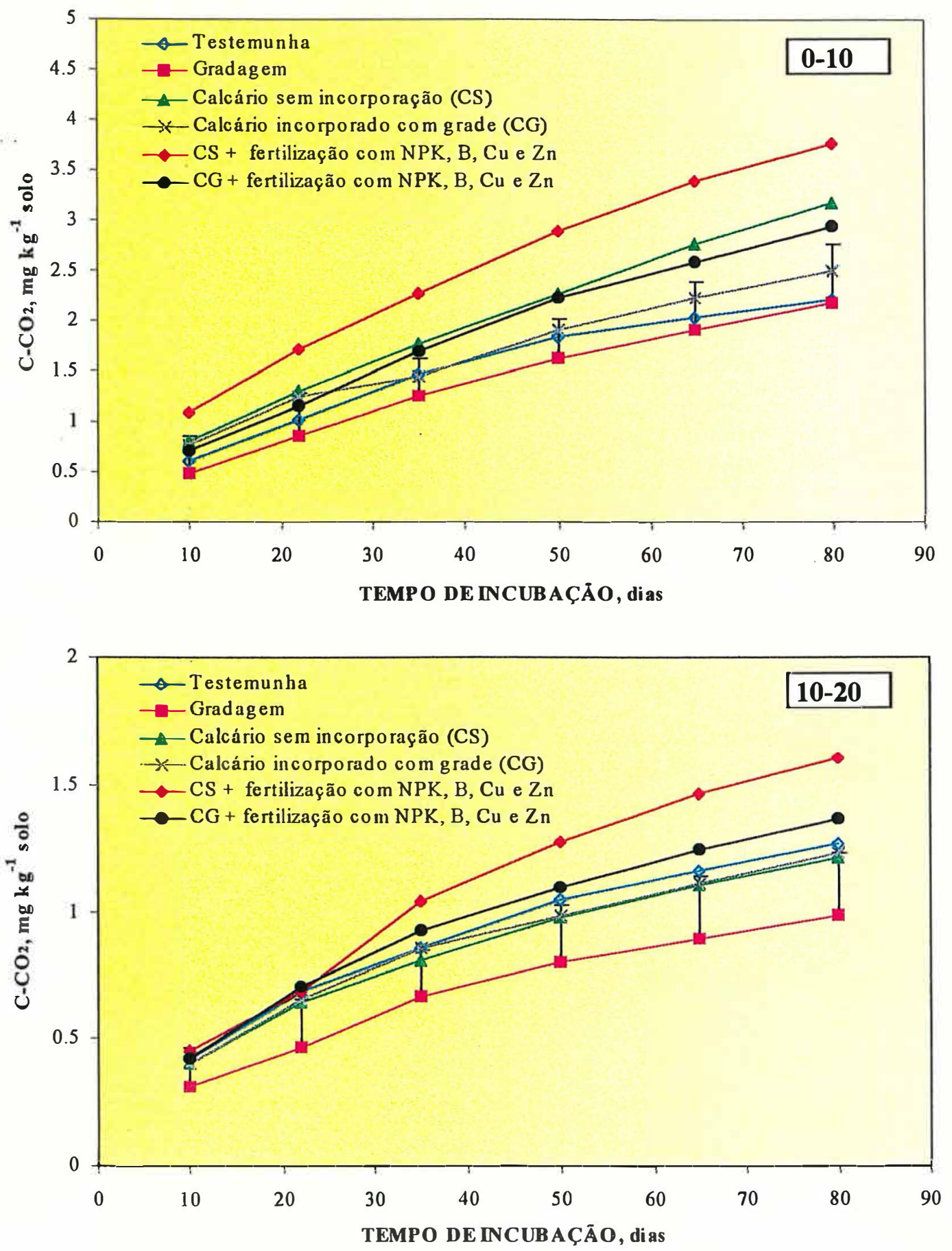

Figura 14. Quantidade acumulada de $\mathrm{C}-\mathrm{CO}_{2}$ despreendido nas amostras de solo, coletadas nas profundidades de 0-10 e 10-20 cm, incubadas em laboratório. As barras verticais indicam a diferença mínima significativa (D.M.S) pelo Teste de Tukey a $5 \%$, em cada tempo de avaliação. 


\subsubsection{Taxas líquidas de mineralização e nitrificação do nitrogênio do solo}

Em termos gerais, os teores de $\mathrm{N}-\mathrm{NH}_{4}{ }^{+}$e $\mathrm{N}-\mathrm{NO}_{3}{ }^{-}$foram mais elevados na estação chuvosa do que na estação seca. $\mathrm{O}$ teor de $\mathrm{N}^{-\mathrm{NH}_{4}}{ }^{+}$foi superior ao teor de $\mathrm{N}$ $\mathrm{NO}_{3}{ }^{-}$em todos os tratamentos, nas duas profundidades estudadas (Tabela 8), e consistiram quase na totalidade do $\mathrm{N}$ inorgânico do solo. Outros autores também têm verificado a predominância da forma amoniacal sobre a nítrica em solos sob pastagem em regiões tropicais (Garcia-Mendéz et al. 1991; Matson et al., 1990; Neill et al., 1997).

A camada de $0-10 \mathrm{~cm}$ de profundidade apresentou maior quantidade de $\mathrm{N}$ inorgânico do que a de $10-20 \mathrm{~cm}(\mathrm{P}<0,01)$, provavelmente em função do maior teor de matéria orgânica na camada mais superficial. Resultados semelhantes foram encontrados por Piccolo et. al. (1994) e Neill et al. (1997) em solos sob pastagem na Amazônia.

Todos os tratamentos promoveram o aumento da concentração de $\mathrm{N}$ $\mathrm{NH}_{4}{ }^{+}$no solo, na profundidade de 0-10 cm, em diferentes magnitudes. Considerando-se que o fertilizante nitrogenado foi aplicado apenas nos tratamentos CSF e CGF, o acréscimo de $\mathrm{N}$ mineral nos demais tratamentos pode estar associado à mineralização da matéria orgânica. Diversos autores têm demonstrado que práticas de manejo do solo, tais como calagem e adubação, estimulam a mineralização do N (Badalucco et al., 1992; Clay et al., 1993; Curtin \& Smillie, 1986).

$\mathrm{Na}$ estação chuvosa, a maior taxa de mineralização do $\mathrm{N}$ ocorreu no tratamento CSF (Tabela 8), provavelmente devido ao maior teor de $\mathrm{N}$ total no solo. Os valores negativos nos demais tratamentos indicam o predomínio do processo de imobilização do $\mathrm{N}$ pelos microrganismos do solo, concordando com os resultados apresentados por outros autores, em solos de pastagem (Fernandes \& Femandes, 1997; Piccolo et al., 1994; Robertson et al., 1993a, 1993b). Na maioria desses trabalhos, a imobilização do $\mathrm{N}$ foi atribuída à alta relação $\mathrm{C}: \mathrm{N}$ e baixa concentração de $\mathrm{N}$ nos resíduos, inferior a $18 \mathrm{~g} / \mathrm{kg}$, considerada como crítica para ocorrer uma mineralização líquida (Cantarutti et al., 1997). 
Tabela 8. Teores de $\mathrm{N}-\mathrm{NH}_{4}{ }^{+}, \mathrm{N}-\mathrm{NO}_{3}{ }^{-}$e taxas líquidas de mineralização e nitrificação do $\mathrm{N}$ em areia quartzosa, sob pastagem degradada de B. decumbens, submetida aos tratamentos: sem tratamento $(\mathrm{T})$; gradagem $(\mathrm{G})$; calcário aplicado na superfície (CS); calcário incorporado com grade (CG); CS + fertilizantes (CSF); e CG +fertilizantes (CGF).

\begin{tabular}{|c|c|c|c|c|}
\hline \multirow{3}{*}{ Tratamentos } & \multicolumn{4}{|c|}{ Epocas de amostragem } \\
\hline & \multicolumn{2}{|c|}{ Estação chuvosa } & \multicolumn{2}{|c|}{ Estação seca } \\
\hline & $0-10 \mathrm{~cm}$ & $10-20 \mathrm{~cm}$ & $0-10 \mathrm{~cm}$ & $10-20 \mathrm{~cm}$ \\
\hline & \multicolumn{4}{|c|}{$\mathrm{N}-\mathrm{NH}_{4}^{+}\left(m g \mathrm{~kg}^{-1}\right.$ solo seco) } \\
\hline $\mathbf{T}$ & $2,40 d A^{(1)}$ & $2,28 \mathrm{~A}$ & $2,04 \mathrm{bA}$ & $1,24 \mathrm{cB}$ \\
\hline $\mathbf{G}$ & $2,81 \mathrm{cdA}$ & $2,39 \mathrm{~A}$ & $1,58 \mathrm{cA}$ & $1,37 \mathrm{bcA}$ \\
\hline CS & $3,35 \mathrm{cdA}$ & $2,07 \mathrm{~B}$ & $2,17 \mathrm{bA}$ & $1,42 \mathrm{bcB}$ \\
\hline CG & $4,72 \mathrm{bcA}$ & $2,76 \mathrm{~B}$ & $2,44 \mathrm{bA}$ & $2,00 \mathrm{aB}$ \\
\hline CSF & $7,65 \mathrm{aA}$ & $2,04 \mathrm{~B}$ & $3,12 \mathrm{aA}$ & $1,76 \mathrm{abB}$ \\
\hline \multirow[t]{2}{*}{ CGF } & $5,57 \mathrm{bA}$ & $2,21 \mathrm{~B}$ & $2,37 \mathrm{bA}$ & $1,39 \mathrm{bcB}$ \\
\hline & \multicolumn{4}{|c|}{$\mathrm{N}-\mathrm{NO}_{3}^{-}\left(\mathrm{mg} \mathrm{kg}^{-1}\right.$ solo seco) } \\
\hline $\mathbf{T}$ & 0,14 & 0,15 & $<0,01$ & $<0,01$ \\
\hline $\mathbf{G}$ & 0,16 & 0,17 & $<0,01$ & $<0,01$ \\
\hline CS & 0,18 & 0,17 & $<0,01$ & $<0,01$ \\
\hline CG & 0,20 & 0,17 & $<0,01$ & $<0,01$ \\
\hline CSF & 0,29 & 0,22 & $<0,01$ & $<0,01$ \\
\hline \multirow[t]{2}{*}{ CGF } & 0,30 & 0,24 & $<0,01$ & $<0,01$ \\
\hline & \multicolumn{4}{|c|}{ Taxas líquidas de mineralização ( $\mathrm{mg} \mathrm{kg}^{-1}$ solo seco dia ${ }^{-1}$ ) } \\
\hline $\mathbf{T}$ & $-0,15 \pm 0,02^{(2)}$ & $-0,15 \pm 0,05$ & $0,18 \pm 0,03$ & $0,19 \pm 0,03$ \\
\hline $\mathbf{G}$ & $-0,11 \pm 0,06$ & $-0,15 \pm 0,05$ & $0,09 \pm 0,04$ & $0,02 \pm 0,01$ \\
\hline CS & $-0,20 \pm 0,07$ & $-0,12 \pm 0,03$ & $0,09 \pm 0,01$ & $0,06 \pm 0,04$ \\
\hline CG & $-0,38 \pm 0,04$ & $-0,26 \pm 0,01$ & $0,10 \pm 0,04$ & $0,03 \pm 0,03$ \\
\hline CSF & $0,46 \pm 0,15$ & $1,19 \pm 0,08$ & $0,08 \pm 0,08$ & $0,03 \pm 0,01$ \\
\hline \multirow[t]{2}{*}{ CGF } & $-0,43 \pm 0,06$ & $-0,18 \pm 0,02$ & $0,32 \pm 0,03$ & $0,22 \pm 0,01$ \\
\hline & \multicolumn{4}{|c|}{ Taxas líquidas de nitrificaçāo ( $m g \mathrm{~kg}^{-1}$ solo seco dia $a^{-1}$ ) } \\
\hline $\mathbf{T}$ & $-0,01 \pm 0,00^{(2)}$ & $0,01 \pm 0,00$ & $0,01 \pm 0,01$ & $0,09 \pm 0,01$ \\
\hline $\mathbf{G}$ & $-0,01 \pm 0,01$ & $0,01 \pm 0,01$ & $0,01 \pm 0,01$ & $0,06 \pm 0,02$ \\
\hline CS & $-0,01 \pm 0,00$ & $0,00 \pm 0,00$ & $0,01 \pm 0,00$ & $0,04 \pm 0,01$ \\
\hline CG & $-0,01 \pm 0,04$ & $-0,01 \pm 0,00$ & $0,02 \pm 0,01$ & $0,05 \pm 0,02$ \\
\hline CSF & $0,10 \pm 0,02$ & $0,04 \pm 0,01$ & $0,05 \pm 0,01$ & $0,06 \pm 0,02$ \\
\hline CGF & $0,10 \pm 0,01$ & $0,01 \pm 0,01$ & $0,03 \pm 0,01$ & $0,04 \pm 0,01$ \\
\hline
\end{tabular}

(1) Médias seguidas da mesma letra, minúscula em cada coluna e maiúscula na mesma linha, dentro de cada atributo avaliado numa mesma época, não diferem estatisticamente pelo teste de Tukey a $5 \%$.

${ }^{(2)}$ Média \pm erro padrão. 
A imobilização líquida em solos é resultado da assimiliação de amônio e nitrato nas células microbianas e é acelerada na presença de uma fonte de carbono prontamente oxidável (Alexander, 1977). Assim, o suprimento de $\mathrm{N}$ através de fertilizantes, durante o processo de decomposição, pode resultar em aumento do $\mathrm{N}$ imobilizado, dependendo da qualidade do substrato orgânico (relação $\mathrm{C}: \mathrm{N}$, teor de lignina e polifenóis). No período chuvoso, que coincide com maior crescimento das plantas e reciclagem do sistema radicular, a deposição de resíduos no solo é aumentada, havendo maior possibilidade de imobilização do $\mathrm{N}$ mineral do solo. No caso de pastagens de Brachiaria esta possibilidade é ainda mais real, devido a produção de elevadas quantidades de resíduos com baixo teor de $\mathrm{N}$ e alta relação C:N (Cantarutti, 1996; Robertson et al., 1993a). Cantarutti et al. (1996) demonstraram que a incubação de amostras de solo misturadas com palha de $B$. humidicola, provocou a imobiliząão de $60 \%$ do $\mathrm{N}$ inorgânico do solo na primeira semana, sendo que ao final da incubação (150 dias) cerca de $15 \%$ do $\mathrm{N}$ ainda permanecia imobilizado. No presente trabalho, embora a liteira não tenha sido analisada quimicamente, a concentração máxima de $\mathrm{N}$ na massa seca da parte aérea da braquiária, encontrada nos tratamentos adubados, não

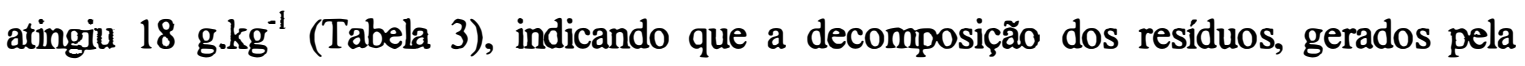
senescência das plantas, pode levar à imobilização do $\mathrm{N}$ do solo e daquele aplicado no fertilizante.

$\mathrm{Na}$ estação seca, a taxa líquida de mineralização foi positiva em todos os tratamentos, embora com valores muito baixos. Luizão et al. (1992) sugeriram que na época das chuvas a grande quantidade de resíduos com elevada relação $\mathrm{C}: \mathrm{N}$ induz à imobilização do $\mathrm{N}$, enquanto a estação seca favorece a mineralização líquida porque a matéria orgânica disponível está associada às partículas de argila e possui menor relação $\mathrm{C}: \mathrm{N}$.

Embora o $\mathrm{pH}$ do solo tenha aumentado em todos os tratamentos que receberam calcário (CS, CG, CSF e CGF), a taxa líquida de nitrificação aumentou somente nas parcelas que adicionalmente receberam fertilizantes (CSF e CGF), as quais continham os maiores teores de $\mathrm{N}-\mathrm{NH}_{4}{ }^{+}$. Tal fato sugere que o efeito do $\mathrm{pH}$ sobre a nitrificação depende, dentre outros fatores, da concentração de $\mathrm{N}_{-} \mathrm{NH}_{4}{ }^{+}$no solo. 
O aumento da taxa de nitrificação no solo pode aumentar o potencial de perda do nitrogênio por lixiviação e/ou desnitrificação, principalmente em solos arenosos. Entretanto, existem indicações de que em solos arenosos cobertos com pastagem de gramíneas, ocorre aumento do estoque de carbono (Fernandes, 1993; Fernandes \& Fernandes, 1997). Esse acréscimo de matéria orgânica facilmente oxidável pode estar levando à predominância de imobilização microbiana do nitrogênio, o que explicaria, em parte, as menores taxas de mineralização e nitrificação de $\mathrm{N}$ em pastagens não fertilizadas, relatadas em diversos trabalhos (Cantarutti, 1996; Fernandes \& Fernandes, 1997; Neill et al., 1995, 1997; Piccolo et al., 1994).

No presente trabalho, as taxas líquidas de nitrificação foram muito baixas ou próximas de zero, mesmo nas parcelas fertilizadas com nitrogênio, sugerindo um baixo potencial de perdas de $\mathrm{N}_{-} \mathrm{NO}_{3}{ }^{-}$por lixiviação ou desnitrificação. 


\section{CONCLUSÕES}

a) Os quatro tratamentos com calcário, independentemente do modo de aplicação ou da presença dos fertilizantes, afetaram de modo similar a reação do solo na camada superficial $(0-10 \mathrm{~cm}), 20$ meses após a sua aplicação, aumentando o pH, neutralizando $\mathrm{o} \mathrm{Al}^{3+}$ trocável e reduzindo a acidez potencial. Contudo, a presença dos fertilizantes aumentou a disponibilidade dos nutrientes adicionados e proporcionou melhor distribuição de $\mathrm{Ca}$ e $\mathrm{Mg}$ no perfil do solo, elevando a saturação por bases e reduzindo a saturação por $\mathrm{Al}$ até $60 \mathrm{~cm}$ de profundidade. Como resultado disso, houve aumento da densidade raízes, da absorção de nutrientes e da relação $\mathrm{N}: \mathrm{S}$ e $\mathrm{K}:(\mathrm{Ca}+\mathrm{Mg})$ na mssa seca da parte aérea, que culminaram em acréscimos superiores a $200 \%$ na produção total de forragem, promovendo a recuperação da pastagem.

b) $\mathrm{Na}$ ausência de adubação, os tratamentos com calcário promoveram $\mathrm{o}$ aumento da densidade de raízes, embora em proporções duas vezes inferiores às dos tratamentos adubados. No entanto, não alteraram a produção de forragem, à qual apresentou baixa concentração de nutrientes, notadamente $\mathrm{K}$, refletindo os baixos teores no solo.

c) A gradagem como prática isolada aumentou a produção de forragem apenas no primeiro ano, às custas da mineralização da matéria orgânica, evidenciada pela redução dos teores de $\mathrm{C}$ e $\mathrm{N}$ total do solo e menor atividade microbiana, avaliada pela quantidade de $\mathrm{C}-\mathrm{CO}_{2}$ despreendido em amostras de solo incubadas em laboratório.

d) A porosidade total do solo e a proporção de macroporos, na camada de 0-10 cm, foram aumentadas nos tratamentos com calcário mais fertilizantes, com melhor perfórmance onde o calcário foi aplicado em cobertura, em função do melhor 
desenvolvimento radicular e maior teor de carbono no solo. Contudo, os valores encontrados nos demais tratamentos indicaram níveis não prejudiciais à aeração e ao crescimento de raízes, mesmo nas camadas mais densas.

e) A atividade e a biomassa microbiana $\mathrm{C}, \mathrm{N}$ e $\mathrm{P}$ do solo foram mais elevadas nos tratamentos com calagem mais adubação, refletindo a redução da toxicidade do $\mathrm{Al}$, o aumento do $\mathrm{pH}$ e da disponibilidade de nutrientes e substrato orgânico, este último decorrente da maior produção e desenvolvimento radicular da pastagem. De modo geral, a biomassa microbiana $\mathrm{P}$ foi sempre superior aos teores disponíveis encontrados no solo, constituindo um importante compartimento de reserva deste nutriente.

f) A maior taxa líquida de mineralização do $\mathrm{N}$ ocorreu na estação chuvosa, no tratamento com calcário aplicado em cobertura mais adubação com macro e micronutrientes. Nos demais tratamentos, neste mesmo período, as taxas foram negativas, indicando imobilização líquida do $\mathrm{N}$ na biomassa microbiana. Nas duas épocas

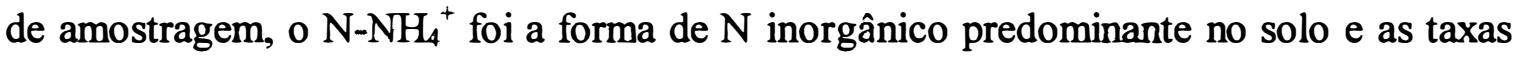
líquidas de nitrificação foram muito baixas, sugerindo um baixo potencial de perdas de $\mathrm{N}$ $\mathrm{NO}_{3}{ }^{-}$por lixiviação e/ou desnitrificação. 


\section{REFERÊNCIAS BIBLIOGRÁFICAS}

ADAMS, S.N.; The interactions between liming and forms of nitrogen fertilizers on established grassland. Journal of Agricultural Science, v.106, p.509-513, 1986.

ADAMS, T.M.; ADAMS, S.N. The effects of liming and soil $\mathrm{pH}$ on carbon and nitrogen contained in the soil biomass. Journal of Soil Science, v.101, n.553-558, 1983.

ALVIM, M.J.; BOTREL, M. de A.; VERNEQUE, R. da S.; SALVATI, J.A. Aplicação de nitrogênio em acessos de Brachiaria spp. 1. Efeito sobre a produção de matéria seca. Pasturas Tropicalis, v.12, p.2-6, 1990.

ALVIM, P. de T. Potencial da produção agropecuária na região Amazônica. In: SANCHEZ, P.A.; TERGAS, L.A.; SERRÃO, E.A.S. (Ed.) Produção de Pastagens em solos ácidos dos trópicos. Brasília: EDITERRA, 1982. p.24-40.

ANDERSON, J.P.E.; DOMSCH, K.H. Ratios of microbial biomass carbon to total organic carbon in arable soils. Soil biology and Biochemistry, v.21, p.471-479, 1989.

ANDERSON, T.H.; DOMSCH, K.H. The metabolic quotient for $\mathrm{CO}_{2}\left(\mathrm{qCO}_{2}\right)$ as a specific activity parameter to asses the effects of environmental conditions, such as $\mathrm{pH}$, on the microbial biomass of forest soils. Soil Biology and Biochemistry, v.25, p.393-395, 1993.

ARRUDA, N.G.; CANTARUTTI, R.B.; MOREIRA, E.M. Tratamentos fisico-mecânicos e fertilização na recuperação de pastagem de Brachiaria decumbens em solos de tabuleiro. Pasturas Tropicales, v.9, p.36-34, 1987.

ASSOCIAÇÃO NACIONAL PARA DIFUSÃO DE ADUBOS E CORRETIVOS AGRÍCOLAS - ANDA. Anuário estatístico do setor de fertilizantes - 1990. São Paulo: ANDA, 1991.149p. 
BADALUCCO, L; GREGO, S. DELLÓRCO, S.; NANNIPIERI, P. Effect of liming on some chemical, biochemical, and microbiological properties of acid soils under spruce (Picea abies L.). Biology and Fertility of Soils, v.14, p.76-83, 1992.

BARCELLOS, A. de O. Recuperação de pastagens degradadas. Curso de Formação e Manejo de Pastagens. Planaltaina: EMBRAPACPAC, 1990. 1v. (Série Treinamento) BARDGETT, RD.; LEEMANS, D.K. The short-term effects of cessation on fertiliser applications, liming, and grazing on microbial biomass and activity in a reseeded upland grassland soil. Biology and Fertility of Soils, v.,19, p.148-154, 1995.

BATAGLIA, O.C.; FURLANI, A.M.C.; TEIXEIRA, J.P.F.; FURLANI, P.R; GALLO, J.R Métodos de análise química de plantas. Campinas: Instituto Agronômico, 1983. 48p. (Boletim Técnico, 78).

BAVER, L.D.; GARDNER, W.H.; GARDNER, W.R Soil physics. 4.ed. New York: John Wiley \& Sons, 1972. 498p.

BLAKE, G.R; HARTGE, K.H. Bulk density. In: KLUTE, A. (Ed.). Methods of soil analysis. 2.ed. Part 1: Physical and mineralogical methods. Madison: ASA, 1986. p.363-376. (Agronomy, 9)

BODDEY, R.R ALVES, B.; URQUIAGA, S. Nitrogen cycling and susteantability of improved pastures in the Brazilian cerrados. In: PEREIRA, RC. \& NASSER, C.B. (Ed.) Simpósio sobre o cerrado, 8.; International Symposium on tropical savannas, 1., Planaltina, 1996. Anais. Planaltina: EMBRAPA/CPAC, 1996a. p.33-38.

BODDEY, RM.; RAO, I.M.; THOMAS, RJ. Nutrient cycling and environmental impact of Brachiaria pastures. In: MILES, J.W.; MAASS, B.L.; VALLE, C.B. Brachiaria: biology, agronomy and, improvement. Cali: CIAT/EMBRAPA-CNPGC, 1996b. p.5371.

BOHM, W. Methods of studying root system. New York: Springer-Verlag, 1979. 189 p.

BOLAN, N.S.; CURRIE, L.D.; BASKARAN, S. Assessment of the influence of phosphate fertilizers on the microbial activity of pasture soils. Biology and Fertility of Soils, v.21, p.284-292., 1996. 
BONDE, T.A.; ROSSWALL. T.; VICTORIA, R.L. The dynamics of soil organic matter and soil microbial biomass following clearfelling and cropping of a tropical rainforest soil in the central Amazon. In: BONDE, T.A. (Ed.) Size and dynamics of active soil organic matter fraction as influenced by soil management. Linkopping: Linkopping University, 1991. Cap.7, p.1-19.

BONO, A.M.; MACEDO, M.C.M. Sistemas de recuperação de pastagem degradada sob um latossolo roxo e alterações na taxa de infiltração (Compact disc). In: CONGRESSO LATINO- AMERICANO DE CIÊNCIA DO SOLO, 13., Águas de Lindóia, 1996. Solo-Suelo; trabalhos. Piracicaba: SBCS/SLCS, 1996.

BOTREL, M.A.; ALVIM, M.S.; MOZZER, O.L. Fatores de adaptação de espécies forrageiras. Curso de pecuária leiteira. Coronel Pacheco: EMBRAPA/CNPGL, 1990. 21p. (Documentos, 13).

BREMNER; J.M; MULVANEY, C.C. Nitrogen - Total. In: PAGE, A.L.; MILLER, R.H.; KEENEY, D.R. (Ed.). Methods of soil analysis. Part 2: Chemical and Microbiological Properties. 2.ed. Madison: ASA, 1982. cap.31, p.595-624. (Agronomy, 9)

BRISTOW, A.W.; JARVIS, S.C. Effects of grating and nitrogen fertiliser on the soil microbial biomass under permanent pasture. Journal of the Science Food and Agriculture, v.54, p.9-21, 1991.

BRITO, M. de M.P. O fósforo dos solos de Rondônia: variabilidade espacial e temporal na conversão de floresta em pastagens. Piracicaba, 1998. 115p. Tese (Doutorado) Escola Superior de Agricultura “Luiz de Queiroz", Universidade de São Paulo.

BROOKES, P.C. Microbial biomass and activity measurements in soil. Journal of the Science Food and Agriculture, v.36, p.269-281, 1985.

BROOKES, P.C.; POWLSON, D.S; JENKINSON, D.S. Phosphorus in the soil biomass. Soil Biology and Biochemistry, v.16, p.169-175, 1984.

BROOKES, P.C.; LANDMAN, A.; PRUDEN, B.; JENKINSON, D.S. Chloroform fumigation and the release of soil nitrogen: a rapid direct extration method to measure microbial biomass nitrogen in soil. Soil Biology and Biochemistry, v.17, p.837-842, 1985. 
BROOKES, P.C.; POWLSON, D.S.; JENKINSON, D.S. Phosphorus in the soil microbial biomass. Soil Biology and Biochemistry, v.16, n.2, p.169-175, 1984.

BROOKES, P.C.; POWLSON, D.S; JENKINSON, D.S. Measurement of microbial biomass phosphorus in soil. Soil Biology and Biochemistry, v.14, p.319-329, 1982.

BROWN, D.A; SCOTT, H. don. Dependence of crop growth and yield on root development and activity. In: BARBER, S.A; BOULDIN, D.R (Ed.) Roots and water influx, and plan growth. Madison: Soil Science Society of America, 1984. Cap.6, p.101-136.

BÜLL, L.T. Influência da relação $\mathrm{K} /(\mathrm{Ca}+\mathrm{Mg})$ do solo na produção de matéria seca e na absorção de potássio por gramínea e leguminosa forrageiras. Piracicaba, 1986. 107p. Tese (Doutorado) - Escola Superior de Agricultura "Luiz de Queiroz”, Universidade de São Paulo.

BUSCHBACHER, R; UHL, C. SERRÃO, A.S. Abandoned pastures in eastern Amazonia, II. Nutrient stocks in the soil and vegetation. Journal of Ecology, v.76, p.682-699, 1988.

CADISH, G.; SCHUNKE, R.M.; GILLER, K.E. Nitrogen cycling in a pure grass pasture and grass-legume mixture on a red latosol in Brazil. Tropical Grasslands, v.28, p.4352, 1994.

CAMPOS, D.C. de. Influência do uso da terra sobre a matéria orgânica do solo no município de São Pedro-SP. Piracicaba, 1998. 83p. Dissertação (M.S.) - Escola Superior de Agricultura "Luiz de Queiroz", Universidade de São Paulo.

CANTARUTTI, RB. Dinâmica do nitrogênio em pastagens de Brachiaria humidicola em monocultivo e consorciada com Desmodium ovalifolium cv. Itabela no Sul da Bahia. Viçosa, 1996. 83p. Tese (Doutorado) - Universidade Federal de Viçosa.

CANTARUTTI, R.B.; ARRUDA, N.G.; MOREIRA, E.M. Eficiência dos macronutrientes na recuperação da produção de Brachiaria decumbens Stapf. em pastagens degradadas. In: REUNIÃO ANUAL DA SOCIEDADE BRASILEIRA DE ZOOTECNIA, 20., Pelotas, 1983. Anais. Pelotas: SBZ, 1983. p.405.

CANTARUTTI, R.B.; URQUIAGA, S.; BODDEY, RM.; BRAGA, J.M.; CASSINI. J.T. Cinética de mineralização do $\mathrm{N}$ contido na palha de Brachiaria humidicola e de 
Desmodium ovalifolium cv. Itabela. In: CONGRESSO BRASILEIRO DE CIÊNCIA DO SOLO, 26. Rio de Janeiro, 1997. Informação, globalização, uso do solo: trabalhos. Rio de Janeiro: SBCS, 1997.

CARRIEL, J.M.; MONTEIRO, F.A.; COLOZZA, M.T. Calagem num podzólico vermelho amarelo para cultivo de três gramíneas forrageiras. Boletim de Indústria Animal, Nova Odessa, v.52, n.1, p.1-8.

CARVALHO, M.C.S.; RAIJ, B. van. Calcium sulphate, phosphogypsum and calcium carbonate in the amelioration of acid subsoils for root growth. Plant and Soil, v.192, p.37-48, 1997

CARVALHO, M.M.; MARTINS, C.E.; SIQUEIRA, C.; SARAIVA, O.F. Crescimento de uma espécie de braquiária, na presença da calagem em cobertura e de doses de nitrogênio. Revista Brasileira de Ciência do Solo, v.16, p.69-74, 1992.

CARVALHO, M.M.; MARTINS, C.E.; VERNEQUE, R da S.; SIQUEIRA, S. Resposta de uma espécie de braquiária à fertilização com nitrogênio e potássio em um solo ácido. Revista Brasileira de Ciência do Solo, v.38, p.195-20, 1991.

CARVALHO, S.I.C.; VILELA, L.; SPAIN, J.M.; KARIA, C.T. Recuperação de pastagens degradadas de Brachiaria decumbens cv. Basilisk na região de cerrados. Pasturas Tropicales, v.12, p.24-28, 1990.

CARVALHO, S.R. Influência de dois sistemas de manejo de pastagens na compactação de uma terra roxa estruturada. Piracicaba, 1976. 89p Dissertação (M.S.) - Escola Superior de Agricultura “Luiz de Queiroz", Universidade de São Paulo.

CENTRO INTERNACIONAL DE AGRICULTURA TROPICAL (CIAT). Fertilidade del suelo y nutrición de las plantas. In: CIAT. Informe anual - 1978: programa de ganado de carne. Cali: Colômbia, CIAT, 1978. p.B86-B104.

CENTRO INTERNACIONAL DE AGRICULTURA TROPICAL (CIAT). Fertilidade del suelo y nutrición de las plantas. In: CIAT. Informe anual - 1978: programa de ganado de carne. Cali, Colômbia, CIAT, 1978. P.B86-B104.

CERRI, C.C. Dinamica da matéria orgânica em solos de pastagens. In: FAVORETTO, V.; RODRIGUES, L.AR.A. (Ed.) Simpósio sobre ecossistema de pastagem, Jaboticabal, 1989. Anais. Jaboticabal: FUNEP, 1989. p. 135-144. 
CERRI, C.C. ; MORAES, J.F.L.; VOLKOFF, B. Dinâmica do carbono orgânico em solos vinculados a pastagens na Amazônia brasileira. Investigación Agraria, Madrid, v.l. p.95-102, 1992.

CERRI, C.C.; ANDREUX, F. Changes in organic carbon content of oxisols cultivated with sugar-cane and pasture, based in 13C natural abundance measurement. In: INTERNATIONAL CONGRESS OF SOIL SCIENCE, 14., Kyoto, 1990. Proceedings. Kyoto: ISSS, 1990. p.98-103.

CHONE, T.; ANDREUX, F.; CORREA, J.C.; VOLKOFF, B; CERRI, C.C. Changes in organic matter in an oxisol from the Central Amazonian forest during eight years as pasture, determined by $13 \mathrm{C}$ isotopic composition. In: BERTHELIN, J. (Ed.) Diversisty of Enviromental biogeochemistry. Amesterdam: Elsevier, 1991. p.397405.

CLAY, D.E.; CLAPP, R.H. DOWDEY, R.R.; MOLINA, J.A.E. Mineralization of nitrogen in fertilizer-acidified lime-amended spoils. Biology and Frtility of Sols, v.15, p.249-25, 1993.

COCHRAN G. C.; COX G. M. Diseños experimentales. Trillas: Mexico, 1978. 615p.

CORSI, M.; MARTHA JÚNIOR, G.B. Manutenção da fertilidadae do solo em sistemas intensivos de pastejo rotacionado. In: PEIXOTO, A.N.; MOURA, J.C.; FARIA, V.P. (Ed.) Simpósio sobre manejo da pastagem, 14: fundamentos do pastejo rotacionado, Piracicaba, 1997. Anais. Piracicaba: FEALQ, 1997. p.161-192.

CORSI, M.; NUSSIO, L.G. Manejo do capim elefante: correção e adubação do solo. In: SIMPÓSIO DOBRE O MANEJO DA PASTAGEM, 10., Piracicaba, 1992. Anais. Piracicaba: FEALQ, 1993. p.87-117.

CORSI, M.; SALLES, P.V.; OLIVEIRA, P.R.A. Recuperação de pastagens degradadas através da utilização do manejo da fertilidade do solo e da fisiologia das plantas. Piracicaba: Departamento de Zootecnia, 1997. 30p. (Relatório Técnico do Projeto FAPESP, processo $n^{0}$ 97/01977)

CRESTANA, S.; GUIMARÃES, M.F.; JORGE, L.A.C.; RALISH, R.; TOZZI, C.L.; TORRES, A.; VAZ, C.M.PP. Avaliação de distribuição de raizes no solo auxiliada por 
processamento de imagens digitais. Revista Brasileira de Ciência do Solo, v.18, p.365-371, 1994.

CRUZ, M.C.P.; FERREIRA, M.E.; LUCHETA, S. Efeito da calagem sobre a produção de matéria seca de três gramíneas forrageiras. Pesquisa Agropecuária Brasileira, v.29, p.1.303-1.312, 1994.

CURTIN, D.; SMILLIE, G.W. Effects of liming on soil chemical characteristics and grass growth in laboratory and long-term field-amended soils. Plant and Soil, v.95, p.15-22, 1986.

DADALTO, G.G. Alteração em caracteristicas fisicas e químicas de solos cultivados com pastagem em áreas de caatinga hipoxerófila no município de Sebastião Laranjeira, Bahia. Viçosa, 1983. 89 p. Disssttação (M.S.) - Universidade Federal de Viçosa.

DAVIES, A.W.; ADAMS, A.; WILLIAM, D, Soil compaction in permanent pasture and its ameloration by slitting. Journal of Agricultural Science, n.113, p.189-197, 1989.

DELLA BRUNA, E., BORGES, A.C., FERNADES, B. BARROS, N.F.; MUCHOVEJ, RM.C. Atividade da microbiota de solos adicionados de serapilheira de eucalipto e de nutrientes. Revista Brasileira de Ciência do Solo. Campinas, v.15, p.15-20, 1991.

DeMARIA. I.C.; VIEIRA, S.R; DECHEN, S.C.F. Assessment of soil quality using parameter indicators (compact disc). In: WORLD CONGRESS OF SOIL SCIENCE, 16. Montpellier, 1998. Proceedings. Montpellier: ISSS, 1998. 3p.

DEMATTÊ, J.I.; DEMATTÊ, J.A.M. Comparações entre as propriedades químicas de solos das regiões da floresta amazônica e do cerrado do Brasil central. Scientia Agricola, v.50, n.2, jun./set., 1993.

DIAS FILHO, M.B.; SERRÃO, E.A.S. Limitações de fertilidade do solo na recuperação de pastagem degradada de capim colonião (Panicum maximum) em Paragominas, na Amazônia Oriental. Belém: EMBRAPA/CPATU, 1987. 19 p. (Boletim de Pesquisa, 87)

DIEZ, J.A.; POLO, A.; CERRI, C.C.; ANDREUX, F. Influência do pousio e da pastagem sobre a dinâmica de nutrientes em oxissolos recentemente desflorestados na Amazônia Oriental. Pesquisa Agropecuária Brasileira., v.26, p.77-83, 1991. 
FALESI, I.C. Ecossistema de pastagem cultivada na amazônia brasileira. Belém: EMBRAPA/CPATU, 1976. 193 p. (Boletim Técnico, 1)

FAQUIN, V.; CURI, N.; MARQUES, J.J.G.S.M.; TEIXEIRA, W.G.; EVANGELISTA, A.R; SANTOS, D. CARVALHO, M.M. Limitações nutricionais para gramíneas forrageiras em cambissolo álico da microrregião Campos da Mantiqueira-MG, Brasil. 2. Nutrição em amcro e micronutrientes. Pasturas Tropicalis, v.17, n.3, p.17-22. 1995.

FEARNSIDE, PM; BARBOSA, RI. Soil carbon changes from conversion of forest to pasture in Brazilian Amazonia. Forest Ecology and Management, v.20, p.147-166, 1998.

FEIGL, B.J.; MELILO, J.; CERRI, C.C. Changes in the origin and quality of soil organic matter after pasture introduction in Rondônia (Brazil). Plant and Soil, v.175, p.21-29., 1995.

FERNANDES, F.A. Matéria orgânica e características físico-químicas de podzóis hidromórficos no Pantanal Mato-Grossence: alterações pelo uso com pastagens cultivadas. Piracicaba, 1993. 75p. Dissertação (M.S.) - Centro de Energia Nuclear na Agricultura, Universidade de São Paulo.

FERNANDES, F.E.; FERNENDES, A.H.B.M. Dinâmica do nitrogênio no solo após a implantação de pastagem no pantanal sul matogrossense. In: CONGRESSO BRASILEIRO DE CIÊNCIA DO SOLO, 26. Rio de Janeiro, 1997. Informação, globalização, uso do solo: trabalhos. Rio de Janeiro: SBCS, 1997.

FERREIRA, E.; RESENDE, A.S.; ALVES, B.J.R.; BODDEY, RM.; URQUIAGA, S. Destino do ${ }^{15} \mathrm{~N}$ da urina bovina aplicado na superficie de um solo podzólico descoberto ou sob cultura de Brachiaria brizantha cv Marandu. In: REUINIÃO DA SOCIEDADE BRASOILEIRA DE ZOOTECNIA, 32., Brasília, 1995. Anais. Brasília: SBZ, 1995. p.109-127.

FIALHO, J.F.; BORGES, A.C. BARROS, N.F. Cobertura vegetal e as características químicas e físicas e a atividade da microbiota de um latossolo vermelho amarelo distrófico. Revista Brasileira de Ciência do Solo, Campinas, v.15, p.21-28, 1991. 
FISHER, M.J.; RAO. I.M.; AYARZA, M.A. LASCANO, C.E. SANZ, J.I.; THOMAS, R.J.; VERA, R.R. Nature, v.371, p.236-238.

FONSECA, D.M.; GOMIDE, J.A.; ALVAREZ V., V.H.; NEVES, J.C.L.; NOVAIS, R.F. DE; BARROS, N.F. DE. Absorção, utilização e níveis críticos de fósforo em Andropogon gayanus, Brachiaria decumbens e Hyparrenya rufa. Revista da Sociedade Brasileira de Zootecnia, v.21, n.4, p.731-743, 1992.

FOY, C.D. Physiological effects of hidrogen, aluminium and manganesetoxicities in acid soils. In: ADAMS, F. (Ed.) Soil acidity and liming. 2.ed. Madison: ASA, 1984. p.57-98.

GARCIA-MÉNDEZ, G.; MAASS, J.M. MATSON, P.A.; VITOUSEK, P.M. Nitrogen transformations and nitrous oxide flux in a tropical decidous forest in Mexico. Oecologia, v.88, p.362-366, 1991.

GERALDES, A.P.A.; CERRI, C.C.; FEIGL, B.J. Biomassa microbiana de solo sob pastagens na Amazônia. Revista Brasileira de Ciência do Solo, v.19, p.55-60, 1995.

GIJSMAN; A.J.; THOMAS, R.J. Evaluation of some physical properties of an oxisol after conversioN of native savanna into legume-based or pure grass pastures. Tropical Grasslands, v.30, p.237-248, 1996.

GONZALEZ-ERICO, E.; KAMPRATH, E.J.; NADERMAN, G.C.; SOARES, W.V. Effect of depth of lime incorporation on the growth of corn an Oxisol of Central Brazil. Soil Science Society of America Journal, Madison, v.43, p.1155-1 158, 1979.

GOYAL, S.; MISHRA, M.M.; HOODA, I.S.; SIMGH, R. Organic matter-microbial biomass relationships in field experiments under tropical conditions: effects on inorganic fertilization and organic amendments. Soil Biology and Biochemistry, v.24, p.1081-1084, 1992.

GREGORICH, E.G.; CARTER, M.R.; ANGERS, D.A.; MONREAL, C.M.; ELLERT, B.H. Towards a minimum data set to assess soil organic matter quality in agricultural soils. Canadian Journal of Soil Science, v.74, p.367-385, 1994.

GUERRA, J.G.M.; FONSECA, M.C.F.; ALMEIDA, D.L.; DE-POLLI, H.; FERNANDES, M.S. Conteúdo de fósforo da biomassa microbiana de um solo 
cultivado com Brachiaria decumbens Stapf. Pesquisa Agropecuária Brasileira, v.30, n.4, p.543-551, 1995.

HE, Z.L.; WU, J.; O'DONNNELL, A.G.; SYERS, J.K Seasonal responses in microbial biomass carbon, phosphorus ans sulphur in doils under pasture. Biology and Fertility of Soils, v.24, p.421-428, 1997.

HOFFMANN, C.R; FAQUIN, V.; GUEDES, G.A.A; EVANGELISTA, A.R O nitrogênio e o fósforo no crescimento da braquiária e do colonião em amostras de um latossolo da região noroeste do Paraná Revista Brasileira de Ciência do Solo, Campinas, v.19, p.79-86, 1995.

WILLIAM, P.H.; HAYNES, RJ. Companison of initial wetting patter, nutrient concentrations in soil solution and the fate of $15 \mathrm{~N}$-labelled urine in sheep and cattle urine patch areas of pasture soil. Plant and Soil, v.162, p.49-59, 1994.

HYNES, RJ.; WILLIAMS, P.H. Nutrient cycling and soil fertility in grazed pasture ecosystem. Advances in Agronomy, v.49, p.119-199, 1993.

INSTITUTO DE PESQUISA TECNOLÓGICAS - IPT. Mapa geológico do Estado de São Paulo. São Paulo: IPT, 1981. Esc. 1:100.000.

JACKSON, L.E.; SCHIMEL, J.P.; FIRESTONE; M.K. Short-term partitioning of ammonium and nitrate between plants and microbes in an annual grassland. Soil Biology and Biochemistry, v.21, p.409-415, 1989.

JARREL, W.M.; BAVERLY, RB. The dilution effect in plant nutrition studies. Advances in Agronomy, v.34, p.197-124, 1981.

JENKINSON, D.S.; LADD, J.N. Microbial biomass in soil measurement and turnover. In: PAUL, E.E.; LADD, E.E. (Ed.). Soil Biochemistry, New York: Marcel Dekker, 1981. v.5, p.415-470.

JENKINSON, D.S.; LADD, J.N. Microbial biomass in soil measurement and turnover. In: PAUL, E.E.; LADD, E.E. (Ed.) Soil Biochemistry, New York: Marcel Dekker, 1981. v.5, p.415-470.

JNKINSON, D.S. Studies on the decomposition of plant material in soil. V. The effects of plantt cover and soil type on the loss carbon from ${ }^{14} \mathrm{C}$ labelled rygrass decomposing under field conditions. Journal of Soil Science, v.28., p.424-434. 
JONES, R.M.; MOTT, J.J. Population dynamics in grazed pastures. Tropical Granslands, v.14, p.218-224. 1980.

BODDEY, R.R ALVES, B.; URQUIAGA, S. Nitrogen cycling and susteantability of improved pastures in the Brazilian cerrados. In: PEREIRA, R.C. \& NASSER, C.B. (Ed.) Simpósio sobre o cerrado, 8.; International Symposium on tropical savannas, 1., Planaltina, 1996. Anais. Planaltina: EMBRAPA/CPAC, 1996a. p.33-38.

HASAWNEH, F.E. Solution ion activity and plant growth. Soil Science Society of America Proceedings, v.35, p.426-436, 1971.

KICKEL, A.N.; MIRANDA, C.H.B.; MACEDO, C.M.M. Uso da cultura do milho para recuperação de pastagens degradadas de Brachiaria decumbens. In: REUNIÃO DA SOCIEDADAE BRASILEIRA DE ZOOTECNIA, 25., Botucatu, 1998. Forragicultura; anais. Botucatu: SBZ, 1998. p.40-42.

KIEHL, E.J. Manual de edafologia: relações solo-planta. São Paulo: Agronômica Ceres, 1979. 246p.

KOPKE, U. Methods for studying root growth. In: SYMPOSIUM ON THE SOIL/ROOT SYSTEM IN RELATION TO BRAZILIAN AGRICULTURE, Londrina, 1980. Proceedings. Londrina: Fundação Instituto Agronômico do Paraná, 1981. p.303-318.

LETEY, J. Relationship between soil physical properties and crop production. Advances in Soil Science, v.1, 1985. p.277-294.

LOPES, A.S. Diretrizes para o manejo sustentável dos solos brasileiros - região dos cerrados (compact disc). In: CONGRESSO BRASILEIRO DE CIÊNCIA DO SOLO, 26. Rio de Janeiro, 1997. Informação, globalização, uso do solo: palestras. Rio de Janeiro: SBCS, 1997.

LOPES, A.S. Solos sob "cerrado": características, propriedades e manejo. Piracicaba, POTAFOS, 1983. 162p.

LOPES, A.S.; GUILHERME, L.R.G. Preservação ambiental e produção de alimentos. São Paulo: ANDA, 1991. 16 p.

LUIZÃO, R.C.; BONDE, T.A.; ROSSWALL, T. Seasonal variation of soil microbial biomass-the effect of clearfelling a tropical rainforest and estableshiment of pasture in the central Amazon. Soil Biology and Biochemistry, v.24, p805-813, 1992. 
LUIZÃO, R.C.C.; BONDE, T.; ROSWALL, T. Seasonal variation of soil microbial biomass - the effects clearfelling a tropical rainforest and estabeleshiment of pasture in the central Amazon. In: BONDE, T.A. Size and dynamics of active soil organic matter fraction as influenced by soil management. Linkopping: Linkopping University, 1991. Cap.6, p.1-22.

LYNCH, J.M.; PANTING, L.M. Cultivation and the soil biomass. Soil Biology and Biochemistry, v.12, p.29-33, 1980.

MACEDO, J. Perspectives for the rational use for the brazilian cerrados for food production. Planaltina: EMBRAPA/CPAC, 1995. 19p.

MALAVOLTA, E.; VITTI, G.C.; OLIVEIRA, S.A. Avaliação do estado nutricional das plantas: princípios e aplicações. 2.ed. Piracicaba: POTAFOS, 1997. 319p.

MARSCHNER, H. Mineral nutrition of higher plants. Norther Ireland: Academic Press, 1986. 674p.

MARUN, F. Propriedades fisicas e biológicas de um latossolo vermelho escuro do arenito Caiuá sob pastagem e culturas anuais. Pesquisa Agropecuária Brasileira, v.31, n.8, p.593-597, 1996.

MASLE, J.; PASSIOURA, J.B. The effect of soil strength on the growth of young wheat plants. Australian Journal of Plant Physiology, v.14, p.643-656, 1987.

MATSON, P.A.; VITOUSEK, P.M.; lavingston, g.p.; swanberg, n.a. Sources of variation in nitrous oxide flux ecosystems. Journal of Geophysics Research, v. 95, p.789-798, 1990.

MELICH, A. Soil test extractant: a modification of the Melich 2 extractant. Communication in Soil Science and Plant Analysis, v.15, p.1409-1416, 1984.

MENGEL, K. \& KIRKBY, E.A. Principles of plant nutrition. 3.ed. Bern: International Potash Institute, 1982. 655p.

MIRANDA, C.H.B.; KICKEL, A.N.; MACEDO, C.V.M. Recuperação de pastagens degradadas de Brachiaraia decumbens com cultivo simultâneo de milho. In: REUNIÃO ANNUAL DA SOCIEDADE BRASILEIRA DE ZOOTECNIA, 33., Fortaleza, 1996. 2v. Forragicultura. Anais. Fortaleza: SBZ, 1996. p.75-77. 
MONTEIRO, F.A.; CARRIEL, J.M. Aplicação de níveis de enxofre na forma de gesso para o cultivo do capim-colonião em dois solos arenosos do Estado de São Paulo. Boletim de Indústria Animal, v.44, n.2, p. 335-347, 1987.

MONTERIO, F.A.; WERNER, J.C. Reciclagem de nutrientes em pastagem In: PEIXOTO, A.M.; MOURA, J.C.; FARIA, V.P. (Ed.). Simpósio sobre manejo da pastagem, 14: fundamentos do pastejo rotacionado. Piracicaba, 1997. Anais. Piracicaba: FEALQ, 1997. p .55-84.

MORAES, A. Pastagens como fator de recuperação de áreas degradadas. In: FAVORETTO, V.; RODRIGUES, L.R.A.; REIS, R.A. (Ed.). Simpósio sobre ecossistemas de patagens, 2., 1993. Anais. Jaboticabal: FUNEP, 1993. p.191-215. MORAES, J.F.L.; CERRI, C.C.; MELILO, J.M.; KICKLIGHTER, D.; NEILL, C.; SKOLE, D.L.; STEUDLER, P.A.. Soil carbon stocks of the Brazilian Amazon basin. Soil Science Society of America Journal, v.59, p.244-247, 1995.

MORAES, J.F.L.; VOLKOFF, B.; CERRI, C.C.; BERNOUX, M. Soil properties under Amazon forest changes due to pasture installation in Rondônia, Brasil. Geoderma, v.70, p.63-81, 1996.

MYERS, R.J.K.; ROBBINS, G.B. Sustaining procdutive pastures in - tropics. 5. Maintaining procdutive sown grass pastures. Tropical Grasslands, v.25, p.104-110, 1991.

NASCIMENTO Júnior, D.; QUEIROZ, D.S.; SANTOS, M.V.F. Degradação das pastagens e critérios para avaliação. In: PEIXOTO, A.M.; MOURA, J.C.; FARIA, V.P. Simpósio sobre manejo da pastagem, 11. Piracicaba, 1994. Anais. Piracicaba: FEALQ, 1994. p.107-151.

NEILL, C.; PICCOLO, M.C.; CERRI, C.C.; STEUDLER, P.; MELILO, J.M.; BRITO, M.

Net nitrogen mineralization and net nitrification rates in soils following deforestation for pasture across the southwestr Brazilian Amazon Basin landscape. Oecologia, v.110, p.243-252, 1997.

NEILL, C.; PICCOLO, M.C.; STEUDLER, P.; MELILLO, J.M.; FEIGL, B.J.; CERRI, C.C. Nitrogen dynamics in soils of forested and active pastures in the Western Brazilian Amazon basin. Soil Biology and Biochem istry, v.25, p.1167-1175, 1995. 
OADES, J.M. The role of biology in the formation, estabilization and degradation of soil structure. Geoderma, v.56, p.377-400, 1993.

OLIVEIRA, J.B; PRADO, H. Levantamento pedológico semi-detalhado do Estado de

São Paulo: folha de Piracicaba. São Paulo: Secretania da Agricultura, 1989. Esc. 1:100.000.

OLIVEIRA, P.P.A. Algumas considerações sobre a recuperação de pastos degradados. Boletim do Leite, CPEA/FEALQ, v.4, n.39, jun., 1997. 1 v.

OLMOS, J.L.J.; CAMARGO, MN. Ocorrência de aluminio tóxico nos solos do Brasil, sua caracterização e distribuição. Ciência e Cultura, v. 28, n.2, p.:171-80, 1976.

OLSEN, S.R; SOMMERS, L.E. Phosphorus. In: PAGE, A.L.; MILLER, R.H.; KEENEY,

D.R (Ed.). Methods of soil analysis. Part 2: Chemical and Microbiological Properties.

2.ed. Madison: ASA, 1982. p.403-430. (Agronomy, 9)

PAULINO, V.T.; COSTA, $\mathrm{N}$ de L.; CARDELLI de L. M.A; SCHAMMAS, E.E.;

FERRARI Jr. E. Resposta de Brachiaria brizamba cv. Marandú a calagem e a fertilização fosfatada em um solo ácido. Pasturas Tropicalis, v.16, p.34-40, 1994.

PEREIRA, J.P. Adubação dos capins do gênero Brachiaria. In: PEDREIRA, J.V.S.;

MEIRELES. N.M.F.. ed. Encontro para discussão dos capins do gênero Brachiaria.

Nova Odessa. 1986. Anais. Nova Odessa: Instituto de Zootecnia. 1986.

PERROT. K.W.; SARATHCHANDRA. S.U.; DOW, B.W. Seasonal and fertilizer effects on the organic cycle and microbial biomass in a bill country soil under pasture. Australian Journal of Soil Research, v.30, p.383-394, 1992.

PHENNING, L.; EDUARDO, B.P.; CERRI, C.C. Os métodos de fumigação-incubação e fumigação-extração na estimativa da biomassa microbiana em solos da Amazônia. Revista Brasileira de Ciência do Solo, v.16, p.31-37, 1992.

PICCOLO, M.C.: NEILL, C.; CERRI, C.C. Net mineralization and net nitrification along a tropical forest-to-pasture chronossequence. Plant and Soil, v.162, p.61-70. 1994.

PINZÓN. A; AMÉZQUTTA. E. Compactación de suelos por el pisoteo de animales en pastoreo en el piedemonte amazónico de Colombia. Pasturas tropicalis, v.13, n.2., p.21-26. 
POWLSON, D.D.; BROOKES, P.C.; CHRISTENSEN, B.T. Measurement of soil microbial biomass provides an early indication of changes in total soil organic matter due to straw incorporation. Soil Biology and Biochemistry, v.19, p.159-164, 1987.

POWLSON, D.D.; BROOKES, P.C.; CHRISTENSEN, B.T. Measurement of soil microbial biomass provides an early indication of changes in total soil organic matter due to straw incorporation. Soil Biology and Biochemistry, v.19, p.159-164, 1987.

JENKINSON, D.S; POWLSON, D.S. A comparison of the organic matter, biomass, adenosine triphosphate and mineralisable nitrogen contents of ploughed and directdrilled soils. Journal of Agricultural Science, v.97. p.713-721, 1981.

QUAGGIO, J.A. Resposta das culturas de milho e soja, à aplicação de calcário e gesso e movimento de íons em solos do Estado de São Paulo. In: SEMINÁRIO SOBRE O USO DE GESSO NA AGRICULTURA, 2., Uberaba, 1992. Anais. Uberaba: IBRAFOS, 1992. p.341-62.

QUAGGIO, J.A.; MASCARENHAS, H.A.A.; BATAGLIA, O.C. Respostas da soja à aplicação de doses crescentes de calcário em latossolo xoxo distrófico do cerrado. II Efeito residual. Revista Brasileira de Ciência do Solo, Campinas, v.6, p.113-8, 1982. QUAGGIO, J·A.; RAMOS, V.J•; BATAGLIA, O.C.; RAIJ, B van.; SAKAI, M. Calagem para a sucessão batata-triticale-milho usando calcários com diferentes teores de magnésio. Revista Brasileira de Ciência do Solo, Campinas, v.44, p.391-406, 1985.

QUAGGIO, J·A.; RAMOS, V.J.; BATAGLIA, O.C.; RAIJ, B van.; SAKAI, M. Calagem para a sucessão batata-triticale-milho usando calcários com diferentes teores de magnésio. Revista Brasileira de Ciência do Solo, v.44, p.391-406, 1985.

RAIJ, B van. A capacidadae de troca de cátions das frações orgânica e mineral dos solos. Bragantia, v.28, n.8, p.85-1 12., 1969.

RAIJ, B. van. Fertilidade do solo e adubação. Piracicaba: POTAFOS, 1991. 343p.

RAIJ, B. van. Gesso agrícola na melhoria do ambiente radicular no subsolo. São Paulo: ANDA, 1988. 88p.

RAIJ, B. van.; CANTARELlA, H.; CAMARGO, A.P.; SOARES, E. Perdas de cálcio e magnésio durante cinco anos em ensaio de calagem. Revista Brasileira de Ciência do Solo, Campinas, v.6, p.33-7, 1982. 
RAIJ, B. van.; QUAGGIO, J.A.; CANTARELLA, H.; FERREIRA, M.E.; LOPES, A.S.; BATAGLIA, O.C. Análise química do solo para fins de fertilidade. Campinas: Fundação Cargill, 1987. 170p.

RAO, I.M.; KERRIDGE, P.C.; MACEDO, M.C.M. Nutritional requirements of Brachiaria and adaptation to acid soils. In: MILES, J.W.; MAASS, B.L.; VALLE, C.B. Brachiaria: biology, agronomy and, improvement. Cali: CIAT/EMBRAPACNPGC, 1996. p.53-71.

RAYMENT, G.E.; KELYAR, K.P. Estimation of maintenance fertilizer needs. Tropical Granslands, v.14, n.3, p. 210-217, 1980.

RESCK, D. Manejo de solos e sustentabilidade dos sistemas agrosilvipastoris na região dos cerrados. In: PEREIRA, R.C. \& NASSER, C.B. (Ed.) Simpósio sobre o cerrado, 8.; International Symposium on tropical savannas, 1., Planaltina, 1996. Anais. Planaltina: EMBRAPA/CPAC, 1996. p.81-89.

RITCHEY, K.D.; SOUZA, D.H.G.; LOBATO, E.; CORREA, O. Calcium leaching to increase rooting depth in a Brazilian Savannah Oxisol. Agronmy Journal, v.72, p.40$44,1980$.

ROBBINS, G.M.; BUSHELL, J.J.; MCKEON, G.M. Nitrogen immobilization in decomposing litter contributes to productivity decline in aging pastures of green panic (Panicum maximum var. trichoglume). Journal of Agricultural Science, v.113., p.401-406, 1989.

ROBERTSON, F.A.; MYERS, RJ.K.; SAFFIGNA, P.G. Carbon and nitrogen mineralization in cultivated and grassland soils in subtropical Queensland. Australian Journal of Soil Research, v.31, p.611-619, 1993a.

ROBERTSON, F.A.; MYERS, R.J.K.; SAFFIGNA, P.G. Dynamics of carbon and nitrogen in long-term cropping system and permanent pasture system. Australian Journal of Soil Research, v.45, p.211-221, 1994.

ROBERTSON, F.A.; MYERS, R.J.K.; SAFFIGNA, P.G. Distribution of carbon and nitrogen in a long-term cropping system and permanent pasture system. Australian Journal of Soil Research, v.44, p.1323-1336, 1993 b. 
ROSS, D.J.; McQUEEN, D.J.; KETTLES, H.A. Land rehabilitation under pasture on vulcanic parent materials: changes in soil microbial biomass and $\mathrm{C}$ and $\mathrm{N}$ metabolism. Australian Journal of Soil Research, v.32, p.1321-1337, 1994.

ROSS, D.J.; McQUEEN, D.J.; KETTLES, H.A. Land rehabilitation under pasture on vulcanic parent materials: changes in soil microbial biomass and $\mathrm{C}$ and $\mathrm{N}$ metabolism. Australian Journal of Soil Research, v.32, p.1321-1337, 1994.

ROSS, D.J.; SPEIR, T.W.; TATE, K.R.; CAIRNS, A.; MEYRICK, K.F.; PANSIER, E.A. Restoration of pasture after topsoil removal: effects on soil carbon and nitrogen mineralization, microbial biomass and enzyme activities. Soil Biology and Biochemistry, v.14, p.575-581, 1982.

ROSS, T.W.; SPEIR, J.C.; COWLING, J.C.; FELTHAM, C.W. Soil restoration under pasture after lignite mining: management effects on soil biochemical properties and relationships with herbage yields. Plant and Soil, v.140, p.85-97, 1992.

RUZICKA, J.; HANSEN, E.H. Flow injection analysis. New York: Wiley Interscience, 1981. 395p.

SALINAS , J.C. \& GUALDERÓN, R. Adaptación y requerimientos de fertilización de Brachiaria humidicola (Rendle) Sccweikt en la Altilanura plana de Los Llanos Orientales de Colombia. In: SIMPÓSIO SOBRE O CERRADO, 6., Brasiilia, 1972. Anais. Planaltina: EMBRAPA/CPAC, 1988. p.457-471.

SALINAS, J.M.; GUALDRON, R. Degradación e rehabilitation de pasturas. In: LASCANO, C; SPAIN, J.M. (Ed.) Establecimento y renovación de pasturas. Cali: CIAT, 1991. 426p.

SANCHEZ, P.A. Suelos del trópico: caracteristicas y manejo. Trad. De Edilberto Camacho. San José, Costa Rica: ICA, 1981. 660p. (Serie de Libros y Materiales Educativos, 48)

SANCHEZ, P.A.; PALM, C.A.; SZOTT, L.T.; CUEVAS, E.; LAL, R. Organic management in tropical agroecossystems. In: COLEMAN, D.C.; OADES, J.M.; UEHARA, G. (Ed.) Dynamics of soil organic matter in tropical ecossystems. Honolulu: NifTAL Project, 1989. Cap.5, p. 125-152. 
SANCHEZ, P.A.; VILLACHICA, J.H.; BANDY, D.E. Soil fertility dynimics after clearing a tropical rainforest in Peru. Soil Science Society of America Journal, v.47, p.1171-1178, 1983.

SANZONOWICS, C.; BARCELLOS, A. de O.; COUTO, W.; PÉREA, J.R.R; ANDRADE, L.R.de M. Identificação de deficiência nutricional de pastagens e sua recuperação. Planaltina: EMBRAPA/CPAC, 1987a. p. 146-149. (Relatório Técnico Anual).

SANZONOWICZ, C.; GOEDERT, W.J. Uso de fosfatos naturais em pastagens. Planaltina: EMBRAPA/CPAC, 1986b. 33p. (Circular Técnica, 21)

SANZONOWICZ, C.; LOBATO, E.; GOEDERT, W. Efeito residual da calagem e de fontes de fósforo numa pastagem estabelecida em solo de cerrado. Pesquisa Agropecuária Brasileira, v.22, n.3, p.233-243, 1987.

SARRUGE, J.R; HAAG, H.P. Análise química de plantas. Piracicaba: Escola Superior de Agricultura "Luiz de Queiroz", 1974. 56p.

SAS Institute. SAS/STAT guide for personal computers. Version 6. Cary, North Carolina: SAS Institute, 1987. $1 \mathrm{v}$.

SCHUURMANN, J.J.; GOEDEWAAGEN, M.A.J. Methods for the examination of root systems and roots. 2.ed. Wageningen: Pudoc, 1971. 86p.

SCHWAB, A.P.; OWENSBY, C.E.; KULYINGYONG, S. Changes in soil chemical properties due to 40 years of fertilization. Soil Science, v.149, p. 35-43, 1990.

SERRÃO E.A.S.; HOMMA, A.K.O. Recuperação e melhoramento de pastagens cultivadas em áreas de floresta amazônica. Belém: EMBRAPA/CPATU, 1982. 22 p. (Documentos, 17)

SHULZE, D.G.; STOTT, D.E. Soil structure alteration: the role of soil mineralogy, chemistry, and microbiology. In: In: CONGRESSO BRASILEIRO DE CIÊNCIA DO SOLO, 26. Rio de Janeiro, 1997. Informação, globalização, uso do solo: palestras. Rio de Janeiro: SBCS, 1997.

SHUURMANN, J.J. Influence of soil density on root development and growth of oats. Plant and Soil, v.22, n.3, p.352-374, 1965. 
SILVA, A.P. da; TORMENA, C.A.; MAZZA, J.A. Manejo físico de solos sob pastagem. In: PEIXOTO, A.N.; MOURA, J.C.; FARIA, V.P. (Ed.) Simpósio sobre manejo da pastagem, 14: fundamentos do pastejo rotacionado, Piracicaba, 1997. Anais. Piracicaba: FEALQ, 1997. p.25-37.

SILVA, S.C. Condições edafoclimáticas para a produção de Panicum spp. In: PEIXOTO, A.N.; MOURA, J.C.; FARIA, V.P. (Ed.) Simpósio sobre manejo da pastagem, 12: fundamentos do pastejo rotacionado, Piracicaba, 1995. Anais. Piracicaba: FEALQ, 1995. p.129-146.

SMITH, R.C.G; STEPHENS, M.J. Importance of soil moisture and temperature on the growth of improved pasture on the Northern Tablekands of New South Wales. Australian Journal of Agriculture Research, v.27, p.63-70, 1976.

SOARES FILHO, C.V.; MONTEIRO, F.A. CORSI, M. Recuperação de pastagens degradadas de Brachiaria decumbens. 1. Efeito de diferentes tratamentos de fertilização e manejo. Pasturas Tropicalis, v.14, p.2-6, 1992.

SOARES FILHO, C.V.; MONTEIRO, F.A. CORSI, M. Recuperação de pastagens degradadas de Brachiaria decumbens. 1. Efeito de diferentes tratamentos de fertilização e manejo. Pasturas Tropicalis, v.14, p.2-6, 1992.

SONEGO, M. Índices agrometeorológicos e a produção de duas gramíneas tropicais.

Viçosa, 1988. 61p. Dissertação (M.S.) - Universidade Federal de Viçosa.

SOUZA FILHO, A.P.S.; TEIXEIRA NETO, J.F.; VEIGA, J.B. Adubação de pastagem

de capim-colonião em degradação, em Santana do Araguia (Pará). Belém: EMBRAPA/CPATU, 1991. 16p. (Boletim de Pesquisa, 120)

SOUZA, D.M.G. de. \& RITCHEY, K.D. Uso de gesso no solo de cerrado.In: SEMINÁRIO SOBRE O USO DO FOSFOGESSO NA AGRICULTURA, 1., Brasilia, 1986. Anais. Brasília: EMBRAPA-DDT, 1986. p.119-44.

SPAIN, J.M.; AYARZA, M.A.; VILELA, L. Crop pasture rotations in the brazilian cerrados. In: PEREIRA, R.C. \& NASSER, C.B. (Ed.) Simpósio sobre o cerrado, 8.; International Symposium on tropical savannas, 1., Planaltina, 1996. Anais. Planaltina: EMBRAPA/CPAC, 1996. p.39-45. 
SPAIN, J.M.; GUALDRÓN, R. Degradación e rehabilitación de pasturas. In: LASCANO, C,; SPAIN, J.M. (Ed.) Establecimento y renovación de pasturas. Cali: CIAT, 1991. 426p.

SPAIN, J.M.; SALINAS, J.G. A reciclagem de nutrientes nas pastagens tropicais. In: CABALA-ROSAND, P. (Ed.). Simpósio sobre reciclagem de nutrientes e agricultura de baixos insumos nos trópicos, Ilhéus, BA, 1984. Anais. Ilhéus: CEPLAC, 1985. p. 259-299.

SPARLING, G.P.; WEST, A.W. A direct extraction method to estimate soil microbial C: calibration in situ using microbial respiration and ${ }^{14} \mathrm{C}$ labelled sells. Soil Biology and Biochemistry, v.20, p.337-343, 1988.

SPENCER, K; JONES, M.B.; FRENEY, J.R. Diagnostic indices for sulphur status of subterraneam clover. Australian Journal of Agricultural Research, v.28, n.3., p.401412, 1977.

TATE, K.R; ROSS, D.J.; RAMSAY, A.J.; WHALE KN. Microbial biomass of measurement procedures, temporal variations, and the influence of $\mathrm{P}$ fertility status. Plant and Soil, v.132, p.233-241, 1991.

TISDALE, S.L. Sulphur in forage quality and ruminant nutrition. Washington: The sulphur Institute, 1977. 13p.

TSAI, S.M.; BARAIBAR, V.L.; ROMANI, V.L.M. Efeito de fatores do solo. In: CARDOSO, J.B.N.; TSAI, S.M.; NEVES, M.C.P. (Ed.) Microbiologia do solo. Campinas: SBCS, 1992. Cap.5., p.59-72.

UEHARA, G. \& GILLMAN, G. The mineralogy, chemistry and phisics properties of tropical soil with variable charge clay. Boulder: Westview Press, 1981. 170p.

VANCE, E.D.; BROOKES, P.C.; JENKINSON, D.S. An extraction method for measuring soil microbial biomass C. Soil Biology and Biochemistry, v.19, p.703-107, 1987.

VEIGA, J.B.; SERRÃO, E.E. Recuperación de pasturas en la región este de la Amazônia Brasilleña. Pastuaras Tropicalis, v.9, p.40-43, 1987.

WARDLE, D.A. A comparative asssessment of factors wich influence microbial biomass. Carbon and nitrogen levels in soils. Biological Review, v.67, p.321-358, 1992. 
WERNER, J.; MONTEIRO, F.A.; CARRIEL, J.M. Efeitos da calagem em capim-colonião (Panicum maximum) Jacq.) estabelecido. Boletim de Indústria Animal, n.36, p.247-253, 1979.

WERNER, J.C. Adubação de pastagens de Brachiaria spp. In: PEIXOTO, A.M.;

MOURA, J.C.; FARIA, V.P. Simpósio sobre manejo da pastagem, 11.

Piracicaba, 1994. Anais. Piracicaba: FEALQ, 1994. p.209-266.

WERNER, J.C. Adubação de pastagens. 2.ed.. Nova Odessa, SP: Instituto de Zootecnia, 1986. 49 p. (Boletim Técnico, 18).

WERNER, J.C; PULINO, V.T.; CANTARELLA, H.; ANDRADE, N.O.; QUAGGIO, J.A.

Forrageiras. In: RAIJ, B. van; CANTARELLA, H. QUAGGIO, J.A.; FURLANI, A.M.C. (Ed.) Recomendações de adubação e calagem para o Estado de São Paulo, 2.ed.. Campinas: Instituto Agronômico \& Fundação IAC, 1996. Cap. 24, p.261-273. (Boletim Técnico, 100)

WERNER,; J.C.; MONTEIRO, F.A. Respostas das pastagens à aplicação de enxofre. In: BORKERT, C.M.; LANTMANN, A.F. (Ed.) Enxofre e micronutrientes na agricultura brasileira. Londrina: EMBRAPA/CNPSO/IAPARSBCS, 1988. p.87-102. WILKSON, S.R; LOREY, R.W. Cyling of mineral nutrients in pasture ecossystems. In: BUTLER, G.W.; BAIlEY, RW. (Ed.) Chemistry and biochemistry of herbage. London: Academic Press, 1973, 2v., p.247-315.

ZIMMER, A.H.; MACEDO, M.C.M.; BARCELLOS, A.O.; HICKEL, A.N. Estabelecimento e recuperação de pastagens de Brachiaria. In: PEIXOTO, A.M.; MOURA, J.C.; FARIA, V.P. Simpósio sobre manejo da pastagem, 11. Piracicaba, 1994. Anais. Piracicaba: FEALQ, 1994. p.153-208. 